\title{
Transhumanism as a Thin-centred Ideology
}

\author{
By Krisztián Szabados
}

\author{
Submitted to: \\ Corvinus University of Budapest \\ Doctoral School of Political Science
}

In Partial Fulfilment of the Requirements

for the Degree of Doctor of Philosophy

Supervisor:

Zoltán Balázs, DSc

Budapest, Hungary

December 2020 


\section{Abstract}

As a product of the ongoing scientific and technological revolution, transhumanism has grown into a worldwide movement and its ideas penetrated the public discourse and popular culture. The transhumanist movement has recently grown political branches that exert influence on policy-making by inviting topics such as human enhancement, robot rights, post-Anthropocene or morphological freedom into the political arena. The latest development is the emergence of transhumanist political proto-parties worldwide. These changes signal an ideational thickening of transhumanism. This paper presents the first ideological analysis of political transhumanism applying Michael Freeden's morphological approach. Its hypothesis is that transhumanism is a thin ideology. To test this hypothesis, this paper conducts the morphological analysis of key transhumanist political texts. It investigates whether transhumanism can be described as having ideological coherency, what core ideas, key values, and claims (decontestation chains) make up its ideational architect, how, if at all, the conceptual structure of transhumanism can best be described, to what extent these transhumanist concepts and claims are distinct from those of other ideologies.

To start with, three arguments will be suggested to support the choice of Freeden's morphological approach to be the right methodology for the ideological analysis of transhumanism. The subsequent section will present the selected transhumanist literature and other texts that the ideological analysis was conducted on explaining the criteria of selection. Next, a concise argument will be put forward to underpin the relevance of transhumanism as the subject of political science.

Then, attention will, turn to the social and cultural context. The dissertation will summarise briefly the intellectual and organisational history of transhumanism. After that, the ideological analysis will be presented. The main issue to settle is whether transhumanism can be a subject of ideological analysis at all. For this purpose, its ideological attributes will be investigated building on Freeden's definition and characterisation of political ideologies. It will explore six main attributes and their components in connection with transhumanism. The definition of transhumanism applied in consensus by proponents of transhumanism will also be presented together with the typology of transhumanism and the variants of current transhumanist theories.

The ideological analysis is divided into four main sections. The first three sections examine the major decontestations within the transhumanist conceptual architecture revealing the core, 
adjacent, and peripheral concepts of the transhumanist ideology and their positions within the ideational structure in accordance with the morphological approach. The development and various articulations of five core and six adjacent concepts will be presented and explained together with a number of peripheral concepts and their role in spawning ideological mutants within transhumanism. Special attention will be given to two critical accounts of transhumanism: the bioconservative critique presented by Francis Fukuyama and the moral philosophical critique put forward by Jürgen Habermas. Additionally, the dissertation will unveil how transhumanism acquires unique issue ownership over a variety of social issues as well as its attempt at creating a novel semantic field to frame and interpret the perceived consequences of techno-scientific progress. Next, the dissertation will present, based on Freeden's sketch, a conceptual map of transhumanism to underpin and visualize the key findings of the conceptual analysis and hopefully providing new insights to the study of transhumanism.

The inferences from these chapters will allow us to test the main hypothesis and to foreground a new account of the transhumanist thought system. A three-part argument will be offered to justify the idea that transhumanism is indeed a thin-centred ideology. Then, a detailed account of James Hughes' innovative spatial theory of $21^{\text {st }}$ century politics will be presented to test the potential of transhumanism to become a full-fledged ideology and to acquire a dominant status among mainstream ideologies in the near future.

To conclude the dissertation will draw these theoretical, methodological and analytical strands together to appraise the main findings of the ideological analysis. It will offer a new account of transhumanism based on its existing conceptual architecture, its power to interpret social reality and its capacity to contest other dominant and emerging ideologies. Then, two distinct scenarios will be outlined that detail the directions of transhumanism's future in the ideological space. 


\section{Content}

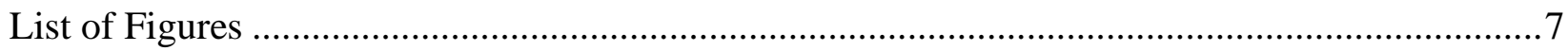

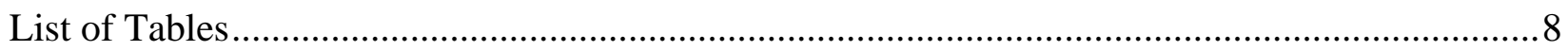

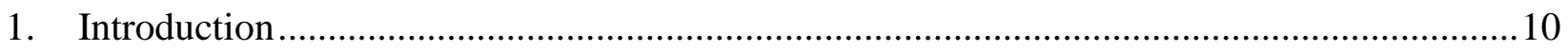

1.1. Research Questions and Hypothesis ........................................................................12

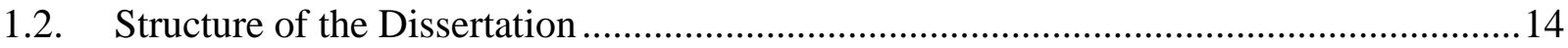

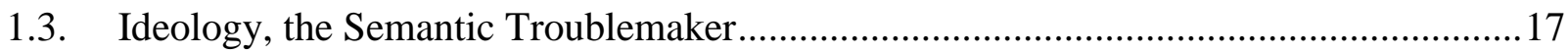

1.4. Methodology: Michael Freeden's Morphological Approach .........................................23

1.4.1. The Benefits of the Morphological Approach.............................................................34

1.4.2. Selection of Literature and Texts .....................................................................

1.4.3. Transhumanism as a Subject of Ideological Investigation ........................................38

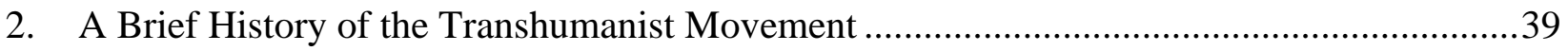

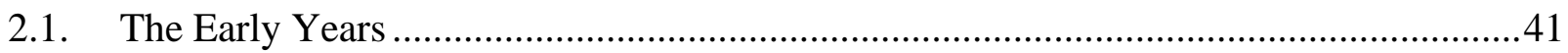

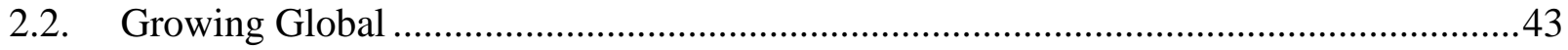

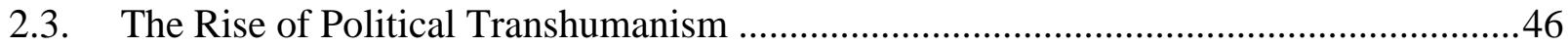

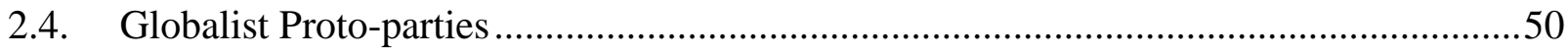

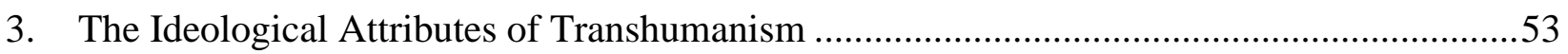

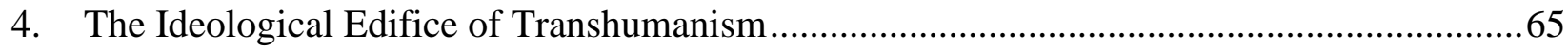

4.1. From Liberty to Morphological Freedom..................................................................67 


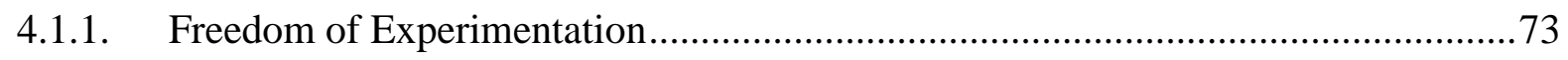

4.1.2. Procreative Beneficence or Procreative Freedom ....................................................76

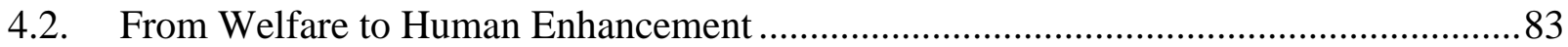

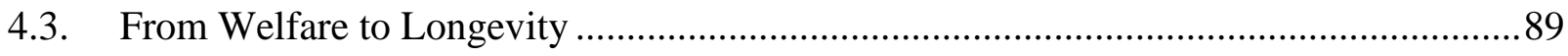

4.4. Progress Driven by the Proactionary Principle...........................................................93

4.5. From Individuality to Post-Anthropocentric Rights .........................................................98

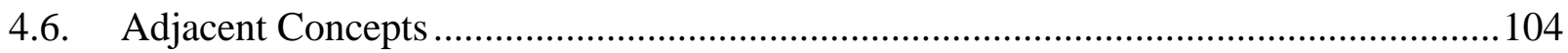

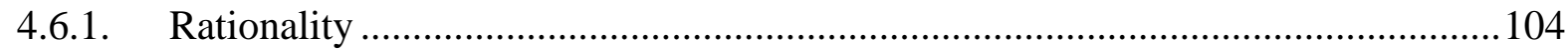

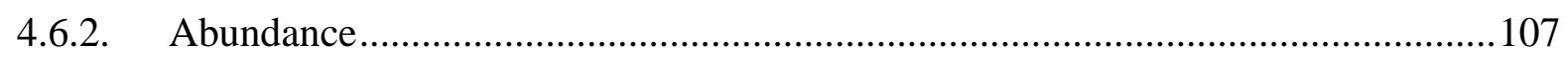

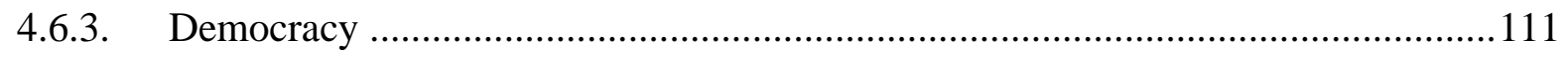

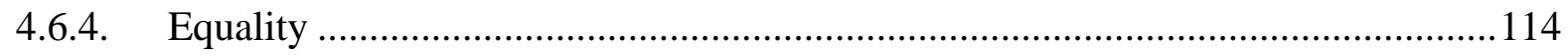

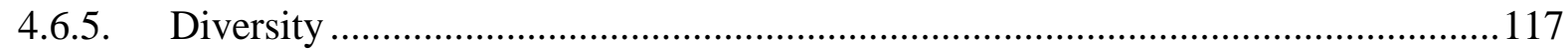

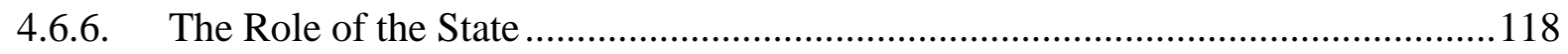

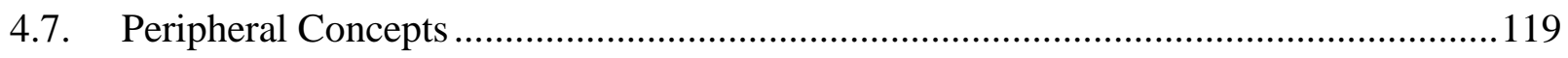

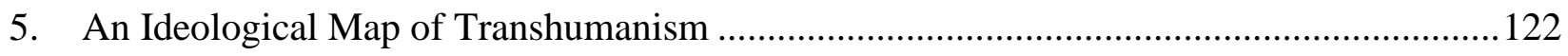

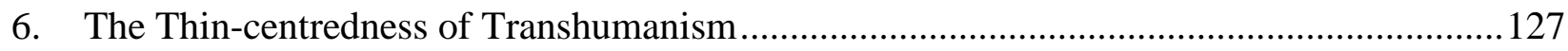

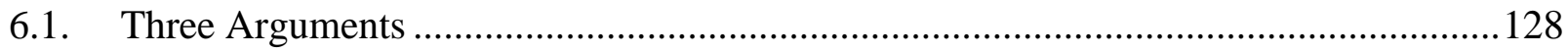

6.2. A Brief Comparison............................................................................................. 133

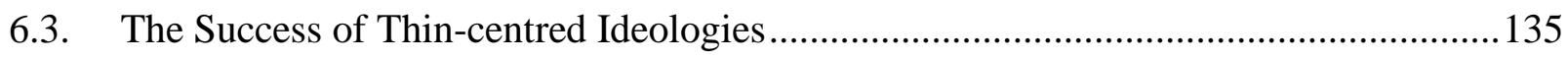


6.4. The Main Ideological Conflict of the $21^{\text {st }}$ Century?

6.5. Hughs's Cube - The Three Dimensions of $21^{\text {st }}$ Century Ideological Space 142

7. Conclusion 146

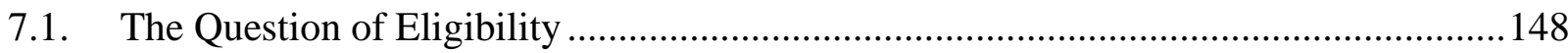

7.2. The Conceptual Arrangement ........................................................................ 150

7.3. Thin-centredness and the Transhumanist Potential ............................................... 153

7.4. Future Research and Closing Remarks........................................................... 158

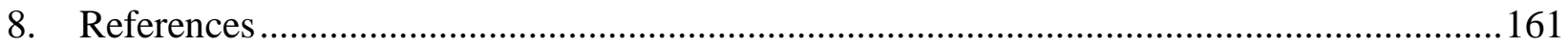

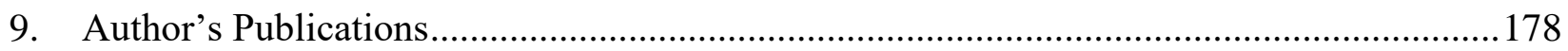

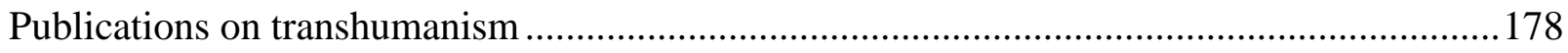

Conference presentations on transhumanism ....................................................... 178

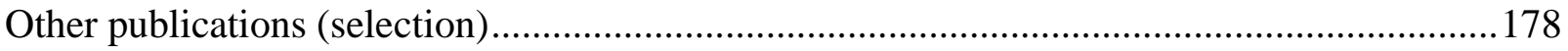

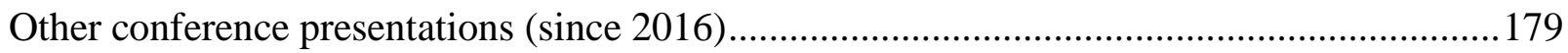




\section{List of Figures}

Figure 1. Maynard's map of the field of contemporary ideological analysis

Figure 2. Percentage of books mentioning the listed terms in the Google Books database, 19702012

Figure 3. Percentage of books mentioning the term 'transhumanism' in the Google Books database, $1980-2012$ .60

Figure 4. Examples of the usage of the ' $\mathrm{H}+$ ' and ' + ' symbols .62

Figure 5. The decontestation chain of scientific citizenship .76

Figure 6. The decontestation of the concept 'human enhancement' .98

Figure 7. Concepts attached to rationality in transhumanism 105

Figure 8. The morphology of the concept 'abundance' 110

Figure 9. Transhumanist decontestation of the concept of equality.

Figure 10. The conceptual map of transhumanism 123

Figure 11. Hughes's cube - The ideological space in the $21^{\text {st }}$ century 143 


\section{List of Tables}

Table 1. Gerring's definitional framework for ideological analysis ........................................19

Table 2. The typology of concepts within the morphological approach ..................................33

Table 3. An incomplete list of diverse transhumanist theories ............................................55

Table 4. Comparison of ideology and philosophy by Michael Freeden .....................................57

Table 5. The reorientation of the wings of the ideological axis ........................................... 97

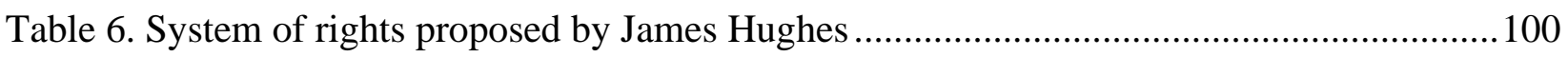

Table 7. Main decontestations of core concepts in transhumanism ....................................... 122

Table 8. Transhumanist concepts and policy proposal derivations ........................................ 126

Table 9. Ideological maturity of transhumanism based on Freeden's description ...................... 130 
The social function of science vis-a-vis ideologies is first to understand them - what they are, how they work, what gives rise to them - and second to criticize them, to force them to come to terms with (but not necessarily to surrender to) reality. The existence of a vital tradition of scientific analysis of social issues is one of the most effective guarantees against ideological extremism, for it provides an incomparably reliable source of positive knowledge for the political imagination to work with and to honor.

Clifford Geertz 


\section{Introduction}

On 22 August 2018, Forbes magazine announced in an article starting with a succinct title that 'It's Official, The Transhuman Era Has Begun' (Nosta, 2018). The author came to this conclusion after reading and processing a report published by Gartner, a leading global business intelligence firm, that explored global technological trends. It was this paragraph of the said report that made media headlines:

Over the next decade, humanity will begin its 'transhuman' era: Biology can then be hacked, depending on lifestyle, interests and health needs. Biohacking falls into four categories: technology augmentation, nutrigenomics, experimental biology and grinder biohacking. (Hype Cycle for Emerging Technologies, 2018)

The terms that describe this alleged new era, 'transhuman' and 'transhumanism', are relatively new additions to the English language and refer to a broader intellectual movement, which serves as the main subject of this dissertation.

Before defining the term, it is important to understand the socio-economic and historical context from which transhumanism was born. We are witnessing a technological revolution - what some call the fourth industrial revolution - fuelled by rapid scientific innovation in fields such as artificial intelligence research, genetic engineering, computational science, nanotechnology, neuroscience, and biotechnology. The peculiarity of the current technological revolution lies in its exponential character, best expounded upon by Moore's Law, which was originally applied solely to the transistor density on semiconductor chips. Ray Kurzweil, the controversial evangelist of this technological revolution, argued that a similar - exponential - pace of change in speed and costeffectiveness is present in other areas of the techno-scientific ecosystem, for instance the internet's penetration into the global population or the per capita growth of global GDP (Kurzweil, 2000).

Further evidence of the current scientific revolution's uniqueness can be identified in its interconnectedness and interdisciplinary character. Boundaries of scientific and academic disciplines are blurred as different fields shape one another to an unprecedented extent, boosting progress even further. Discoveries in neuroscience are applied to artificial intelligence research; 
the development of autonomous machines has heralded a new golden era of moral philosophy; and superfast quantum computers are built upon the achievements of quantum mechanics research, just to list a few examples.

The speed of change intensifies the dynamic interaction between science, technology, society, and the arts. Public discourse has come to revolve around themes that previously belonged to the realm of science fiction literature. Any discussion of a specific scientific achievement always and inevitably leads to the contemplation of its impact on society and the policy implications it entails. That is the reason why we contemplate universal basic income (UBI) in connection with the spread of robotisation; why we discuss the necessity of multilateral legal agreements about autonomous weapons with regard to the latest achievements in artificial intelligence; or debate ethical issues raised by the latest gene editing technologies. These changes terrify many individuals, who envision dystopian outcomes, while making others overly optimistic about the future. Those calling themselves transhumanists tend to belong to the latter group.

Transhumanism holds that humanity will transcend its biological limits of existence through technology and science, which will consequently have far-reaching implications for the political realm. This turbulence in science and technology has penetrated public and academic discourse and calls for new practices in policy-making and novel approaches in political science. As a starting point, this dissertation intends to put forward the first ideological analysis of transhumanism. Political scientists have only recently recognised the relevance and impact of the transhumanist movement, despite the great influence of transhumanist topics on other disciplines such as philosophy, bioethics, human rights theory, or economics.

For political scientists, the relevance of studying transhumanism may lie in the fact that key transhumanist issues are already discussed at different levels of policy-making. Supranational bodies as well as national governments frequently debate what actions to take in relation to the disruptive technologies of gene editing, artificial intelligence, or automation. There are now numerous white papers, committee hearings, advisory papers, and draft legislation on transhumanist topics and their number is rapidly growing. Furthermore, during the most recent five years, transhumanist political parties have emerged all over the world. Although these parties are at an embryonic stage and have yet to affect party competition, there is great potential for transhumanist topics to influence the party system because rapid techno-scientific advances raise 
the same issues transhumanists otherwise advocate (Szabados, 2019). Thus, these topics will inevitably be addressed with increasing intensity by political parties and other political actors with or without the presence of political representatives of a pro-science and pro-tech intellectual movement. Finally, transhumanist thinkers have devised novel theoretical suggestions that may shape many political science subfields. For instance, the three-dimensional spatial theory of $21^{\text {st }}$ century politics put forward by James Hughes (2004, p. 70), which is discussed later in this dissertation, may offer an analytical framework for political theorists that promises to be more suitable for describing the recent developments in both political theory and practice than any established concept. This approach incorporates and gives proper significance to the technological and scientific advances of our times.

Perhaps equally as interesting, opponents of transhumanism have formed a 'rainbow coalition' uniting politicians, civil activists, opinion-leaders, and political theorists - from the religious right to moderate conservatives and liberals to the Green left - who echo Francis Fukuyama's warning that transhumanism is '(the) world's most dangerous idea' (Fukuyama, 2004). The fact that advocates with such diverse ideological backgrounds have joined forces to denounce a newly-born intellectual movement provides further argument for a deeper examination of transhumanism by scholars of political science. After all, it is not very common in political discourse that radical left-leaning activists agree with religious conservative zealots in condemning a small group of sci-fi lovers. It is important for both theoretical and practical policy and political points of view to understand the background, dynamics, and future implications of this strange phenomenon.

\subsection{Research Questions and Hypothesis}

The purpose of this dissertation is to better understand transhumanism as an ideology, to identify its main ideational components, reveal its conceptual architecture, and position it in the ideological space. The main research question and hypothesis can be conveyed as follows:

\section{R: Is transhumanism an ideology?}




\section{H: Transhumanism is a thin-centred ideology.}

To answer the main research question and test the validity of the hypothesis, this dissertation will conduct an ideological analysis based on Michael Freeden's morphological approach, which will be applied through a content analysis of key transhumanist texts. As part of the analysis, the following secondary research questions will be answered:

- R1) Does transhumanism exhibit conceptual coherency?

- R2) What are the core ideas, key values, and claims (decontestation chains ${ }^{1}$ ) that make up transhumanism?

- R3) How can the conceptual structure of transhumanism be described?

- R4) What is the extent to which these concepts and claims are distinct from other ideologies?

Answering the secondary research questions is a precondition to the provision of a scientifically solid and accurate answer to the main research question, as each secondary question refers to distinct premises of an ideology. In pursuing satisfactory responses to these questions, Section 1.4. will explore the issues surrounding the definition and characterisation of ideologies in greater detail. At present, however, it can be asserted that the maturity of any political theory or belief system should be gauged through its ranking of values, issue-preferences, and main claims about the preferred social order. Every political ideology, philosophy, or theory presents concepts to describe and interpret reality; those concepts need to be structured, and a certain level of coherence is expected from that conceptual set-up. Therefore, to identify a set of ideas as an ideology, a thorough analysis is required that reveals and understands the main components and their connections.

Only after unveiling the conceptual arrangement can we make our final judgement about whether transhumanism can be considered an ideology; if the answer is yes, we still need to describe its typology. Maintaining this order is particularly important in the case of a novel theory

\footnotetext{
${ }^{1}$ The term 'decontestation chain' was coined by Manfred B. Steger to describe the decontestation process as a chain of concepts and ideological claims (Steger, 2008).
} 
such that has never been the subject of such scholarly investigation before, where the analyst cannot build on previous works of other researchers. The ambition of this dissertation is to present the first ever ideological analysis of transhumanism, based on Freeden's methodology, and to put forward a solid argument that transhumanism is a thin-centred ideology.

\subsection{Structure of the Dissertation}

To advance the abovementioned aim, this dissertation is structured as follows:

The first part (Sections 1.3. and 1.4.) will discuss why the morphological approach is the ideal method of analysis in the case of transhumanism. First, it will outline the foundations of ideological analysis and the currently available methodologies for such investigation. It will briefly discuss the definitional issue and how scholarly debates over the definition of ideology led to methodological variations, drawing on the work of Maynard (2013) to explore different modes of ideological study in this context. Then, the attention will turn to the morphological approach established by Michael Freeden (1996, 1997, 2003, 2004, 2005a, 2006, 2013, 2015, 2017), one of the most acknowledged scholars in the field, who developed a unique approach to ideological analysis that this dissertation will follow in its methodology.

In pursuing this investigation, it is insightful to understand the process of development, the theoretical influences, and the critiques of other modes that shaped Freeden's unique approach. Next, the details of the morphological approach will be outlined, uncovering its typology of concepts, the principles upon which concepts are discerned from texts, and the processes through which ideologies transform their meanings (also known as the process of decontestation). Then, the need will be asserted for a form of analysis that is able to reflect the diverse factors to take into consideration when selecting the most appropriate methodology. In this respect three arguments will be suggested to support the choice of the morphological approach as the proper methodology for the ideological analysis of transhumanism. The subsequent section will present the selected transhumanist literature and other texts that underpin the ideological analysis to further clarify the 
selection criteria. Finally, a concise argument will be put forward to underpin the relevance of transhumanism for political science.

Chapter 2 will focus on the social and cultural context. This chapter is the updated version of the relevant sections of an earlier paper published in the Journal of Posthuman Studies (Szabados, 2019). It will summarise briefly the intellectual history of transhumanism, revealing its theoretical roots, introducing its main theorists and their key ideational claims, and highlighting the impulses that it received from other ideologies. Then, it will guide the reader through the milestones of the history of the transhumanist movement: the formation of various organisations think-tanks, NGOs, advocacy groups, and art ensembles - and its development into a global phenomenon with a multinational membership. Next, the quest to accept transhumanism in academic circles as an eligible subject for scientific scrutiny will be explained. To comprehensively reveal the process of institutionalisation, the final section in this chapter will cover the emergence of political representation among transhumanists and showcase the creation and current status of transhumanist political parties. Since the morphological approach utilises synchronic and diachronic analyses simultaneously, it is important to illuminate the embeddedness of transhumanism in its intellectual and social environment as well as its disruptive potential to challenge the political status quo. Such contextualisation is essential for a conceptual analysis as it reveals the presence or lack of particular ideological attributes.

In Chapter 3, the dissertation first engages in ideological analysis. The core issue concerns whether transhumanism can be a subject of ideological analysis in the first place. For this purpose, its ideological attributes will be investigated, building on Freeden's definition and characterisation of political ideologies. It will explore six main attributes and their components in connection with transhumanism to decide on its eligibility before moving forward with a more in-depth examination. This chapter will also review the description of transhumanism applied in consensus by its proponents. Furthermore, the typology of transhumanism will be presented together with the variants of transhumanist theories to show a full picture of the state of contemporary transhumanism.

Chapter 4 will be devoted in full to the Freedenian ideological analysis, which is divided into four main sections. The first three sections examine the major decontestations within the transhumanist conceptual architecture to reveal the core, adjacent, and peripheral concepts of 
transhumanist ideology and their positions within the ideational structure in accordance with the morphological approach. The development and articulations of five core and six adjacent concepts will be presented and explained alongside a number of peripheral concepts and their role in spawning ideological mutants within transhumanism. Special attention will be given to two critical accounts of transhumanism: the bioconservative critique presented by Francis Fukuyama and the moral philosophical critique put forward by Jürgen Habermas. Both were key in the articulation and morphology of main concepts of transhumanism. The analytical process will strictly follow Freeden's guidelines, drawing on his works about liberalism, social democracy, eugenics, feminism, nationalism, and ecologism, and will develop answers to the secondary research questions. Additionally, this section will unveil how transhumanism acquires unique issue ownership over a variety of social issues. It will further address its attempt to create a novel semantic field to frame and interpret the perceived consequences of techno-scientific progress, revealing an intellectual project far more substantive, complex, and encompassing than its frequent reduction to a mere dystopia.

Based on Freeden's sketch, Chapter 5 will present a conceptual map of transhumanism. This will underpin and visualise the key findings of the conceptual analysis and provide new insights into the study of transhumanism. Conceptual maps are one of the main outputs of the morphological approach in addition to decontestation chains: they are useful tools to render the complex structures of ideologies comprehensible.

The inferences from the preceding chapters will allow us to test the main hypothesis and to foreground a new account of the transhumanist thought system in Chapter 6. First, Freeden's definition of ideological thin-centredness will be discussed. Subsequently, a three-part argument will be offered to justify the categorisation of transhumanism as a thin-centred ideology. This section will collate the list of ideological components that are either present or missing from transhumanism and the consequences of this incompleteness. Finally, a detailed account of James Hughes's innovative spatial theory of $21^{\text {st }}$ century politics will be presented to test the potential of transhumanism to serve as a full-fledged ideology and to acquire dominant status among mainstream ideologies in the near future.

In the concluding chapter, the dissertation will draw these theoretical, methodological, and analytical strands together to appraise the main findings of the ideological analysis. It will offer a 
new account of transhumanism based on its existing conceptual architecture, its power to interpret social reality, and its capacity to contest other dominant and emerging ideologies. Then, two distinct scenarios will be outlined that detail the future of transhumanism in the ideological realm. In appraising these themes, the unique contribution of this work and routes for further analysis will be discussed, asserting that transhumanism has the capacity to become a mature ideology and has equal chances to realise either dystopian or utopian prognoses. Although it is impossible to precisely forecast the future trajectory of transhumanist ideology, an additional benefit of its ideological analysis for political scientists can confidently be asserted: it will aid any understanding of the relationship between ideology and techno-scientific progress.

\subsection{Ideology, the Semantic Troublemaker}

What is an ideology? Since the coinage of the term, an almost endless number of scholars have presented their own - sometimes incompatible - accounts of ideology. From Marx to Mannheim, from Althusser to Sartori, from Ricœur to Lukács, it is far beyond the permissible length of a doctoral dissertation to list the definitions provided by each scholar throughout history. As Anthony Giddens best summarised in reference to the frustration of attempting to find a concerted understanding of the concept ideology, 'if there were a prize for the most contested concept, the concept of ideology would very nearly rank first' (Giddens, 1983). Bernard Susser (1996) highlighted that the various definitions reflect the ideological bias of their authors, therefore conservative, liberal, and Marxist approaches can be distinguished that emphasise either the hyperrational, dogmatic, or power-related character of the concept. John Schwarzmantel (1998) argued that the lack of consensus about the role, position, and relevance of ideologies is another manifestation of the crisis of postmodernity in the social sciences and societies in general. John Gerring has referred to ideology as a 'semantic troublemaker' that raises irreconcilable definitional problems:

One is struck not only by the cumulative number of different attributes that writ essential, but by their more than occasional contradictions. To some, ideology is 
dogmatic, while to others it carries connotations of political sophistication; to some it refers to dominant modes of thought, and to others it refers primarily to those most alienated by the status quo (e.g., revolutionary movements and parties). To some it is based in the concrete interests of a social class, while to others it is characterized by an absence of economic self-interest. One could continue, but the point is already apparent: not only is ideology far-flung, it also encompasses a good many definitional traits which are directly at odds with one another. (Gerring, 1997, p. 957)

Instead, it is a more realistic endeavour to summarise the two mutually reinforcing topics in academic debates surrounding the study of ideology: the issue of characterisation and the ample variants of the methodology of ideological analysis available. Consequently, this dissertation will present a short list of the most significant comparative approaches to ideological analysis. It is important to note that each of those chosen for further discussion added new elements to the study of ideology and impacted the work of Michael Freeden in the course of developing his own account.

One of the first attempts at illuminating the various analytical forms was proposed by David M. Minar, who distinguished structural, functional, applied, and locally determined approaches to ideologies, each offering their own definitions, characterisation, and criteria (Minar, 1961). Instead of proposing another 'catch-all' definition to the plenitude of existing definitions of ideology, John Gerring collated an exhaustive list of all definitional attributes associated with the term within the available scholarly literature and ordinary usage of his time. Gerring's framework then allowed students of ideology to select from the basket of attributes those that best fit their analytical purposes. This type of freedom explains why a number of contradictory attributes are listed in his framework. As we will see, Gerring's list (see Table 1) is of particular importance to understand the Freedenian approach to ideological analysis.

Extensive and comprehensive as it is, Gerring's list had peculiar benefits for designing this dissertation. First, it provided a useful starting point for an initial test of the hypothesis and whether an analysis of transhumanism from an ideological perspective was a worthwhile approach. A rapid 'check list' revealed that transhumanism could indeed be located in the realms of philosophy, political behaviour, and language formation simultaneously: its subject covers a far-reaching 
worldview previously unseen among contemporary ideologies; and it offers strikingly novel and sometimes shockingly disturbing political solutions and presents a unique approach to power relations. Furthermore, transhumanism performs at least four out of the five functions from Gerring's list, and it can confidently be described by multiple attributes of the affective structure. Secondly, Gerring's account served as a thread in the labyrinth of methodological possibilities and finally guided the author of this dissertation to Michael Freeden's approach. Related to this point, the next section will reflect on the various noteworthy options that arose during the search for the correct methodology. Each option, to a certain extent, contributed to the final choice of methodology.

Table 1. Gerring's definitional framework for ideological analysis

1. Location
a. Thought
b. [Political] behaviour
c. Language

2. Subject matter
a. Politics
b. Power
c. The world at-large

3. Subject
a. Social class
b. Any group
c. Any group or individual

4. Position
a. Dominant
b. Subordinate

5. Function
a. Explaining
b. Repressing
c. Integrating
d. Motivating
e. Legitimating

Source: (Gerring, 1997, p. 967).
6. Motivation
a. Interest-based
b. Non-interest based
c. Non-expedient

7. Cognitive/affective structure
a. Coherence (internal)
b. Contrast (external)
c. Abstraction
d. Specificity
e. Hierarchy
f. Stability
g. Knowledge
h. Sophistication
i. Facticity
j. Simplicity
k. Distortion
1. Conviction
m. Insincerity
n. Dogmatism
o. Consciousness
p. Unconsciousness

One adherent of the discursive analytical school, Teun Van Dijk (1998, 2006), applied a multidisciplinary approach to the study of ideology by combining social cognition, society, and discourse as its analytical basis. His approach allowed for a general, non-pejorative definitional framework. Andreas Fagerholm (2016) distinguished two distinct types of ideology: the communal 
ideology re-defined as a full-fledged belief system with a wide range of semantic and linguistic apparatuses that dominate a society, and the particular ideology with a narrower collection of ideas consumed by and associated with certain groups within a society. The communal-particular distinction, which will be explained later, mirrors the thick-thin disparity applied in other, more popular approaches to ideological analysis. The main difference between the former and the latter lies in their conceptual approach to ideological analysis, which leads to a broader analytical perspective and a scope that extends beyond the semantic field of ideology. Carmines at al. (2015), for example, offered a broader, multi-dimensional view of ideology, adding values and principles held by individuals to the scope of empirical research on belief systems. Mostafa Rejai identified five dimensions of ideologies and their manifestations: cognitive (knowledge and belief), affective (emotions and feelings), evaluative (norms and judgements), programmatic (plans and actions), and social-base (supporting groups and collectivities) (Rejai, 1995, p. 4). The functionalist school emphasised that ideologies serve as guides to cultural and political orientations. The system justification theory within the functionalist approach posits that 'people adopt ideological belief systems at least in part to help them understand, predict, and perhaps even rationalize current societal arrangements (or alternatives to those arrangements)' (Jost, Kay and Thorisdottir, 2009, p. 8). This can result in the perplexing phenomenon of the acceptance, even defence, by the underprivileged of the sometimes stark inequalities in wealth, status, and power in societies.

Simultaneously with the expansion of the definitional discussion, scholars have argued that ideologies are artificial constructions, that ideology itself is such an incomprehensible term that it is better to entirely neglect it, or, alternatively, have concluded via empirical studies that the mass public is unsophisticated and nonideological. Among the reductionist accounts, Philip E. Converse's seminal work stands out. Converse minimised ideology to a belief system, in which idea-elements are bound together by logical, psychological, and socio-cultural constraints and form a recognisable structure (Converse, 2006). Even more radically, Slavomir Zizek, frustrated by this definitional elusiveness, posed a provocative question about this charged term: 'Is not its utterly ambiguous and elusive character in itself a sufficient reason to abandon it?' (Zizek, 1994, p. 3). Beyond this 'de-ideologised world' theory of the late $19^{\text {th }}$ century and its re-emergence in the 1960s, the 'end of ideology' debate was given a new impetus when Fukuyama presented his 'dominant ideology' theory (Fukuyama, 1992). However, the academic community, including 
Fukuyama himself, today agree that the 'end of ideology' theories failed the test of history (Steger, 2009, pp. 2-6).

Incertitude surrounding the various accounts of the definition of concept, the main components of ideologies, further exacerbated the definitional issue. Max Weber explained this uncertainty with the contextual indeterminacy of concepts:

The attempt to determine the 'real' and the 'true' meaning of historical concepts always reappear and never succeed in reaching their goal. [...] [N]one of those systems of ideas, which are absolutely indispensable in the understanding of those segments of reality which are meaningful at a particular moment, can exhaust its infinite richness. [...] The progress of cultural science ... is the perpetual reconstruction of those concepts through which we seek to comprehend reality. The history of the social sciences is and remains a continuous process passing from the attempt to order reality analytically through the construction of concepts ... and the reformulation anew of concepts on the foundations thus transformed. (Weber, 1949, p. 105)

Walter B. Gallie, and later John Gray, explained this elusiveness by referencing the essential contestability of any concept, given that 'our social and political thought occurs in a social environment marked by profound diversity and moral individualism' (Gallie, 1955; Gray, 1977, p. 337). Concepts do not attain temporally and spatially fixed meanings, but are flexible creations that are open for re-interpretation as historical context changes.

From this cacophony one may outline a broad definition of ideology, which does not reflect scholarly consensus, but may serve as a starting point from which Freeden's contribution to this debate can be properly examined: ideology is a general political and socio-economic worldview, a 'highly differentiated attitude structure' held by individuals, and comprises of a set of 'interconnected and functionally interrelated beliefs' (Campbell et al., 1960, pp. 192-193). When a set of interrelated beliefs with a coherent conceptual structure is shared by a group of people, it starts to develop into a full-fledged ideology (Denzau and North, 1994). 
Despite the polemical atmosphere surrounding its definition, what contemporary scholars agree on, however, is that ideologies can be subjects of rigorous empirical research (Minar, 1961, p. 327). If decades-long scholarly debates have not resulted in a consensus about a single universal definition of ideology, then it is not surprising that contemporary discussions are also divided regarding the adequate methodology of ideological analysis. Jonathan Leader Maynard (2013) has presented an excellent summary of current methodologies that scholars may apply to ideological analysis. His methodological map distinguishes three broadly defined approaches: conceptual, quantitative, and discursive analysis. Figure 1 shows the various branches of methodological approaches to ideologies put forward by Maynard.

Figure 1. Maynard's map of the field of contemporary ideological analysis

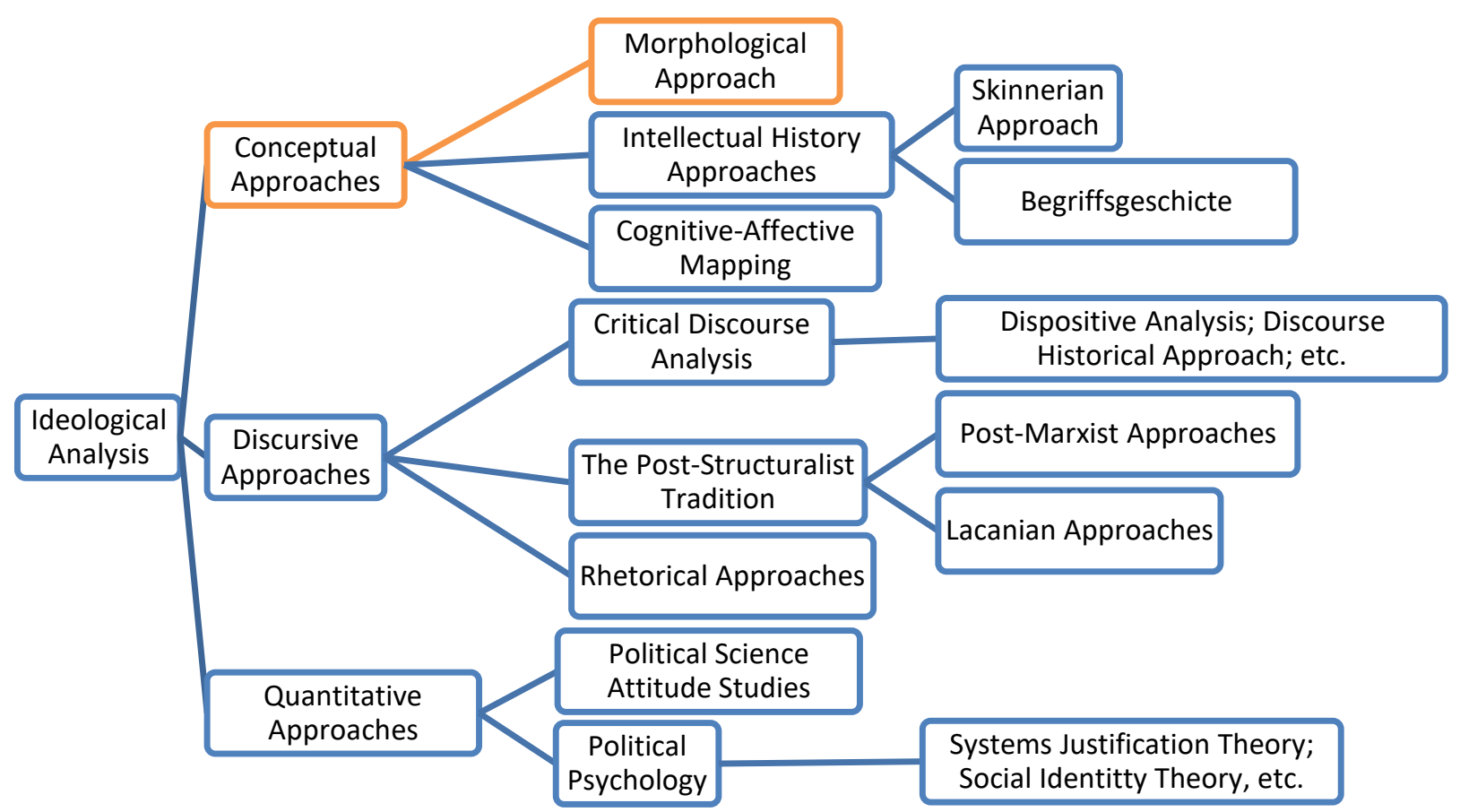

Source: Maynard (2013).

According to Maynard's description, the conceptual family of methodology focuses on the ideational content of belief systems instead of their discursive, institutional, or cognitive layers. Its main sources are the seminal works of leading intellectuals, the discursive activities of key political 
players - both persons and organisations - and the arsenal of symbols - both linguistic and nonlinguistic - that are utilised to make ideological claims palatable for mass consumption. Conceptual methodologies attempt to reveal how ideologies attain control over political language through allocating particular meanings to essentially contested concepts in order to generate (or avoid) changes in society. The conceptual approach, claimed Maynard, is non-pejorative (as opposed to critical discourse and post-structuralist methodologies) and disapproves of the traditional unidimensional (on the liberal-conservative axis) theorisation of ideologies, offering instead a multi-dimensional or non-dimensional conceptualisation.

Today, the central role of ideology is reflected in the great number of scholarly publications that gauge various aspects of the effects of belief systems in modern societies. There is widespread academic consensus that ideology affects electoral behaviour, the acceptance or denial of public policy proposals, and a person's moral and philosophical attitudes. The methodological variegation of the study of ideology is a further attestation of its salience as a subject of scholarly interest.

\subsection{Methodology: Michael Freeden's Morphological Approach}

Within the concept-based group, Michael Freeden's morphological analysis is considered one of the most influential. Freeden outlined his theory of ideology - what he has called the morphological approach to ideological analysis - in a multitude of texts, book chapters, and journal articles. This dissertation mostly consulted three books, Ideologies and Political Theory: A Conceptual Approach, published in 1996; Ideology: A Short Introduction, published in 2003; and Liberal Languages, published in 2005, as well as the book chapters that appear in Reassessing Political Ideologies: The Durability of Dissent (2001), in the Handbook of Political Theory (2004), and in The Oxford Handbook of Political Ideologies (2013). Additionally, he applied his methodology to liberalism, nationalism, ecologism, fascism, feminism, and eugenics in various articles to which this paper will extensively refer in its course of analysis. In his works, Freeden has provided a detailed account of his intellectual progress: which theories of ideology influenced the development of his own trademark methodology and which ideas from the vast array of 
proposals put forward by theorists of ideology in the last two centuries he questioned or neglected, and for what reasons.

From the outset, Freeden was cautiously critical of the Marxist understanding of ideology. He rejected the monolithic Marxist idea that ideology is an abstract category that only serves to obscure and distort reality and, further, its definition as a temporal pathology of historical developments that will disappear once class struggle reveals true social relations and ends exploitation. He disapproved of the exaggerated importance of the perilous role that Marxists associated with ideologues in maintaining oppressive social hierarchies. He also argued vehemently against the disparaging opinion of the study of ideology expressed by Marxist scholars, many of whom claimed that there was less scientific value in the thorough examination of the nature and variations of ideologies. Instead, Freeden remained faithful to Antoine Destutt de Tracy, who coined the term, and his original mission to develop a science of ideas on an empirically verifiable basis.

Despite his criticisms, Freeden found several benefits of the Marxist interpretation of ideology. He incorporated into his own approach the idea that the scientific examination of ideologies should take into consideration the historical circumstances and the socio-cultural environment in which variations of ideologies are born out and develop. He also approved of and assigned even more significance than Marx to structured thought patterns, as they provide an interpretation of the political reality that groups of people share as truth claims. However, he denied the Marxist premise that ideology necessarily and in each case creates a false illusion. Freeden accepted that ideologies are to a certain extent linked to power relations in that their main function serves to inspire and rationalise political actions and legitimise or question the power of decisionmakers. Finally, Marxist theorists and Freeden agreed that ideologies create a surplus of meaning, including layers of ideas that do not necessarily reveal themselves to the consumer of ideological claims. Therefore, Freeden concluded that 'the study of ideology encompasses ... decoding, and identifying structures, contexts, and motives' that are hidden from the followers of ideologies (Freeden, 2003, p. 11).

Relatedly, the work of three Marxist theorists greatly contributed to the development of Freeden's study of ideology: Karl Mannheim, Antonio Gramsci, and Louis Althusser. From Mannheim, Freeden highlighted the invention of the concept of relationism: the interdependent 
nature of ideas, the qualitative pluralism of co-existing interpretations of social reality, the ideological basis of the sociology of knowledge, and, most importantly, the potential positive roles of ideologies. Gramsci refined the concept of hegemony within the ideational framework inasmuch as hegemony can be exercised through cultural means by non-state actors (intellectuals), not simply by the ruling classes who control the coercive power of the state. Gramsci's theory, as Freeden interpreted it, shifted greatly from Marx's understanding of ideology as an abstract and elusive concept, and emphasised instead the close link between thought and (political) practice, the interaction of which creates cultural domination in society through forging consensus and solidarity between intellectuals and the masses. The most important takeaways for later scholars from Althusser's description of ideology were the claims that it possessed a set of intrinsic features irrespective of spatial and temporal historical circumstances, that ideologies materialised in what he called social apparatuses (norms, laws, institutions, and practices), and that ideologies are not only group products but are owned by individuals as subjects. Despite its undisputable contribution to the study of the subject, its fallacies and pathologising nature led Freeden to conclude that the 'Marxist conception had apparently brought Western theories of ideology to a dead end' (Freeden, 2003, p. 38).

Within the - mostly U.S. based - behaviourist tradition of the 1960s and 1970s, Freeden extolled its exploration of ideologies as 'observable forms of human conduct' that develop into belief systems 'acknowledged as emotionally charged rationalizations and justifications' (Freeden, 2003, p. 39). But he also criticised the behaviourist approach for its treatment of ideology as an unstructured and intellectually superficial phenomenon and maintained that behaviourist scientists analysed ideologies with simplistic methods (e.g. opinion polls, field research).

Among the many representatives of the various disciplines beyond political science who contributed to the research of ideology, Freeden praised the anthropologist Clifford Geertz for revealing the autonomous process of symbolic formulation as the main connecting element between ideology and its effects. Geertz described ideologies as 'systems of interacting symbols, as patterns of interworking meanings' (Geertz, 1973, p. 207) and provided an analytical framework to gauge the figurative language of ideologies used to interpret social reality. He, as did Freeden, considered ideologies maps of a country that guide us from one town to another, connected by roads and railways. In this metaphor, towns are concepts that are located closer or further from 
each other, have direct and strong connections, or are accessible only through other concepts. The geographical arrangement of towns endows a country with a particular and easily recognisable aerial view, just like the arrangement of concepts is unique to each ideology.

The study of ideology was also heavily influenced by the discipline of linguistics. Approaching ideologies as linguistic and semantic products opened up a totally new dimension for researchers. As an example, Freeden praised the contribution of Ludwig Wittgenstein, who posited that languages are games played according to the rules of grammar. Building on this, Freeden wrote:

ideologies ... are a form of language game, whose meaning and communicative importance can only be determined by noting their grammar (the fundamental structures and patterns of relationship among their components), their conventional employment in a social context, and the degree of acceptability of the rules by which they play. (Freeden, 2003, p. 43)

Wittgenstein's notion of family resemblance helped scholars to identify temporal variants of ideologies more precisely by revealing, classifying, and grouping their shared or distinct properties. It also illuminated the intrinsic flexibility and inclusive nature of ideologies in their historical context. But most importantly, the linguistic approach revealed the significance of the unconscious layer of the consumption of ideologies by individuals. This process manifested in what Paul Ricœur - borrowing from and reformulating Marx - termed the surplus of meaning. The French philosopher, a prominent representative of the psychoanalytical school, claimed that 'ideology functions to add a certain surplus-value to our belief in order that our belief may meet the requirements of the authority's claim' (Ricœur, 1986, p. 183). For the students of ideology, the main take-away from Ricœur's insight was that the consumption of ideological claims is as worthy of investigation as its production: the internalisation of ideologies is partly an unconscious process at the individual level, therefore this surplus of meaning may have unintentional and unforeseeable effects on the bearers of an ideology.

From the hermeneutical school, Freeden borrowed two main ideas: first, that the meaning of ideational texts needs to be decoded by taking into consideration their historical and social 
embeddedness, in the Mannheimian sense; and second, the polysemic nature of ideological texts, in that there is no single authoritative interpretation of an ideology, although cultural and historical constraints reduce the available space of comprehension and rule out scientific relativism.

Probably the closest approach to Freeden's is represented by Begriffsgeschichte, or conceptual history - an offshoot of the hermeneutic school - which gauges ideas diachronically, thus proposing that the genesis and evolvement of their meanings is a historically cumulative process. Reinhart Koselleck's theory of historical time and his conceptual use of horizon and the resulting framework were especially inspiring for ideological studies; they described the complex interrelations of concepts and their impact on interpreting past and present social realities. As Koselleck claimed, '[n]o event can be narrated, no structure represented, no process described without the use of historical concepts which make the past "conceivable", (Koselleck, 1990, p. 112). The dual - diachronic and synchronic - perspective of conceptual history provides crucial clues for the ideational and cultural settings in which ideological products are conjured as well as revealing the future-oriented characteristic of ideologies. 'Time and space become two intertwined parameters', as Freeden stated (1997, p. 5). Ideologies seek to transform, transcend, or preserve prevailing social and political arrangements through political activism, mobilisation, and the promise of a better world that may or will happen. This is not to be mistaken for utopian visions of the future: established ideologies such as liberalism or socialism offer realistic means and (at least seemingly) achievable goals, adding open-ended time into political discourse, while conservativism warns of a negative possible future as a consequence of disruptive social changes.

In addition to its illuminating contributions, Freeden also drew attention to the reduced applicability of conceptual history regarding ideological analysis. Most importantly, this approach focuses on the seminal works of outstanding individuals, ignoring that ideologies are group products emerging from a wide semantic field, which are formed by the interaction of rational thinkers exchanging and contesting ideas at a given time and space. He concluded that

[conceptual history] tells us about what happens to political concepts, but not about what happens to ideologies when political concepts interact in different ways. It is only a partial perspective on the ideational complexity and abundance that ideologies present. (Freeden, 1997, p. 7) 
As we have seen, Freeden borrowed ideas, methods, and insights from the long history of ideological analysis and was inspired by theorists with various disciplinary backgrounds when developing his own approach. He also provided a detailed guide to his hallmark methodology, which he described as

a general method of investigating and decoding the internal structure of ideologies, highlighting the central role of that structure in fashioning the semantic fields of all ideologies, and offering a revealing insight into the ways ideologies consequently construct the political and navigate through it. (Freeden, 2013, p. 115)

Freeden posited that the morphological approach 'explores the choices any given combination of norms and political concepts opens up or closes, which can then be appraised against whatever political arrangements are deemed desirable by the analyst'. It decodes preferences and understandings of the social world and unpacks the beliefs contained within a given ideology, accounts for them, and maps their complexity. It then 'examines the logical and cultural constraints that make a particular set of political concepts intelligible, attractive, or legitimate' (Gaus and Kukatha, 2004, pp. 7-9).

Freeden's approach focuses on the ideational content and the conceptual structure of belief systems and is less concerned with the manifestation of those concepts in institutional or psychological layers. Morphological analysis also reveals the macro- and micro-structures of concepts, their relative positions to each other, and the interdependence and interactions among various concepts and conceptions. The results of such investigations are always comprehensive frameworks through which groups of people understand their political and socio-economic world, express their identity, and allocate meaning and significance to certain concepts. The morphological approach holds that the core elements of an ideology are concepts, for example liberty, equality, order, authority, and welfare (2004, 2005a, 2005b, 2006). Freeden thus defined ideologies as 
distinctive configurations of political concepts [that] create specific conceptual patterns from a pool of indeterminate and unlimited combinations. That indeterminate range is the product of the essential contestability of political concepts, and essential contestability provides the manifold flexibility out of which ideological families and their subvariants are constructed. (Freeden, 1996, p. 4)

In short, concepts form complex combinations and clusters, the structured patterns of which create a particular ideology. However, it is impossible to provide a universal evaluation of a political concept because the concepts themselves are not solid, fixed ideas, but rather fluid and flexible elements that always contain further components. For example, there is a broad, universal definition of the concept democracy, but added components - such as 'liberal', 'illiberal' or 'direct' - help deploy specific meaning and context to the original concept. This results in sometimes incompatible variations in its manifestations and interpretations. Thus, Freeden concluded, political concepts always contain manifold conceptions. 'Foundational concepts ... are essentially contested; they will inevitably have multiple incompatible meanings, reflecting the multiple differences in worldview' (Jost, Kay and Thorisdottir, 2009, p. xiv).

This flexibility is further strengthened by the polysemy of language, as described by the hermeneutic school, which prevents concepts from acquiring a single, reduced, and unanimously shared meaning. Meanings are in a permanent state of contention in a given time and place. Therefore, concepts must be simultaneously analysed from a diachronic perspective, due to their 'strong historical grounding' (Freeden, 1996, p. 52), and their synchronic position, which is determined by their cultural embeddedness - a claim that Freeden borrowed from the discipline of conceptual history.

The flexibility of concepts (similarly to a language or a word) derives from semantic ambiguity, indeterminacy, vagueness, and inconclusiveness (Freeden, 2015, pp. 121-122). Concepts are ambiguous - possessing multiple meanings - which can be resolved or ameliorated by contextualisation. Conceptual indeterminacy means that the ideational components of a given concept can be arranged in endless ways that - in the simplest cases - finetune but may completely redefine its meaning, and these components have their own conceptual histories and semantic issues, similar to their host concept. Vagueness refers to the blurred boundaries and overlap among 
concepts, as can be seen in the case of socialism and social democracy. Inconclusiveness is a symptom of the limits of human cognitive capabilities: as an argument shifts from the most precise meaning of a concept to its particularities, for example, we are unable to reach an endpoint. It is impossible to comprehend a concept through revealing all its microscopic details, just as it is impossible to define the notion of consciousness by identifying and describing each and every neuron of the human brain. This extreme flexibility may seem to be a curse, but in reality, it is a blessing for ideologies (and ideologues) as it allows for injecting concepts with new layers of meaning. For example, the term 'migrant' was restricted to academic usage in the Hungarian language - absent from the vocabulary of ordinary people - until Viktor Orbán deployed it regularly in his populist political discourse, after which it became a part of everyday usage.

It is the desire to constrain this extreme flexibility that explains how, in its quest for semantic hegemony, ideology confers a specific meaning to a political concept. Freeden has termed this the process of decontestation: an ideology 'attempts to end the inevitable contention over concepts ... by removing their meanings from contest'; in other words, decontestation is the determination of meaning based on a specific morphological arrangement (Freeden, 2013, p. 120). Decontestation is the way an ideology allocates a particular meaning or adds a stipulative definition to a concept distinguishing it from how other ideologies conceptualize the same concepts. As Freeden perspicaciously expressed wrote:

the main feature of ideologies is the morphological act of decontestation, of prioritizing among options, of accepting or ruling out paradigms that interpret political reality, of competing over the legitimate meanings assigned to political language, of pronouncing not on which political values are true or false, but on which conceptual combinations are available to be applied to the understanding and shaping of the political world. (Freeden, 1996, p. 551)

Concepts are imbued with distinct, though by no means permanent, meanings. Meaning can change temporally within a given ideology, or spatially - as decontestation allows for two ideologies to allocate completely different meanings to the same concept (as is the case with the liberal concept 
self-determination, which has been decontested in an entirely different way in transhumanism, as will be discussed in Chapter 4).

Using the notion of decontestation, Freeden further elaborated his own definition of ideology, adding that (1) an ideology is a wide-ranging structural arrangement that attributes decontested meanings to a range of mutually defining political concepts; and (2) ideologies compete over the control of political language, through which the competition over public policy is primarily conducted (Freeden, 2003, p. 53). Furthermore, decontestation, or using Richard Shorten's subtle metaphor the 'sacralization of a concept' (Shorten, 2007), is the process by which a concept is promoted to a position of supreme ineliminability (Freeden, 1996, pp. 62-65). Ineliminability, another key term introduced by Freeden, means that if an ideology is deprived of a certain concept it loses its ideological position. A prime example is the concept of liberty within liberalism: without it, liberalism is undiscernible, and its internal coherence collapses.

In addition to the notions of decontestation and the ineliminability of concepts, the third pillar of Freeden's method is the structural analysis of concepts. Ideologies exert control over political language, political arrangements, and political processes, not only through allocating meanings to various political concepts. Ideologies prioritise and position concepts as well as define their interrelations in the political space based on the '4Ps':

- proximity: political concepts can only be understood when examined within a particular idea-environment of surrounding concepts;

- priority: the allocation of significance to each concept, the ranking of concepts;

- permeability: there are no exclusive ideas, concepts, and conceptions; they intersect with one another at multiple points of contact;

- proportionality: the relative space within each ideology allotted to a particular theme, or cluster of concepts. (Freeden, 2003, pp. 60-65)

Utilising the 4Ps model, morphological analysis differentiates core, adjacent, and peripheral concepts when examining the macro-structure of an ideology (Freeden, 1996, p. 77). As Freeden discussed: 
[i]deologies possess an elaborate structure, analysable on two main axes. First is a three-tier distinction between concepts (the middle tier), their micro-components, and their macro-conceptual concatenations ... the arrangements among the components generate diverse conceptions of any concept; while the clusters of concepts form the specific anatomy of an ideology. Within those relatively flexible clusters lies the second axis, the distinction between core, adjacent, and peripheral concepts. The relationships among concepts are decisive here: the relative positioning of concepts is not set in stone and will fluctuate - though at variable speeds - over time and across space. (Freeden, 2013, p. 124)

Core concepts are characterised by their long-term durability, ubiquitousness, and indispensability. They are present in all versions and mutations of the ideology and determine the ideational content of the belief system. However, Freeden dismissed the notion that major ideologies can be identified by a single, central concept. He posited instead that 'even ideological cores contain a number of key concepts that, although omnipresent, may be accorded different proportional weight in each particular manifestation (of a given ideology)' (Freeden, 2013, p. 125). He also noted that 'the core concepts of an ideology are non-specific, allowing for diverse interpretations to be attached to them through adjacent and peripheral concepts' (Freeden, 1996, p. $85)$.

Adjacent and peripheral concepts refer to the mutations of core concepts. They appear less frequently than core concepts and refine the meaning of the ideological core. Combinations of adjacent and core concepts create different versions of an ideology. Adjacency can be determined by logical inferences as well as cultural variables. As Maynard has described:

[t]he mapping of morphological changes, the analysis of logical and cultural adjacency between ideological concepts, and the identification of ... 'ineliminable' features of concepts (not mystical intrinsic meanings, but generally shared and therefore de facto conventionally 'constant' elements), are thus central tasks for morphological analysis. (Maynard, 2013, p. 303) 
Concepts are logically adjacent if their connection reflects some type of necessity that either allows for a more concrete, accurate, and comprehensible specification of the original or, on the contrary, it creates the possibility of novel interpretations. Logical adjacency is therefore a two-way road: it can both reduce or expand the variants of a given concept (Freeden, 1996, pp. 68-69). Cultural adjacency, on the other hand, exerts contextual constraints on the meaning of concepts: the socioeconomic environment, institutions, traditions, ethical norms, mass beliefs, etc. prevalent in a specific era or geographical location may limit the number of interpretative paths of decontestation, thus preventing the concept from overloading with too many meanings that the logical adjacency would otherwise permit. Nevertheless, in certain cases cultural adjacency overrides logical connections between concepts. For example, women are human beings just like men, thus their deprivation of equal voting rights is illogical, but this practice was culturally legitimate for a very long time (Freeden, 1996, p. 71).

Table 2. The typology of concepts within the morphological approach CONCEPT TYPE

\begin{tabular}{|c|c|c|c|}
\hline & Core & Adjacent & Peripheral \\
\hline Lifetime & long-term durability & shorter & appear and disappear \\
\hline Presence & ubiquitous & less frequent & react to externalities \\
\hline Location & central, indispensable & attached to the core & $\begin{array}{l}\text { capable of shifting to } \\
\text { adjacency or core } \\
\text { position }\end{array}$ \\
\hline Role & $\begin{array}{l}\text { determines the } \\
\text { ideational content of an } \\
\text { ideology }\end{array}$ & $\begin{array}{l}\text { combinations of adjacent } \\
\text { and core concepts create } \\
\text { different versions of the } \\
\text { ideology }\end{array}$ & $\begin{array}{l}\text { marginal, partially } \\
\text { readjust the core and } \\
\text { adjacent concepts }\end{array}$ \\
\hline Example & liberty in liberalism & liberal democracy & immigration \\
\hline
\end{tabular}

Peripheral concepts play a marginal role, rapidly change both culturally and diachronically, and are capable of moving to the ideological centre to become adjacent concepts or - in rare cases - core concepts. They react to externalities and, therefore, are sometimes connected to social practices, cultural variances, or historical events. In short, 'peripheral concepts ... link ideology to a particular context' (Stanley, 2008a, p. 107). Ideologies can react to these externalities in three 
modes: acceptance, rejection, or obfuscation (Freeden, 2013, p. 126); peripheral concepts determine the first and third modes. Table 2 summarises the Freedenian typology of concepts and their main features.

Freeden demonstrated the conceptual arrangement of an ideology with the analogy of a room: whereas all rooms contain furniture, it is the selection and configuration of the furniture that truly reflects the type of room and the activities performed within it. As he illustrated:

[a] room with a table at its centre may be a billiard room, a dining room, or a study. It is unlikely to be a bedroom. If a table is surrounded by four chairs and a tablecloth, rather than by strong arc lights, surgical equipment, and an anaesthetised person, it is most probably a dining table, not an operating one. Now this is exactly the case with an ideology. If we find liberty, rationality and individualism at its centre, while equality - though in evidence - decorates the wall, we are looking at an exemplar of liberalism. If, order, authority and tradition catch our eye upon opening the door, while equality is shoved under the bed or, at best, one of its weaker specimens is displayed when the guests arrive, we are looking at a version of conservatism. (Freeden, 1996, p. 162)

The task of the political scientist is to explore the furniture in the transhumanist room and then infer from the findings what purposes they serve and what people might live there.

\subsubsection{The Benefits of the Morphological Approach}

The overview in the previous section outlined the analytical framework Freeden developed to account for ideology, detailing his focus on concepts and their spatial and temporal arrangements. But why should one choose Freeden's method over others to explore the furniture in the transhumanist room?

The morphological approach has multiple advantages for the student of ideologies, among which the most important is its lack of negative preconception against the subject of its scrutiny: it disapproves of the pathologisation of ideologies. As many scholars and Freeden himself pointed out, the analytical critical discourse and post-structuralist approaches inherited the historical 
prejudice against ideologies. Their advocates always conduct their analyses within a socioeconomic framework, which connotes that ideologies are socially constructed, play a central role in shaping power relations and dominance within society, and inevitably serve the interest of power holders over the underprivileged. Therefore, their predisposition towards ideologies is necessarily, though to a varying degree, derogative. Yet the morphological approach is not loaded with such value-laden bias and the student of ideology is not obliged to be critical towards the object of their research from the outset. Despite praise for its lack of prejudice, this is by no means intended to imply that the morphological approach is superior to other methodologies. Nor is this meant to suggest that the morphological approach lacks any qualitative characteristics and valorises all ideologies equally, disregarding either the negative intentions that certain ideologies hold or the horrible consequences that zealous advocates have induced (e.g. fascism). On the contrary, the Freedenian analysis of layered thought patterns does provide qualitative assessment on two levels, ethical and structural:

Nor does morphological analysis ally itself with extreme relativist positions; it can still maintain that ideologies exhibit better and worse conceptual arrangements, and evaluate them on the work that its practitioners are charged with accomplishing. Communicability, persuasiveness, electoral success, popular support, intellectual soundness (to include minimal logical coherence and affinity with an empiricallyobservable world), affective identification, imaginative creativity, the durability of problem-managing, adaptability, are some of the criteria for assessing the quality and the efficacy of an ideology, quite apart from the ethical values it endeavours to promote. (Freeden, 2013, p. 131)

This dual assessment allows for a deeper understanding of the role a particular ideology plays in a given socio-economic context: why it is successful, what political disruption it generates, how it challenges the social order and the dominant belief system(s). At the same time, it leaves ample space for the critical assessment of its performance, effects, and consequences in terms of social arrangements. 
Second, the morphological approach seems suitable for detecting immature or protoideologies that do not yet participate in the ideational competition as a salient player. For instance, for a post-structuralist researcher, transhumanism would have been nearly unnoticeable due to its low number of followers and that it is absent from well-disguised mass media and mainstream political discourse. On the other hand, it is fair to note that transhumanism can easily be analysed within those theoretical frameworks that focus on power relations and dominance-seeking in societies. Since morphological analysis considers intellectuals - 'theoretical influencers' - the main agents of an ideology, it seems more capable of spotting emerging ideologies that have the potential to transform the ideational contest. Theorists, philosophers, novelists, and artists are as - or sometimes even more - important for the morphological analyst as political organisations or leading political figures.

Third, the morphological approach does not separate ideologies from each other with theoretical barbwire. Conversely, the borders between various ideologies are permeable and allow for the exchange of ideas, conceptualisations, or definitions without weakening a belief system's solidity or undermining its internal coherence. As we will see, transhumanism borrows - or more aptly incorporates - complete meaning structures from contested ideologies without losing its unique character or enfeebling its ideational macro-structure.

Fourth, unlike other approaches, Freeden's morphological analysis moves beyond the leftright axis of conceptualisation, deploying instead a multi-dimensional research toolkit for the ideational study. The constraints of traditional unidimensional approaches hinder the researcher of ideology from properly understanding, describing, and utilising the great variety of elements applied in contemporary political discourse and actions. The limitations of one-dimensionality are particularly conspicuous in the case of transhumanism, which attempts to render new understanding and content to the political left and right. Thus, a morphological analysis seems to be more applicable for a substantive research.

Finally, conceptual mapping is a highly accessible mode of ideological analysis: such a visualisation provides a clear representation of ideological composition, which at the same time reveals the differences between ideologies and their mutations and can trace spatial and temporal changes to describe the position, ranking, and prevalence of components. The morphological approach enables researchers to pinpoint an ideological position at a given point in time and 
conduct a synchronic comparison with contested ideologies within the socio-economic context of that era, whereby the historical evolution of the given ideological position can also be revealed. These possibilities are conceptually and methodologically appealing as they not only improve the adequacy of the analysis, but also provide guidelines by which to map and explain long-term trends. Freeden's method is a particularly neat tool for the contextual mapping of the structural arrangement of transhumanism, which in the $21^{\text {st }}$ century aims to translate techno-optimistic, proscience theories into full-fledged political programmes.

\subsubsection{Selection of Literature and Texts}

The morphological analysis will be conducted using key texts that have exerted lasting influence on the political ideas of transhumanism. Ideologies are articulated in three basic forms according to Freeden. First, a few outstanding thinkers lay down the basis of a new theory, outlining its fundamental concepts in philosophical books and other scholarly texts. Then, the theory penetrates further discursive levels and appears in various written sources that reach a wider audience: political articles, pamphlets, party manifestos, blog posts, or tweets. Finally, the theory develops its creative, symbolic, and visual manifestations in the form of flags, logos, national anthems, slogans, uniforms, and other instruments that translate and transmit political messages. This dissertation's ideological analysis is based on scholarly texts that fall into the first two categories.

The core tenets of transhumanist politics have been outlined in a few key books, articles, and papers authored by FM-2030, Max More, Natasha Vita-More, James Hughes, Nick Bostrom, Anders Sandberg, Stefan Lorenz Sorgner, and, most recently, David Wood. The analysis will also include the works of philosopher Julian Savulescu. Although Savulescu does not consider himself a transhumanist, his views on the ethics of genetic engineering have greatly inspired transhumanists and provided useful arguments for key transhumanist ideas. The works of these thinkers are the most frequently quoted and referenced texts in both scholarly and vernacular debates on transhumanist issues, therefore, this dissertation will extensively refer to them.

The extension of the analysis to the second discursive level is supported by the fact that key theorists of transhumanism have been actively participating in the formation of transhumanist political organisations. It underpins why political texts (manifestos, declarations) can and ought to 
be included in an ideological analysis. Natasha Vita-More, one of the founders of the early transhumanist movement and a leading theorist of transhumanist art and design, was the first transhumanist elected to a political position; Zoltan Istvan, the author of the bestselling novel, The Transhumanist Wager, is the founder of the U.S. Transhumanist Party and was the movement's first presidential candidate in 2016; philosopher James Hughes, the former chairman of the World Transhumanist Association, is a protagonist of the technoprogressive movement, the left-leaning political branch of transhumanism; and David Wood, the author of eight books on miscellaneous transhumanist topics, is the executive director of Transpolitica, a UK-based transhumanist political think-tank, as well as the treasurer of the UK's Transhumanist Party. Not surprisingly, the programmatic political texts reflect their theoretical works and serve as useful sources for an ideological analysis.

\subsubsection{Transhumanism as a Subject of Ideological Investigation}

The study of transhumanism as an ideology has various benefits. First, it can provide farsighted explanations of the effects of techno-scientific achievements on political theory and practice in general, as well as illuminating the growing popularity of the pro-science transhumanist movement among specific social groups. By uncovering ideological morphologies, it is possible to depict how certain transhumanist ideas, manifested as decontested concepts, interlink to form a unique, multi-layered, utopian vision of society that currently no other ideologies represent. Second, it helps follow and gauge the historical development of transhumanist thought, therefore, both diachronic and synchronic analyses are possible. Furthermore, only by showing its interactions with other, competing ideologies can one understand the articulation of transhumanist political offerings and the policy initiatives put forward by transhumanist political parties in recent years. Finally, bringing ideology into the analysis of transhumanism allows us to look at current trends in political theorising from a valuable and new perspective. 


\section{A Brief History of the Transhumanist Movement ${ }^{2}$}

Nick Bostrom, the Swedish-born Oxford scholar, has named the epistemic maximalism of the Enlightenment one of the most important theoretical antecedents of transhumanism (Bostrom, 2005b, pp. 2-3). From Newton to Kant to Condorcet, many thinkers in the seventeenth and eighteenth centuries posited that rational thought and the desire for and moral duty to acquire ever greater knowledge are the key drives for humanity to maximise happiness and the fulfilment of the self. Some later followers in the nineteenth and twentieth centuries further developed this idea, claiming that the greatest obstacles to realising the human telos lie in its 'human' nature, understood as biological, physical, and cognitive limitations. These thinkers have contemplated the possibility of overcoming these boundaries.

One might infer from the idea of overcoming human boundaries that transhumanism is strongly attached to Nietzsche's philosophical ideas, particularly his concept of the Übermensch. However, transhumanists are deeply divided over the Nietzschean heritage. Nick Bostrom argued that this connection is only superficial because Nietzsche did not refer to a 'technological transformation but rather a kind of soaring personal growth and cultural refinement in exceptional individuals' (Ibid.). On the other hand, Stefan Lorenz Sorgner, an acclaimed Nietzsche scholar and a prominent researcher of transhumanism, insisted that, according to Nietzsche, the process of making the evolutionary step to 'overhuman' would require that science and scientific-minded people deprive God and metaphysics of their dominance in the near future (Sorgner, 2009). In Sorgner's view, the Übermensch has been presented as the embodiment of a higher order of cognition, psyche, and morality, an expanded and more inclusive understanding of normalcy with regard to the physical body, and a higher mode of human existence. The dispute has not been settled until this day.

The transhumanist endeavour to dismantle the obstacles to endless human development with the help of science and technology led to the creation of futuristic visions of new social models, improved human conditions, and abundant economic wealth, as well as producing its dystopian counterculture. The term 'transhumanism' was first used by Julian Huxley, the brother of Aldous

\footnotetext{
${ }^{2}$ This chapter is an updated, revised, and extended version of the relevant parts from the author's earlier paper, published in the Journal of Posthuman Studies (Szabados, 2019).
} 
Huxley, an advocate of eugenics and the first director general of UNESCO, who wrote in an essay in 1957 that 'the human species can, if it wishes, transcend itself ... We need a name for this new belief. Perhaps transhumanism will serve: man remaining man, but transcending himself, by realizing new possibilities of and for his human nature'. ${ }^{3}$ Huxley's description today remains widely accepted by the advocates of transhumanism as a broad definition.

After WWII, transhumanist themes sprang up in popular culture, especially in the science fiction literature (in the works of such popular authors as Isaac Asimov, Arthur C. Clarke, and Stanislav Lem) and comic books. It developed in parallel to the early advances of new fields in the sciences, such as cloning, robotics, artificial intelligence, cryonics, and space exploration (Hughes, 2004, pp. 160-161). The noun 'transhuman' first appeared in an encyclopaedia - and thus became officially registered in the English language - in 1966, which it was defined as 'surpassing; transcending; beyond' (The Readers' Digest Encyclopaedia, 1966).

In one important example, Robert Ettinger, a physicist and mathematician, authored a highly controversial book on life expansion through freezing people after clinical death and storing them in liquid nitrogen until technology reaches the possibility of their revival. His book, The Prospect of Immortality, became an international bestseller in 1964 and was praised by futurist thinkers, albeit its scientific basis is contested to this day (Ettinger, 1964). Nevertheless, the book spawned the cryonics movement - companies sprang up to offer body-freezing services for the financially affluent - and its core idea of life extension or the promise of immortality inspired many, including Isaac Asimov. The cryonics movement later served as the foundation of the transhumanist movement and Ettinger outlined his own account of 'transhumanity' in another popular book (Ettinger, 2005). Within a couple of years, authors of science fiction literature began popularising the term.

The current chapter is broken into the following four subsections, which present the history and development of the transhumanist movement from various perspectives and contexts. Firstly, it begins by introducing the initial influential theorists and their main ideas, which stimulated a growing number of intellectuals in the United States to form the early transhumanist movement. Next, it moves to offer a broad-based, descriptive outline of the movement's process of

\footnotetext{
${ }^{3}$ For a detailed analysis of the controversies surrounding the usage and origin of the term, see Harrison and Wolyniak (2015).
} 
institutionalisation and reflects on the various noteworthy considerations which arose over the course of its growth as a global phenomenon as well as its efforts to gain academic acknowledgement. Then it turns to the emergence of political representations of transhumanism and transhumanist policy offers. Related to this point, the final section closes by presenting the history of transhumanist political parties and analysing their current status within electoral competitions.

\subsection{The Early Years}

A consensus among transhumanist theorists exists that it is the futurist Fereidoun Esfandiary (who later changed his name to FM-2030) who can be identified as the first representative of transhumanism and, further, who conveyed the earliest evolutionary interpretation of transhumanism:

It is important to understand that some of the breakthroughs now burgeoning all around us are no longer simply historic - but evolutionary. The asexual creation of new mutants and the emergence of cyborgs are not historic developments. They are evolutionary breakthroughs. The biological upheaval now in its infancy is moving toward radically new concepts of life - beyond animal/human. (Esfandiary, 1973, p. 6)

Esfandiary also began to formulate the initial political ideas of the transhumanist ideology, proposing a radical utopian vision of democracy that moved beyond the traditional left-right political orientations; he called the purveyors of this new model of democracy 'up-wingers' (Esfandiary, 1973, p. 8). In Esfandiary's vision, the global order built on nation states and determined by domination and submission should be replaced by a world government and global citizenship. His ideas greatly influenced a new generation of thinkers who started to organise themselves within the newly-born transhumanist movement in the 1980s in the United States. 
The new cultural movement started to attract artists and other intellectuals inspired by science fiction literature, who expressed their concern about how science and technology may transform the human condition and shape the future of humanity. In 1983, a group of intellectuals in California, who 'simply wanted to think about and talk about where technology was heading' (Vita-More, 2019, p. 51), came together. Natasha Vita-More, one of the members of the group, published the Transhuman Manifesto and the Transhumanist Arts Statement - the latter further evidences the relevance of the cultural dimension in the early development of the movement which outlined some key ideas that later became intrinsic to transhumanist thought, such as life extension, cognitive and psychological enhancement, or space colonisation (Vita-More, 1983).

In 1988, a British philosopher, Max More and his companion, Tom Morrow, an attorney from Silicon Valley, launched Extropy, the first regularly published print magazine dedicated to transhumanism. Max More laid out his own, radically libertarian version of transhumanism in 1990, in a manifesto entitled Transhumanism: Towards a Futurist Philosophy. More named his theory extropianism, to distinguish it from other variants of transhumanism. Further, his manifesto hints at the first evidence of an intellectual divergence within the movement, claiming that "while all transhumanists as such will agree on many overall goals, they may differ over the principles that will get us to a posthuman stage' (More, 1990d). This dissertation will extensively gauge Max More's account of transhumanism and its changes over time, but at this stage it suffices to state that the British philosopher and entrepreneur is one of the most prominent, creative, and fertile thinkers of the transhumanist movement whose influence is crucial and far-reaching until this day.

More and Morrow launched the Extropy Institute in 1991, which would then organise a series of conferences and gatherings of scientists, artists, and other intellectuals (Regis, 1994), as well as disseminating transhumanist thought through an electronic mailing list using the new communication platform, the internet. This mailing list attained historic importance in the development of the transhumanist movement as it not only helped the spread of transhumanism but also provided an interactive communication channel between transhumanists and the representatives of other intellectual movements to exchange ideas and influence each other.

Among the many satellite influences, it is worth mentioning Gareth Branwyn's 1991 Cyberpunk Manifesto, which gave birth to the cyberanarchist movement and later inspired the pirate parties (Branwyn, 1991). Donna Haraway's Cyborg Manifesto and her subsequent works 
launched the cyberfeminist movement (Haraway, 1987, 1991; Scott, 2016), which greatly shaped the gender-related ideas of transhumanism that culminated in the theory of post-genderism (Dvorsky and Hughes, 2008).

David Pearce, another central figure within the transhumanist movement, put forward his utopian Hedonistic Imperative in 1995, in which he argued that the progress in the scientific fields of nanotechnology and genetic engineering will enable humankind to eliminate and finally eradicate - both physical and mental - pain and suffering in life, significantly improving the human condition, and that 'a naturalistic, secular paradise of effectively everlasting happiness is biotechnically feasible' (Pearce, 1995). He claimed that what he referred to as the 'abolitionist project' is not only scientifically and technologically realistic (though he projected that it would take thousands of years to achieve it), but it is also the moral obligation of scientists and other policy-makers to dismantle all obstacles and fully support the necessary research (especially in genetic engineering). Pearce's utilitarian ethicist argument incorporated the theory of moral perfectionism into transhumanism (Hurka, 1993; Bostrom, 2003b).

\subsection{Growing Global}

In 1998, Nick Bostrom and David Pearce co-founded the World Transhumanist Association (WTA) with the mission to have transhumanism accepted by the scientific community as the adequate subject for scholarly investigation, and to formulate policy proposals for the movement. The creation of the WTA meant that transhumanism had reached its adolescence and its supporters demanded scientific and political recognition. The organisation presented the first version of the Transhumanist Declaration, which would be modified in several instances during the following years. The declaration encompassed in its four articles all the main and consensual proposals put forward by various transhumanist thinkers in the preceding decades, including life extension, the hedonistic imperative, the right to self-improvement beyond biological limits with the help of technology, the need for public platforms of deliberation to discuss the social implications of technological progress, and the demand for a redesigned (post)human rights system ('The Transhumanist Declaration', 2002). At that time, the authors felt it important to declare non- 
partisanship and distance themselves from any political platform in order to avoid the alienation of transhumanism from academic and political actors.

To raise academic awareness, WTA launched the Journal of Evolution and Technology, the first peer-reviewed journal dedicated entirely to transhumanist studies, in 1999. That same year, the organisation issued the Transhumanist FAQ to raise public awareness of key transhumanist ideas and respond to the most common concerns voiced against the futurist philosophy (Humanity+, no date). It also contained a short, vague paragraph on the transhumanist account of society and politics. Admitting that it is unclear yet what intellectually and technologically advanced posthumans will be like, it claimed that at today's human cognitive level, it is impossible to construe or even imagine the ideal social order of the future. But the document envisioned a world order in which groups of sentient beings of various levels of cognitive augmentation or nonaugmentation will be free to choose to live in secluded societies.

Although the WTA was founded in an attempt to integrate all branches of the ideologically increasingly diverse and polyvocal transhumanist movement, a latent and inevitable conflict between the libertarian and the leftist wings surfaced. This led to the gradual shift of the organisation's political orientation to the ideological left: the liberty-centred approach was incrementally replaced, giving prominence to egalitarian and distributive issues. At that time, the topic that sparked fierce debate was about the role of the state in providing equal access to enhancement technologies. With the election of James Hughes, an adamant socialist, as the new chairman of the organisation in 2005, the political struggle ended and the libertarian wing of the movement retreated mostly to the United States, while European transhumanist groups approved of the left political turn. Then, WTA was rebranded as Humanity+ in 2012, when H+ became the international symbol of the transhumanist movement. Subsequently, proponents have started to use the ' + ' sign to brand transhumanist proposals of various kinds (for example 'P+' refers to the transhumanist political programme).

The ideological conflict between the two main branches of the transhumanist movement raises another issue that is topical to this dissertation: what is the importance of the movement's left-right division in the ideational development of the transhumanist belief system? Does it serve as proof of transhumanism's inability to develop its own, distinct ideational blueprint? If this is the case, then transhumanism may be nothing more but a temporary phenomenon that will inevitably 
dissolve into other mature ideologies, impregnating them with the idea (or threat) of technological determinism. Or will the left-right discord among transhumanists signal an interim phase along the long path towards ideological adolescence? In this case, there must be a set of ideas within transhumanism that is inconsumable by other ideologies, and this idea group has the capacity to serve as the core from which transhumanism can develop into a full-fledged ideology that transcends the traditional left-right ideological dimension. This will be thoroughly investigated in later chapters.

Meanwhile, the emergence and growing popularity of transhumanist thought has drawn the attention of the scientific community. Unsurprisingly, this growing interest meant mostly the strong criticism of transhumanism by scholars. To counterweigh the negativity of academic circles, Nick Bostrom and James Hughes founded the Institute for Ethics and Emerging Technologies in 2004, a think-tank aiming to support scholarly investigation of the impact and 'the safe and equitably distributed' use of transhumanist technologies, and also to strengthen the scientific base of the leftleaning technoprogressive wing of the transhumanist movement. ${ }^{4}$

The German Nietzsche scholar, Stefan Lorenz Sorgner - together with a small group of academics and artists - launched the Beyond Humanism conference series in 2008, which by now has grown into the most significant academic event for trans- and posthuman studies. Each year, hundreds of scholars with various disciplinary backgrounds gather to present their latest research on transhumanist and posthumanist topics. In 2018, Sorgner launched the Journal of Posthuman Studies, another peer-reviewed academic journal dedicated solely to papers on the critical and normative analysis of transhumanism and posthumanism. The bi-annual journal is published by Penn State University Press, and its host institute is the Ewha Institute for the Humanities, which is based in South Korea, providing further evidence of the global outreach of transhumanism.

\footnotetext{
${ }^{4}$ On IEET's mission see: https://ieet.org/index.php/IEET2/about.
} 


\subsection{The Rise of Political Transhumanism}

Parallel to the growing popularity of transhumanism and the incorporation of a great variety of distinct issues, views, and ideologies, the question of political representation was raised by prominent transhumanists (Pendry, 2013; Rothman, 2014) as a logical next step in the development of the movement. As awareness of the omnipresent technological and scientific progress had grown beyond academic and elite circles, penetrating vernacular thinking as well as popular culture, certain devotees of transhumanist ideology felt that the time had come to articulate the distinct transhumanist conception of the political. In addition to participating in intellectual debates, a more activist branch of the transhumanist movement began to formulate the transhumanist political agenda.

The involvement in politics was further motivated by the fact that transhumanist themes had already entered political discourse and policy debates in many countries. Different aspects of the bioethical discussion over the regulation of genetic enhancement were presented - among other places - in the 2003 Beyond Therapy Report of the Council on Bioethics (Kass, 2003), a report to the U.S. National Science Foundation (Allhoff et al., 2009), and several hearings held by various U.S. congressional committees ('Genetics and Other Human Modification Technologies: Sensible International Regulation or a New Kind of Arms Race?', 2008; Scharre, 2015). Perhaps the most prominent example of transhumanism's growing importance in political discourse in the U.S. can be found in the reference to chimeras, 'human-animal hybrids' in George W. Bush's 2006 State of the Union Address:

Tonight I ask you to pass legislation to prohibit the most egregious abuses of medical research: human cloning in all its forms; creating or implanting embryos for experiments; creating human-animal hybrids; and buying, selling, or patenting human embryos. ${ }^{5}$

\footnotetext{
${ }^{5}$ Full text of the speech is available at https://georgewbush-whitehouse.archives.gov/stateoftheunion/2006/.
} 
At different levels, the European Parliament also engaged with the topic of human enhancement in committee hearings ('The Science of Genetics and Modern Medicine', 2001), think-tank studies (Coenen et al., 2009; Making Perfect Life. European Governance Challenges in 21st Century Bioengineering, 2012), and answers to members' questions (Staes, 2009), but also covered other transhumanist-promoted issues such as robot rights (Nevejans, 2016; Recommendations to the Commission on Civil Law Rules on Robotics, 2017) or the ethics of artificial intelligence (Woensel, Kurrer and Kritikos, 2016). Similar issues are being advanced in Russia (Novossiolova, 2017, p. 134) and China (Schaefer, 2016), albeit with much less transparency.

The involvement with politics - though many transhumanists have questioned the need for partisan advocacy as reflected in the passage of the Transhumanist Declaration - started with running transhumanist candidates in national elections under the flags of established parties, but soon led to the formation of transhumanist parties all over the world. Taking into consideration the fact that followers of the Green ideology are listed among the most pugnacious opponents of transhumanism, it is surprising that the first transhumanist to hold a political position was elected on the Green party ticket in the U.S. Natasha Vita-More won a county council seat in Los Angeles in 1982 after campaigning for the use of transhumanist technologies to solve environmental issues. Yet, this early political success was not followed by active participation in party politics. Instead, the transhumanist movement abstained from partisan advocacy for three decades.

Then in 2012, Italy's Giuseppe Vatinno, an adamant transhumanist, was elected to the national assembly, as a member of the populist Italia dei Valori party. Following a controversial parliamentary question on UFOs, however, the Italian transhumanist H+ Network disassociated itself from him, and in 2015 he was deprived of all his positions in international transhumanist organisations (Network Italiani H+ Transhumanisti, 2013). In the United States, the transhumanist Gabriel Rothblatt stood as a candidate for the Democratic Party in the 2014 congressional election in Florida but lost against his Republican opponent (Transhumanity.net, 2014). In that same year, the author of the popular novel The Transhumanist Wager, Zoltan Istvan, founded the U.S. Transhumanist Party and compiled a key document for the transhumanist movement: the Transhumanist Bill of Rights ('The Transhumanist Bill of Rights', 2015a). Albeit having undergone several modifications since its first publication, it is still considered one of the fundamental documents of transhumanist politics. The document lists the key transhumanist issues put forward 
for public discussion and policy evaluations: life extension, post-anthropocentric rights systems, enhancement, bodily self-determination, space colonisation, freedom of scientific research, and the avoidance of dystopian uses of technology.

Istvan ran as the first transhumanist presidential contender in the 2016 U.S. presidential elections. Although his visually creative campaign (he travelled across the United States in a coffinshaped campaign bus, the 'Immortality Bus', promoting life extension) gained attention in mainstream global media outlets (Maughan, 2015), his name did not appear on the ballot, as he had not been able to collect the required number of supporting signatures from voters. In 2017 , Istvan stood as a Libertarian Party candidate in the California gubernatorial election (Istvan, 2017), but failed again. His political activism and strong libertarian leanings stirred numerous controversies within the U.S. Transhumanist Party and the wider transhumanist movement, ${ }^{6}$ and he was replaced in a peaceful way by Gennady Stolyarov II as the new chairman of the U.S. Transhumanist Party in November 2016.

But continued political engagement led to sharp rivalry and ideological confrontation within the transhumanist community. For example, during the preparation for the 2020 U.S. presidential election, Zoltan Istvan announced that he would join the race as a Republican candidate (Mack, 2019), whereby many transhumanists considered Andrew Yang, the pro-science and protechnology candidate of the Democratic Party, as the applicant with a political programme closest to the transhumanist ideas. ${ }^{7}$ But following a long electronic selection process among party members, the U.S. Transhumanist Party announced it would nominate its own, independent party candidate, Johannon Ben Zion (US Transhumanist Party, 2019).

In Russia, the 'Evolution 2045' transhumanist political organisation, established in 2012, boasts today more than 48,000 members on its website. ${ }^{8}$ However, one must take this figure with caution, since anybody can join the party with a simple e-mail registration. The number seems surprisingly high when compared with the 14,000-person membership of the largest transhumanist

\footnotetext{
${ }^{6}$ In 2018, a transhumanist Facebook group held a vote to evaluate Istvan's activism and the result was overwhelmingly negative.

${ }^{7}$ See this Facebook group: https://www.facebook.com/groups/612994059052031/ or this article: 'Andrew Yang and Zoltan Istvan Subvert the Political Binary', Aero, 2 December 2019. Available at: https://areomagazine.com/2019/12/02/andrew-yang-and-zoltan-istvan-subvert-the-political-binary/.

${ }^{8}$ Available at http://evolution.2045.com/.
} 
Facebook group. ${ }^{9}$ In Europe, transhumanist parties have sprung up in almost every Member State of the European Union, among which the Transhumanist Party UK and the technoprogressivist French AFT are the most active (though the latter is not a formal political party). H+pedia, the transhumanist Wikipedia site, lists 23 transhumanist parties and supporting organisations worldwide, and a simple search on Facebook finds at least a dozen more in Asia, South America, and Australia. However, the majority of these organisations and parties have few followers and infrequent social media activities (Szabados, 2019).

In Europe, the left-leaning wing of the transhumanist movement published the Technoprogressive Declaration at the TransVision conference in Paris in 2014, which gave rise to the technoprogressive political movement. The declaration reflected the political programme put forward by the British philosopher Amon Twyman. Tyman's Social Futurism initiative 'seeks to influence the ideological basis of the emerging global transhumanist parties' (Benedikter and Siepmann, 2016, p. 4) through its critique of capitalism and demands that the development of transhumanist technologies take place independently from the global financial sector (Twyman, 2014).

Building on Twyman's socialist perspective, the Technoprogressive Declaration in 2014, which focused on equality and social justice, emphasised the need for regulation and the universal accessibility to transhumanist technologies, and declared solidarity with workers who will negatively be impacted by automation ('Technoprogressive Declaration', 2014). In 2015, Twyman co-founded the UK Transhumanist Party, which issued a press release in October 2015 harshly criticising Zoltan Istvan and his political activism, stating that 'he is bringing the movement as a whole into disrepute' and 'has no mandate to speak on behalf of any other transhumanists in terms of policy or anything else'; it also blamed him for hindering the development of an effective party organisation ('Zoltan Istvan does not speak for the Transhumanist Party', 2015). The press statement signed by Twyman reflected a schism within the political arm of the transhumanist movement marred by the libertarian-socialist divide and personal conflicts. Ironically, only a couple of months later - following the disappointing election result of the only transhumanist candidate in the 2015 general election in the UK - Twyman himself resigned from party leadership,

\footnotetext{
${ }^{9}$ Transhumanism: The Future of Humanity Facebook group: https://www.facebook.com/groups/TranshumanRevolution/.
} 
admitting that he failed to build a well-functioning party organisation ('Agile organisations for agile politics', 2016).

Frustrated by the bureaucratic and organisational hurdles of party activism, technoprogressives in the UK temporarily abandoned party politics and launched a new think-tank, called Transpolitica, to provide background services for transhumanist politicians worldwide. The organisation issued its first manifesto in 2016, demanding among other initiatives an inclusive new social contract and the reform of democracy to enable societies to prepare for the upcoming technoscientific disruption (Transpolitica Manifesto, 2016). The emergence of the Transpolitica thinktank coincided with the rise of David Wood, a software engineer and philosopher, who became a leading figure and ideologue of political transhumanism and technoprogressivism in particular. He authored several books covering the politics of transhumanism, which this dissertation will to a great extent analyse in subsequent chapters. Recently, Wood was elected as party leader of the rebooted UK Transhumanist Party.

\subsection{Globalist Proto-parties}

From the above it can be inferred that transhumanist parties have not yet been able to influence traditional party politics or even enter the party competition for reasons that are beyond the scope of analysis of this dissertation. However, attention should be given to two attributes of political transhumanism that have relevance for an ideological analysis. First, it is a shared attribute of these proto-parties that they desire to rise above the traditional left-right dichotomy:

transhumanist parties overall envision a first global political ideology of politically organized technophilia with the goal to transcend the usual political pattern of left and right toward technology-centred 'post-' or 'meta-' politics. (Benedikter and Siepmann, 2016, p. 2)

Speaking of the transhumanist desire to overcome the left-right axis, Istvan positioned the U.S. Transhumanist Party as an anti-establishment movement that rose out of the frustration among the 
general public with traditional politics and mainstream parties, similar to populist parties. But he made it clear that any resemblance with the populists ended there, as they are irrational protest parties, while the transhumanist political offer is based on the strict rationality of science and technology, prefers globalisation to populist nativism, and promotes the indiscriminate unity of humankind against populist exclusivity (Bartlett, 2014). As indicated in the previous chapter, surpassing the left-right axis seems to be a great challenge for the transhumanist movement as it is deeply divided along traditional libertarian-leftist orientations. Promoting technology and scientific rationalism as the universal solutions for all the earthly problems from health through climate change to inequality is accepted by all transhumanist political organisations, but their party manifestos and policy proposals attest that they struggle to leave behind the conventional single dimension of ideological orientation.

Apart from the desire to transcend unidimensional, traditional politics, the second attribute of political transhumanism is its globalist character. From the beginning, transhumanism shows deep disrespect for the contemporary hierarchy of the world order based on national sovereignty, but it particularly disapproves of nation states and the ideology of nationalism. FM-2030 declared the nation state an anachronism 'with distinct disadvantages' and portrayed nationalism as a reactionary force, while claiming that 'subcontinentalism, continentalism, globalization ... are the progressive movements of our times. They run concurrently reinforcing one another' (FM-2030, 1989, p. 97). Transhumanists unequivocally consider themselves members of a globalist movement, offering their techno-optimistic ideas to the entirety of humanity. Although transhumanist proto-parties sprang up within national borders, that was only due to the limitations of party systems which operate at the national level. But the institutionalisation of political transhumanism took place simultaneously at the international level. After founding the U.S. Transhumanist Party in 2014, Zoltan Istvan (together with his later critic, Amon Twyman) immediately set up the Transhumanist Global Party with the intention of collecting all transhumanists with distinct ideological affiliations under the umbrella of a single political organisation. ${ }^{10}$ The majority of transhumanist parties are open to the admission of members or supporters of other nationalities than that of the country where the given party operates.

\footnotetext{
10 The Transhumanist Global Party ceased functioning as the conflict between Twyman and Istvan grew in 2016.
} 
Related to this, Steger (2009) distinguished three types of globalist ideologies: neoliberal (or market) globalism, justice globalism, and fundamentalist religious (or jihadist) globalism. Transhumanism - especially technoprogressivism - can be understood as a variant of justice globalism since all of its various theoretical and political fringes reject the nationally and raciallybounded approaches to politics. Instead, the transhumanist offer cuts across national borders, cultural lines, and racial differences. Its advocacy for world government, the abolition of the nation state, the strengthening of global institutions, and the synchronisation of (post)human rights worldwide makes transhumanism a truly globalist theory.

Today, political transhumanism is in its embryonic stage as far as institutionalisation is concerned. In consulting Facebook group memberships, the number of votes cast on various party referendums, and the number of participants at transhumanist political events, the total number of transhumanists actively participating in party organisations can be estimated between 3,000 to 5,000 globally. Transhumanist proto-parties are 'at an early stage of the party life cycle, do not measurably affect the party system, introduce novel issues that transcend the traditional economic dimension of party competition, and "own" issues that are already part of political discourse, but do not yet significantly affect the issue agenda' (Szabados, 2019, p. 232). More importantly, as different transhumanist groups have embarked on articulating their political views and policy recommendations in various documents - declarations, manifestos, party constitutions, etc - in the last decade, it also allows for the in-depth examination of their ideological stances. 


\section{The Ideological Attributes of Transhumanism}

Why is it that transhumanism became so popular? The transhumanist appeal may lie in its provocative approach and controversial answers to the burning existential questions that humanity faces today. The transhumanist perspective offers a distinctive and fiercely contested understanding of the technological and scientific revolution, the profound cultural changes that this revolution entails, and the 'post-postmodern' politics that these alterations will necessitate. Contemporary transhumanist theory holds that the biological limits of human existence can and should be surpassed by means of merging technology with the biological-physical body. It is the guide to a path along which humanity evolves from its primitive animal state towards a posthuman condition. In this respect, transhumanism is a transitory configuration. As Max More defined it:

[t]ranshumanism is a class of philosophies of life that seek the continuation and acceleration of the evolution of intelligent life beyond its currently human form and human limitations by means of science and technology, guided by life-promoting principles and values. (More, 1990c, p. 6)

The Transhumanist FAQ also provided a slightly modified definition of transhumanism:

Transhumanism is a way of thinking about the future that is based on the premise that the human species in its current form does not represent the end of our development but rather a comparatively early phase. Transhumanism is:

1. The intellectual and cultural movement that affirms the possibility and desirability of fundamentally improving the human condition through applied reason, especially by developing and making widely available technologies to eliminate aging and to greatly enhance human intellectual, physical, and psychological capacities.

2. The study of the ramifications, promises, and potential dangers of technologies that will enable us to overcome fundamental human limitations, and the related 
study of the ethical matters involved in developing and using such technologies. (Transhumanist FAQ - Version 3.0, 2001)

Although scholarly consensus exists about the definition of transhumanism, it is far more complicated to find a proper typology of transhumanism. There are many variations in the transhumanist literature: it is defined as a perspective, a world view, a cultural and intellectual movement, a philosophy, a theory, a cultural ecology, a social narrative, and a scientific study sometimes concurrently within the same text. Clearly, each of these terms is applicable to transhumanism, however, none provides a scholarly convincing and typologically appropriate definition. As Max More wrote:

[Transhumanism] includes a broad metaphysical perspective on the development, direction, goal and value of life and consciousness. It goes beyond humanism by peering into the future in order to better understand our possibilities. As we move forward through time our understanding of our immense potentials will evolve; there can be no final, ultimate, correct philosophy of life. Dogma has no place within transhumanism - transhumanism must be flexible and ready to move on, reconfiguring into higher forms, new versions of transhumanism and, one day, posthumanism. (More, 1990c)

Given this broad perspective on development, it is not surprising that transhumanism branched out into many versions, each focusing on a single issue such as patriarchy, environment, critique of capitalism, or exponential growth, to name a few, to articulate a specific transhumanist response to the given issue. These issues and the transhumanist policy proposals they inspired overlap most of the time. For example, feminist transhumanists are concerned with the dangers of the emergence of a patriarchal new order as a result of radical life extension through technology. Christian transhumanists pursue the reconciliation of Christian eschatology with the theory of human enhancement and the advocacy of human immortality. Table 3 lists the contemporary versions of transhumanist thought: 
- Anarcho-transhumanism

- Christian transhumanism

- Cosmism

- Cyberfeminism

- Extropianism

- Immortalism (Radical life extensionism)

- Longevism (Life extensionism)

- Postgenderism

- Postsecularism

- Singularitarianism

- Techno-optimism

- Techno-utopianism

- Technogaianism (Eco-conscious transhumanism)

- Technolibertarianism

- Technoprogressivism (Democratic transhumanism)

- Transhumanist inevitablism

Source: $\mathrm{H}+$ pedia

One of the aims of an ideological analysis of transhumanism is to reveal the shared core concepts where each of the above accounts agree and identify those conceptual components that gave rise to these ideational renderings.

Since their first appearance in the late twentieth century, transhumanist ideas have penetrated many areas of life - from popular culture to academic disciplines to public policy. Such intellectual expansion logically suggests the possibility that transhumanism has by now developed into an ideology, or at least that it has the potential to grow into a full-fledged belief system. This assumption is further strengthened by the fact that a growing number of recent scholarly articles define transhumanism as an ideology (Tirosh-Samuelson, 2015, p. 67; Benedikter and Siepmann, 2016, p. 8; Porter, 2017, p. 255; Dévédec, 2018, p. 5).

But is such a definition justified? 
Indeed, the political prominence of disruptive changes in science and technology has generated increasing interest in the nature and influence of transhumanist ideas. However, to date, this has rarely led to a focus on the distinctively ideological properties of these visions. Instead, critical analysts were predominantly engaged with (mis)interpreting cherry-picked transhumanist proposals, particularly those associated with the potential of creating and legitimising novel types of inequality or alleged existential threats. Most of these critical analysts did not hide their ideological bias, prejudice, and preconceptions against the subjects of their investigation. Very few academics outside of the transhumanist movement have attempted to understand, explore, and describe transhumanism in its entirety. This dissertation intends to fill the void and present the first ideological analysis of transhumanism, hypothesising that it has already achieved the ideational maturity of a distinctive, coherent belief system.

In what follows, the main contours of transhumanism will be explored through Freeden's lens, making use of the detailed set of criteria he established for identifying a belief system as an ideology. His definition of an ideology is as follows:

A political ideology

- is a set of ideas, beliefs, opinions, values and non-verbal instruments

- exhibits a recurring, sustainable pattern of complex combinations and clusters of political concepts

- is held by significant groups

- is a wide-ranging structural arrangement that attributes decontested meanings to a range of mutually defining political concepts

- compete over providing and controlling plans for public policy primarily through exerting control over political language

- does so with the aim of justifying, contesting or changing the social and political arrangements and processes of a political community. (Freeden, 2003, pp. 32, 5152)

This definition, however, is incomplete, as some of the above claims can also be attributed to political philosophies. Freeden recognised this problem, but instead of zeroing in on a more definite 
delineation, he presented an incisive comparison of ideology and political philosophy in an attempt to comprehensibly illuminate his understanding of ideology (Gaus and Kukatha, 2004, pp. 11-14). Table 4 summarises the key items in Freeden's comparison, which is important for two reasons. First, it offers a more accurate picture of political ideologies in the Freedenian sense. Second, it provides further guidance for the examination of transhumanism from an ideological perspective.

Table 4. Comparison of ideology and philosophy by Michael Freeden

\begin{tabular}{lc}
\hline \multicolumn{1}{c}{ IDEOLOGY } & \multicolumn{1}{c}{ POLITICAL PHILOSOPHY } \\
\hline - disseminated and consumed by large & $\bullet$ consumed by specialists only, needs \\
groups of people to create shared & interpretation to have political appeal \\
understandings that can direct political & \\
practices & \\
\hline - serves as a means to control the use of & uses semi-private or restricted language \\
political language: an ideology needs a \\
broad circulation, and must be phrased in \\
simple language
\end{tabular}

- emphasis on effectiveness of consumption - emphasis on quality of production

- ideologies are not merely directed at $\quad$ individualistic bias: only talented persons groups, but always are group products and great thinkers can produce philosophy

- role of emotions:

- prefers reflective arguments based on non-

- wrap rational discourse in varying negotiable values (to which a philosopher layers of emotive idiom

- they assign emotional importance to can be emotionally committed without recognising it) their key values

- they openly recognise the centrality of emotion in socio-political interaction

- the ultimate success of an ideology lays in - the ultimate success of a philosophical its mobilisation of significant groups who argument is the rational persuasion of its targeted audience in its good sense 
compete ideationally in order to impact on

acts of collective decision-making

- focus on both intentional and unintentional neglect for unintentional messages

messages (equivalence of overt and coded

messages

- the function of ideology is to impose a

logically arbitrary but culturally significant

set of meanings on political reality

- a good argument is one whose morphology

good argument is rational, logical,

of conceptual decontestations can coherent, precise, reflexive, and self-

transform or preserve political practices, critical

which may not always be in rational or

precise terms. A good argument brings

about a change in power relationships,

through prescription or through the

denying of transparency

- creativity in interpreting social reality

- creativity with metaphors or thought

exercises through which to test the

robustness of assumptions, premises, and

hypotheses

From the above comparison, together with the broad definition that Freeden put forward, a more precise methodological guidance can be outlined. The above attributes form a set of criteria along which the ideological analysis of a thought system can properly be conducted. Furthermore, it is hard not to notice the similarity between Gerring's and Freeden's lists of descriptive criteria for ideologies. Indeed, Freeden developed and structured further what Gerring collated, and the result is a comprehensive framework that allows for the differentiation of an ideology from a political philosophy. It can be logically inferred from this comparison that the basic difference between an ideology and a political philosophy is that the former is designed for the masses. It aims to change or at least challenge the existing socio-economic reality through convincing a gradually growing 
(in number or influence) sub-group within the society that its own and unique interpretation of reality is relevant and justified and has the potential to become dominant. To achieve this, an ideology utilises a simplified language combined with an exhaustive range of visual and other nonlinguistic tools that can easily be consumed by laypeople without any expertise in policy issues.

To maximise reach and effectiveness, an ideology increasingly tends to evoke emotions (especially fear, hate, or desire) and applies emotionally loaded arguments even to package otherwise rational claims. While both political philosophies and ideologies introduce novel concepts or modify the meaning of existing concepts in public discourse, the main goal of ideologies is to force mainstream political players to react, and thus stir public debate. Consequently, the ideological newcomer has the opportunity to alter and control the language of politics, mobilise followers, and collect advocates and adherents. The outcome of an ideology is always some sort of organisation: a movement or a political party. Ideology and activism therefore go hand in hand.

Hence, our first task is to examine the eligibility of transhumanism to be the subject of ideological analysis. Can transhumanism be considered an ideology at all? For that purpose, the current status of transhumanist thought, and the maturity of the transhumanist movement, should be examined along Freeden's aforementioned ideological attributes: relevance, influence, efficiency, consumability, level of institutionalisation, and most importantly, conceptual coherence.

It is beyond doubt that transhumanism addresses one of the most vital issues of our times: scientific and technological progress and their consequences. Genetic engineering and its related disciplines, nanotechnology, machine learning, artificial intelligence, robotics, and data science appear at the forefront of scientific research, where progress is the most spectacular. Figure 2 shows how the frequency of mentions of some of the above terms increased in books published between 1970 and 2012 in the Google Books database, whereby Figure 3 shows the frequency of the word 'transhumanism' using an identical approach. The trends are obvious, and the connection can easily be comprehended if one considers how often transhumanist thinkers refer to these scientific disciplines. 
Figure 2. Percentage of books mentioning the listed terms in the Google Books database, 1970-2012

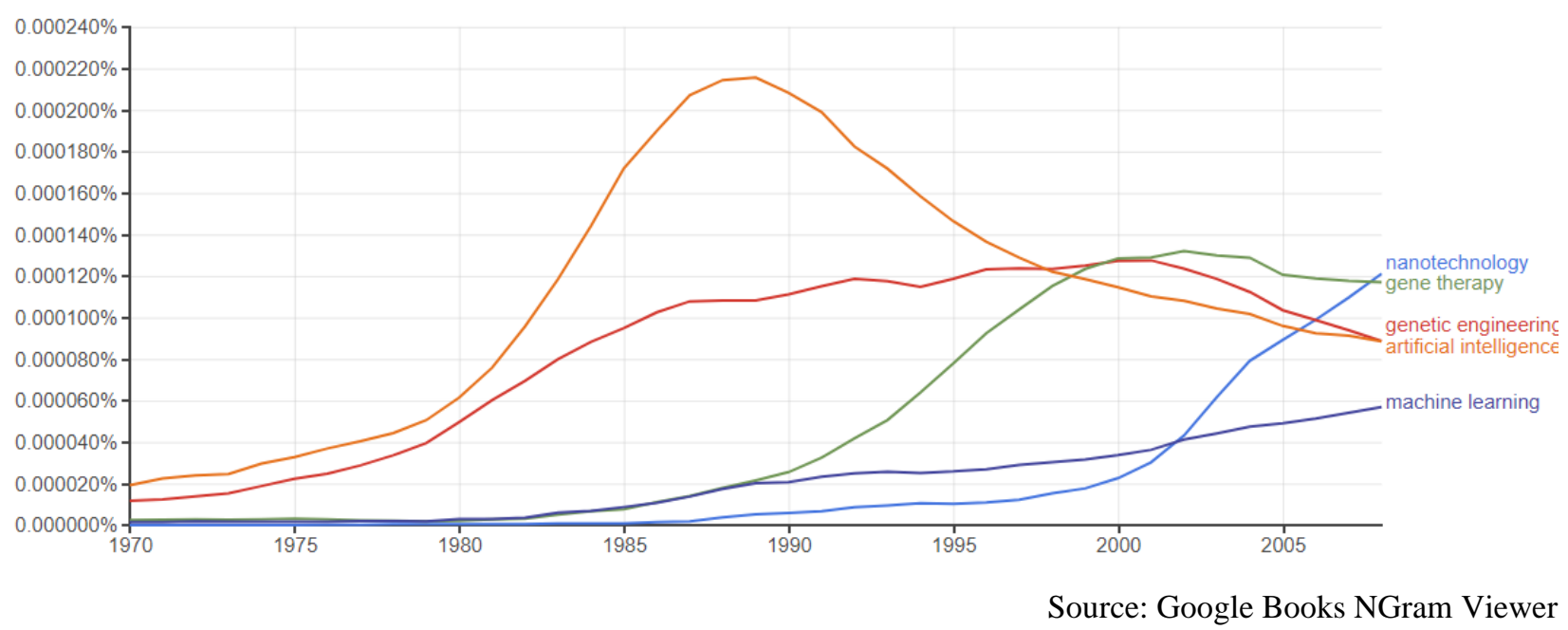

Figure 3. Percentage of books mentioning the term 'transhumanism' in the Google Books database, 1980-2012

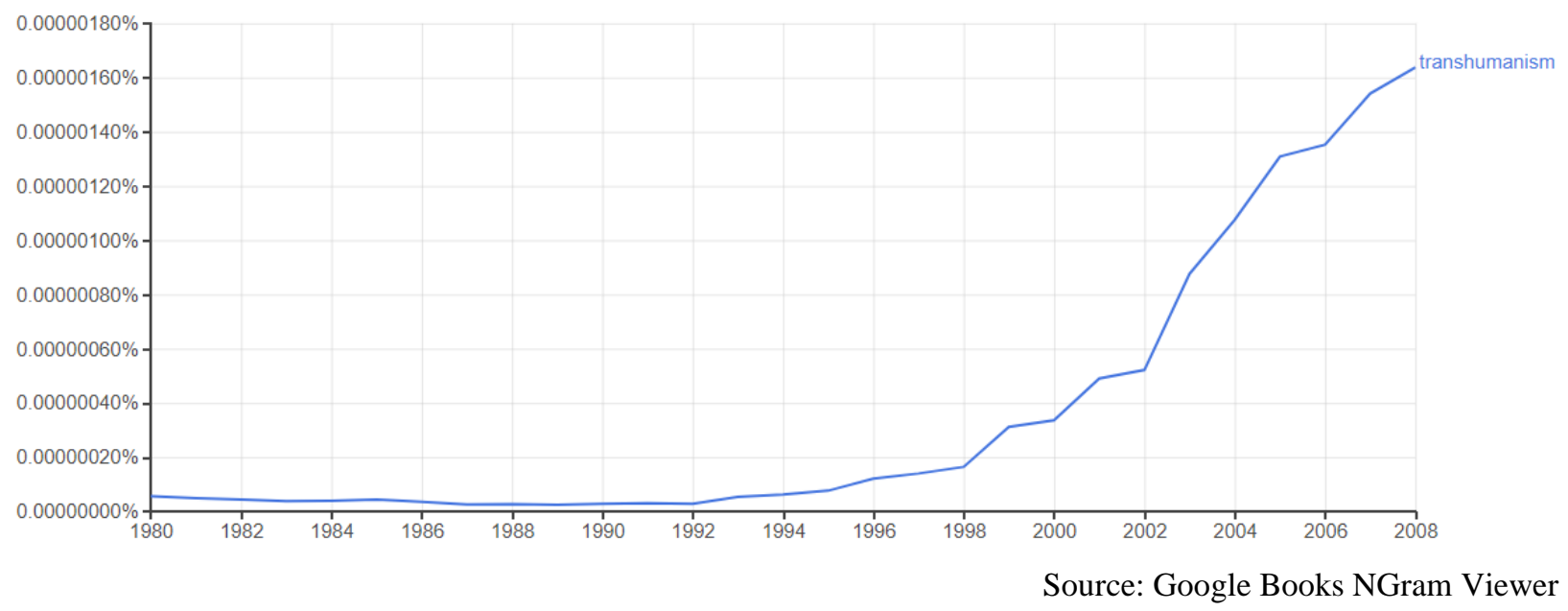

But transhumanism not only reflects relevant social issues, it is also capable of impacting political discourse, permeating decision-making, and commanding respect - albeit to a limited extent and in a controversial fashion - among scholars. The efforts of Nick Bostrom and his fellow transhumanists to achieve the acknowledgement of the scientific community for transhumanism and transhumanist topics bore fruit: the transhumanist advocacy for germline modification is now at the centre of debates in bioethics (Porter, 2017), various issues of robot rights from the legal 
status of sex robots (Shen, 2019) to the proliferation of autonomous weapons ('Lethal Autonomous Weapon Pledge', 2019) are being discussed among legal scholars, and the controlled extension of the healthy human lifespan beyond its current biological limit - longevity - has achieved its initial scientific approval. Indeed, a serious academic journal launched an open discussion about classifying ageing as a disease (McCrory and Kenny, 2018; The Lancet Diabetes \& Endocrinology, 2018). Furthermore, as mentioned previously, transhumanist topics have infiltrated the realm of political decision-making, whereby transhumanist themes, and in a few cases direct transhumanist thoughts, have appeared and continue to appear in government white papers, committee hearings, policy papers, or questions in parliamentary meetings, adding further weight to the relevance argument and buttressing the moderate transhumanist influence on policy-making.

As far as consumability is concerned, this attribute is defined within the Freedenian analytical framework as the attractiveness of an ideological argument among non-expert laypeople. The consumability of a doctrine can be improved by extensively using simplified language, emotive arguments, and visual elements. In this respect, transhumanism has clear advantages, almost similar to populism. Its main promise is improving the human condition through eliminating pain and suffering with the help of science and technology. Transhumanists address those universal issues with which people are generally most concerned: health, ageing, death, scarcity of resources, wealth, work, happiness, or human rights. But it is also flexible in offering its own, unique solutions to current affairs and emerging social issues, for example, climate change, elder care, or the crisis of democracy. If there were a competition among ideologies about which promises the happiest, most straightforward, and most unproblematic future, the 'techno-optimism' of transhumanism would probably rank among the top. The ability of transhumanism to entertain the aim of bettering human life in such an overwhelmingly optimistic fashion makes it highly suitable for mass consumption.

This optimism is reflected in the unique transhumanist visuality (Frommherz, 2017): as discussed earlier, 'H+' has become the international abbreviation and symbol of the transhumanist movement that appears in party logos, conference badges, leaflets, websites, blogs, and transhumanist media titles. Additionally, transhumanists started to use the ' + ' symbol to represent transhumanism-related issues and topics. 'P+' was adopted by the Transpolitica think-tank to indicate transhumanist proposals for the transformation of politics; ' $\mathrm{C}+$ ' became the symbol of the 
Christian Transhumanist Association; whereas 'I+' was coined in reference to the libertarian, individualist branch of transhumanism represented mostly by Zoltan Istvan ('H+', 2018). Figure 4 shows various usages of the ' $\mathrm{H}+$ ' and the ' + ' symbols:

Figure 4. Examples of the usage of the 'H+' and ' + ' symbols

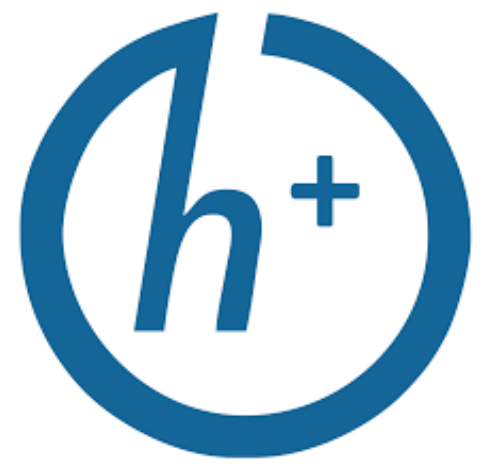

Official logo of transhumanism

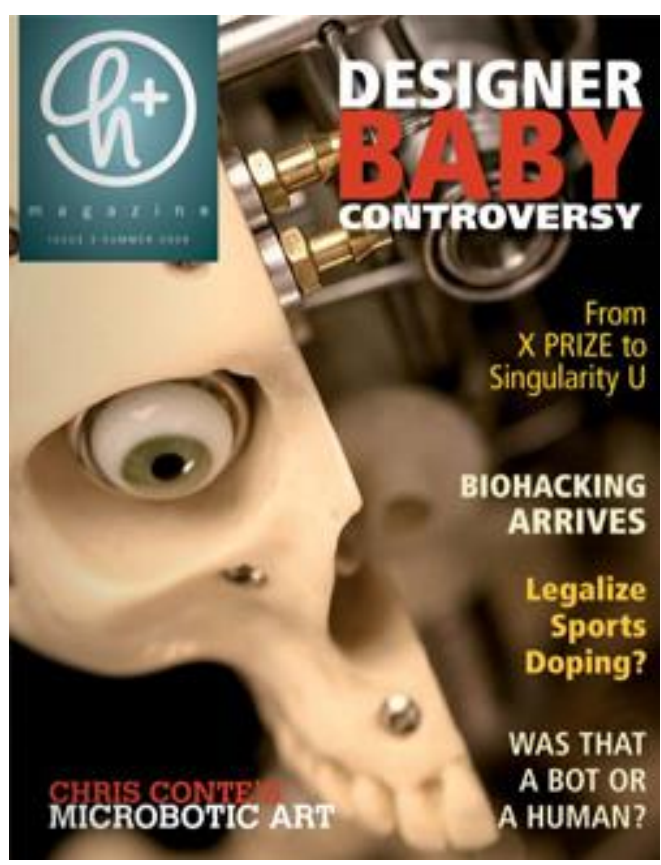

Front page of h+ Magazine

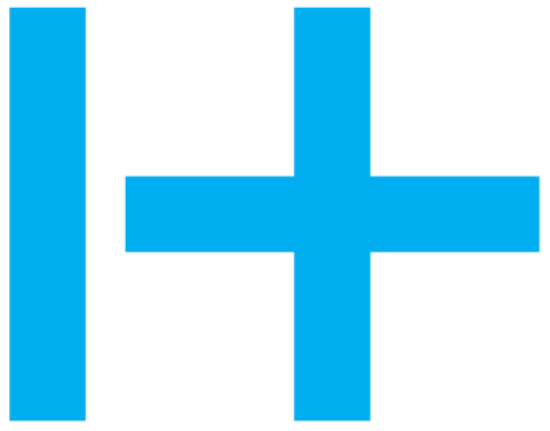

Ivan Raszl's alternative logo design

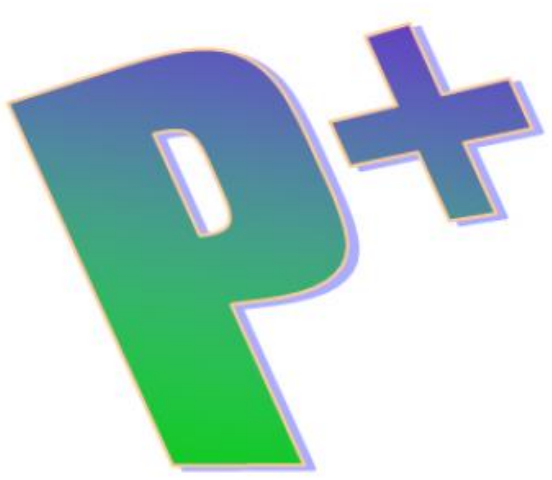

Politics 2.0 logo by Transpolitica 
Further, the easy consumability, the unique visuality, and the capacity to evoke strong emotional reaction - desire - explains why transhumanism is capable of reaching wider audiences beyond the scientific community and political actors.

The consumability of transhumanism is further improved by the fact that it is embedded in popular culture. It was born out of science fiction literature and the superhero universe of comic books, seeking a scientifically possible realisation of what creative minds imagined. Today, popular culture and transhumanism mutually reinforce each other: transhumanism provides ideas for various genres of cultural production from movies, TV shows, sci-fi novels, to computer animation, and traditional or mixed visual arts and other performances. In exchange, popular culture promotes transhumanist ideas and topics. For example, transhumanist topics have appeared in popular TV shows such as Friends, Black Mirror, The Big Bang Theory, Head Case, Silicon Valley, Altered Carbon, Westworld, and most recently, Orphan Black and Years and Years reaching hundreds of millions of viewers worldwide.

The two-way interaction between pop culture and transhumanism enables the latter to create and introduce new meanings to language that spread fast among wide audiences. Terms such as longevity, extropianism, or human enhancement are novel additions to the language of politics, while human welfare, singularity, and UBI have acquired new meaning or were clothed with different interpretations within the transhumanist semantic field. As ideologies compete to achieve hegemony over language, semantic creativity, and transformative power are key attributes of emerging ideologies.

Proposing disruptive changes to the current socio-economic system, raising novel ideas about topics that mature ideologies have so far neglected, and presenting provocative responses to relevant social issues enable transhumanism to not only exert influence on public discourse and policy decision-making, but also allow for the effective recruitment of advocates and followers. Taking into consideration its co-operation with popular culture, it is not surprising that transhumanism has been able to attract a highly influential audience. ${ }^{11}$ While at its current stage the transhumanist movement counts only several thousand active devotees and a couple of hundred thousand sympathisers, the fact that Big Tech entrepreneurs in and beyond Silicon Valley openly

\footnotetext{
11 The growing transhumanist influence on Silicon Valley entrepreneurs is frequently portrayed in mainstream media. A few recent examples are found in Valovic (2018), Metzinger (2017), and Sahota (2018).
} 
or surreptitiously support transhumanist ideas proves that the movement still has enormous mobilisation potential in the near future.

The only attribute in which transhumanism clearly lags behind other young and mature ideologies is the level of institutionalisation. The institutionalisation of an ideology is identified by the number, size, and influence of political movements, organisations, and parties that represent the given ideology, and the subsequent electoral performance of these parties and candidates. As shown earlier, transhumanists have already set up their global organisation, established a handful of think-tanks and academic research institutes, and launched their proto-parties. However, the movement has not reached the organisational level required to consider it a serious contender even against other young ideologies such as ecologism or feminism. Its political representation is weak and marred by internal conflicts, as discussed in Section 2.4. To date, very few transhumanist politicians have managed to be elected to political or administrative positions, and their political legacy is close to invisible. Transhumanism is not yet embedded in society and, while transhumanist ideas are widely accessible through the media, many do not associate those ideas with a peculiar ideology. Its current state can be compared to the institutional level of the Green movement and their political parties in the early 1980s.

In this chapter, it was pointed out that for four out of six attributes - relevance, influence, efficiency, consumability - transhumanism meets Freeden's criteria of the eligibility for ideational analysis, while its level of institutionalisation is immature. The transhumanist movement - in its intellectual, cultural, and political forms - is slowly growing in number and has attracted highly influential adherents. The emergence of transhumanist political parties and the increasing frequency with which transhumanist topics appear at various levels of public policy and political discourse, together with the gradual shift of focus within the transhumanist movement towards politics, indicate the transhumanist desire to rupture or at least to offer an alternative to current socio-political arrangements. All these aspects make transhumanism an appropriate subject for ideological analysis. Next, the investigation will continue by exploring the conceptual coherence of transhumanism, the most important ideological property in Freeden's set of criteria. 


\section{The Ideological Edifice of Transhumanism}

Even a superficial reading of transhumanist literature evinces that a certain level of conceptual coherence exists among the various texts. Following Freeden's methodological guide, four interconnected and interdependent core concepts were identified. Removing any of these tenets leads to the collapse of the coherence of transhumanism. Liberty (freedom), progress, human welfare, and individuality emerged as core concepts in the form of five unique decontestations: human enhancement, morphological freedom, longevity, the proactionary principle, and personhood. They point to the existence of a sound and unique ideological structure, a conceptual distinctiveness that corresponds to the first of Freeden's set of criteria for determining an ideational cluster's degree of ideological maturity.

From the four core concepts, one may logically infer that transhumanism is deeply rooted in liberal ideology, sharing the same conceptual pillars. This assumption may be further buttressed by the historical fact that early transhumanists - mostly those linked to Max More's Extropy Institute - espoused classical liberal and libertarian ideals. However, as we will see, transhumanism is neither the descendant nor a variant of liberalism. Instead, their commonality is limited to a set of shared concepts. Indeed, transhumanism conducts entirely different decontestations and introduces a plethora of new adjacent and peripheral concepts that create a distinct conceptual morphology compared with liberalism. This difference gains importance when considering the morphologies of novel versions of transhumanism that emerged in the 2000s and attempted to restructure the conceptual arrangement of early, laissez-faire transhumanism in order to reconcile the transhumanist conceptual core with equality-focused or eco-conscious criticism.

Also, transhumanism possesses a high degree of adaptive capabilities. Among its adjacent and peripheral concepts, numerous examples can be found that are borrowed from other ideologies, then decontested in a unique fashion, and incorporated into the transhumanist ideological architecture. The main role of these borrowed concepts is in part to fill the ideational gaps that transhumanist ideas cannot fulfil and in part to respond to cultural constraints. These borrowed concepts rearrange the conceptual design of transhumanism and the outcome is a more robust, more coherent ideational set-up. 
Despite the fact that there are numerous examples of the conceptual contiguity of transhumanism and liberalism, a thorough examination reveals the fundamental difference in how the two ideologies mutate core concepts along a variety of logical and cultural constraints. Throughout the history of liberalism, proponents have been preoccupied by the logical and cultural inferences of constraints when articulating variations of the concept of liberty. As Freeden stated regarding the ideational development of liberalism:

[w] hat differed were the types of restraint (formal, physical, social) and the features of human conduct that were being restrained (conduct harmful to others, irrational choices, conduct harmful to self). (Freeden, 1996, p. 202)

Early transhumanist theorists applied the laissez-faire approach to constraints on individual liberty, narrowing it to the informed consent of the agent and John Stuart Mill's harm principle as the sole limits to action (Ranisch, 2014). Otherwise, they promoted the decoding of liberty as free choice and free action; as instruments of individual self-realisation and self-expression irrespective of any communitarian or egalitarian considerations. Surprisingly, transhumanists included cultural aspects in their argument for a permissive and minimalist conceptualisation of liberty, namely that it will entail greater diversity in society that is desirable and conducive to the (post)human condition.

As in liberalism, it is the individual who forms the unit of analysis in transhumanism. Even the more egalitarian variants of the ideology remain firmly attached to individuality. The transhumanist view of human nature is inherited from the epistemic maximalist tradition of the Enlightenment: it is rational and right to pursue the development of the self. In transhumanism, this development is decoded as the individual's desire and society's need for the enhancement of cognitive, physical, psychological, and moral capabilities. Enhancement is decoded as the ultimate form of self-development, the moral and biological upgrade of the human species, and the new self-conscious life forms that technology will create.

The liberal roots of transhumanism can also be found in its promotion of neutrality, conceived as the indifference to any particular definition of good life or value allocation to a particular lifestyle (Freeden, 1996, pp. 259-267). It prioritises capability enhancement over 
remaining natural, though the nature-oriented way of living deserves protection in the name of diversity. However, it does not express preferences regarding the application of enhancements. Nor does it pinpoint any specific capability that ought to be improved or set qualitative ends concerning what enhanced living should be like.

As mentioned above, one of the main characteristics of an ideology is the production of action-oriented policy programmes. Transhumanism meets this criterion inasmuch as it promotes the action of enhancement, but it stops there and does not further any concrete end result for the capability improvement. However, as in the case of liberalism, the immunity from determinate views of good (enhanced) life does not entail that transhumanism lacks value-assumptions in general. All choices are considered equally valuable without the imposition of a universal (or group) norm or external preferences for a particular outcome. Value is attached solely to the action itself of choosing enhancement. An important distinction ought to be made here, however. Transhumanists do not want to enforce enhancement; they merely promote the action itself and the plurality of life conducts such actions create on social level. Nor do they ascribe what the new enhanced life forms ought to be like. In a society run by transhumanist ideas, moral agreement on the definition of a good life and the emergence of a consensual criteria of human welfare may develop independently of any coercion by the state or any group. Transhumanists solely insist that the definition and criteria be subject to constant critical re-assessment and self-reflection in light of scientific and technological developments. In this respect, transhumanism is the opposite of eugenics - or at least in its racist practice - in which the coercive element of human alteration is central.

\subsection{From Liberty to Morphological Freedom}

Transhumanism decontests liberty as morphological freedom, a concept positioned in the gravitational centre of the transhumanist ideological universe, and adds it to the set of traditional basic liberties. According to Anders Sandberg's broad definition, morphological freedom is 'the right to modify oneself according to one's desires' (Sandberg, 2013). This modification must aim to enhance the subject's physical, cognitive, and emotional capabilities through utilising the 
advances of technology and science. The concept of morphological freedom has been present since the earliest articulations of transhumanist thought. Max More used the term self-transformation, ${ }^{12}$ defined as ' $[\mathrm{u}] \operatorname{sing}$ technology - in the widest sense to seek physiological and neurological augmentation along with emotional and psychological refinement' (More, 2003). From this point on, morphological freedom has been an intrinsic part of the many and diverse manifestations of transhumanism, including scholarly works, party manifestos, or works of art. It is also an eliminable part of every contemporary ideological version of transhumanism.

In December 2014, founder and then-president of the U.S. Transhumanist Party Zoltan Istvan, drove his eerie, coffin-shaped campaign bus to Washington, DC, where he presented the Transhumanist Bill of Rights to the Capitol. ${ }^{13}$ Though the event did not send shockwaves through political circles, it did manage to make headlines in international media, drawing - for the first time - public attention to the concept of morphological freedom. The Transhumanist Bill of Rights comprises an article that applies a broad definition of morphological freedom and defines the agents that are accorded with this freedom as a right, implying a shift beyond the anthropocentrism of other ideologies:

Article 3. Human beings, sentient artificial intelligences, cyborgs and other advanced sapient life forms agree to uphold morphological freedom - the right to do with one's physical attributes or intelligence (dead, alive, conscious, or unconscious) whatever one wants so long as it doesn't hurt anyone else. (The Transhumanist Bill of Rights, 2015b)

The salience of the concept of morphological freedom within transhumanist ideology lies in that it reconfigures other transhumanist core and adjacent concepts and determines the ideational framework. Morphological freedom has acquired a strong gravitational force that attracts other core and adjacent concepts and transforms them in such a way that none can be discerned without first understanding it. Its central role is further demonstrated if we understand that morphological

\footnotetext{
12 While More uses the term 'self-transformation' in his seminal Principles of Extropy, he nevertheless coined the phrase 'morphological freedom' in 1993. The right to self-transformation and morphological freedom are used as synonyms in transhumanist literature.

${ }^{13}$ https://www.huffingtonpost.com/zoltan-istvan/immortality-bus-delivers-_b_8849450.html
} 
freedom itself alone can be easily defined and articulated, while other core and adjacent concepts of transhumanism - like human enhancement or longevity - lose their ideational coherence if we deprive them of their logical attachment to morphological freedom.

The concept's origins can be traced back to the Enlightenment empiricist epistemology (especially Bacon) and the natural rights individualistic tradition outlined famously in Locke's Second Treatise of Government. The first conceptualisation of morphological freedom in 1990 was mostly influenced by Nozick's self-ownership doctrine (Nozick, 2013) and Ayn Rand's 'virtue of selfishness' (Rand, 1964):

For transhumanists, morphological freedom is generally understood as John Locke's egalitarian liberal conception of the personal agency taken to its logical conclusion, even beyond what the great late libertarian philosopher Robert Nozick had imagined. Whereas Nozick presumed that we are free to do whatever we want (as long as others' freedom is not restricted in the process), transhumanists presume that are also free to be whoever we want. (Fuller, 2016, p. 34)

The ideational expansion of the concept of liberty from 'to do' to 'to be' should not be mistaken for the right (and obligation) to self-development inherent in the liberal tradition and on which liberal theorists and political actors based their strong advocacy for education. Morphological freedom, as Steve Fuller points out, amplifies the concepts of liberty and self-improvement through the inclusion of the possibility of transforming one's body and one's physical and mental traits beyond biological limits. Therefore, it overturns the Lockean egalitarianism that is based on the natural and random distribution of finite human capacities (Fuller, 2016, p. 34). By promoting the alternative models of existence attained through acquiring capabilities beyond our biological imagination, morphological freedom shifts our focus from the actual person to the possible, but so far unimaginable, individual. In this process, it adds a radically different moral angle to the concept.

More specifically, morphological freedom fundamentally transforms the debate over whom we ought to be because it expands not only our capabilities, but also our moral horizon given the possibility of the beyond-human perspective created by science and technology. However, it does not prescribe what we exactly 'ought to be', as in what bodily modifications we are compelled to 
implement. Instead, it allows for and promotes pluralism in the life of the individual, with the limitation of not doing harm to others. This explains why contemporary transhumanists delve so deeply into the issue of moral enhancement (Persson and Savulescu, 2010). It also explains why most of the criticism against transhumanism is morally grounded and targets the concept of morphological freedom. Morphological freedom logically entails and promotes the removal of cultural constraints from the creation of radically novel and diverse forms of existence: humans with artificial implants that provide them with super-capabilities (superhumans), genetically altered humans with super-capabilities, genetically enhanced animals with human traits (or even with human-level intelligence), human-animal chimeras, human-machine cyborgs, minds uploaded to computers, uploaded minds connected and united through computer networks (hive minds), robots with human-level artificial intelligence, or robots with artificial intelligence surpassing that of humans - and the combinations of any of these. This list may at first seem to be created by someone deeply obsessed with science fiction literature and non-transhumanists may find some of the items on this list undesirable or even repulsive. However, the recent progress of science and technology has made many of these seemingly unrealistic developments either a reality or near-possibility.

For example, news broke out in 2018 that a Chinese scientist carried out an experimental prenatal genetic manipulation on human twin embryos and the mother successfully gave birth to the seemingly healthy babies. The scientist altered a gene called CCR5 using CRISPR, a recently developed editing technique, in an attempt to make the new-born children resistant to HIV. The intervention was made with the consent of the parents, one of whom was HIV infected. The scientific community almost unanimously condemned the scientist as 'unethical' and the Chinese authorities sentenced him to three years in jail (Sample, 2019). However, a few scientists came to his defence and while voicing their reservations about the transparency and methodological accuracy of the intervention. They warned fellow scientists to stop being bullish and urged them to 'move forward from ethical permissibility to outline the path to clinical translation ... in order to bring this technology forward' (Begley, 2018; Cohen, 2018).

Less embattled is the latest business venture of the famed entrepreneur and tech-tycoon, Elon Musk. His company, Neuralink, has embarked on developing a non-invasive or minimally invasive technology to upload and download thoughts from a human brain to a computer network (Musk, 2019). The science behind such brain-machine interfaces has already been proven when a 
group of researchers backed by Facebook announced that they were able to 'read' words from human minds using an interface connected to a computer (Makin, Moses and Chang, 2020). But the most popular example of capability-enhancing technologies is literally embodied in Nail Harbisson, a Swedish artist and transhumanist who was born with colour-blindness. To turn his disability into an advantage, many years ago he decided to implant an antennae-like sensor into his head that translates optical wavelengths into vibrations on his skull, which he then perceives as sound. But his antennae also recognises ultra-violet light, thus enabling him to 'see', or more precisely sense more than people with natural visual capabilities (Donahue, 2017). Nevertheless, even the quest to create chimeras has moved forward in scientific laboratories. Recently, a group of scientists transplanted human brain tissue into the brains of mice to create a brain-organoid (a mini-brain that scientists use to study neural activities in a life-like environment) to check its viability. The brain-organoid not only continued to develop, but also sprouted life-sustaining blood vessels as well as new neuronal connections with the host animal's brain. Thus, scientists provided evidence of 'the most amazing phenomenon of organoids - their almost unstoppable drive to reach ever increasing levels of self-organization' (Mansour et al., 2018). The experiment also proved the possibility of creating mouse-human chimeras with enhanced cognitive capabilities.

What is the relevance of the above arbitrary list of examples for the ideological analysis of the concept of morphological freedom? This list buttresses the forward trajectory of science and technology in the exact direction that transhumanists envisioned decades ago, and these advances first raise a logically deductible set of ethical issues, followed by several political ones. The concept of morphological freedom can no longer be reduced to an ideological notion. It demands diverse forms of policy actions: public deliberation, regulation, institutionalisation, or ban. Freeden claimed that one of the main characteristics of ideologies that distinguishes them from political philosophies is that ideologies always inspire political action. The same claim can be extrapolated to ideological concepts as well. In this regard, morphological freedom has an extraordinarily strong motivational power on politics.

Later conceptualisations of morphological freedom embraced a more egalitarian approach while upholding the fundamentally individualistic character of the concept (Bostrom, 2005a). Sandberg (2013), for example, derives morphological freedom from natural rights. According to him, the most fundamental natural right is the right to life. However, to realise one's right to life, 
the right to seek happiness is also needed. Happiness-seeking logically requires other freedoms: the freedom to act in one's best interest, the freedom of choice between different conceptions of happiness, and the freedom to test, evaluate, and pursue different approaches. The right to life cannot be practiced without the right to one's body, which is derived from the concept of ownership. From this, Sandberg inferred that, 'if my pursuit of happiness requires a bodily change... then my right to freedom requires a right to morphological freedom' $(2013$, p. 59).

Max More has described the socio-cultural context in which the freedom of experimentation and innovation can be guaranteed and supported the development of the technology required for the kind of augmentation and refinement that transhumanists promote. Firstly, this society cannot be authoritarian; secondly, the freedom to experimentation must be restricted only by the rule of law and the responsibility of the members of the society; thirdly, no coercion is allowed to force an enhancement on any member of the society. Self-transformation is voluntary and entails 'existential choices instead of empirical absolutes' (Hughes, 2010). For many critics, More's definition was not and is still not compelling. Because transhumanists' attempt to distance their ideology from eugenics raises numerous logical problems, Steve Fuller called the transhumanist enhancement project 'soft eugenics' (Fuller, 2013) or 'eugenics 2.0' (Fuller and Lipińska, 2014a, p. 62). This issue will be discussed in more detail later.

Similar to other basic rights, morphological freedom ought to prescribe that the subject is aware to a substantial level of the risks of the decision to their personal well-being, and the impact it will have on others within society; it should also stipulate that the subject must bear legal responsibility for their actions. Only well-informed agents can make decisions based on proper rational and moral judgements. Hence the prerequisites to morphological freedom are rationally consumed information and consensus. Bostrom refers to this as the 'informed wish' of the subject who decides to avail themselves of any enhancement technology, making it a logically adjacent concept to morphological freedom (Bostrom, 2003a).

An additional argument for the salience of morphological freedom within the ideological analytical context stems from the fact that its emergence is a purely cultural phenomenon. Its birth and elevation to the height of a conceptual arrangement is due to the disruptive techno-scientific advances that characterise our times. Genetically enhanced humans, cross-species, human-machine hybrid life forms, machines with human-level - or even surpassing human-level - cognitive 
capabilities have been unfathomable for those thinkers who laid down the theoretical foundations of the concept of liberty in previous centuries. However, science provides new evidence on a daily basis that the traditional conceptualisation of the notion human needs fundamental reconsideration and that transcending human exceptionalism is a necessary prerequisite for theorising any form of liberty. What used to be speculative, seen as the phantasmagoria of dreamers or the subject of science fiction literature, has become the new reality that demands on its own the correct novel approaches, new concepts, and the re-evaluation of earlier perspectives. Due to these external socio-economic and cultural factors, the concept of morphological freedom gained a central position in a newly born ideology, but it also has the potential to disrupt and reconfigure the manifold decontestations of the concept of liberty in other, if not all, mature ideologies as well.

The scholarly and political debate about morphological freedom is mostly theoretical and concentrates on the ethical aspects of transhumanist technologies, but these theoretical considerations have given birth to several new concepts that transhumanist thinkers developed in response and use to contest any ethics-based criticism. Therefore, it is essential to understand this philosophical debate and how it enriched the ideological edifice of transhumanism.

\subsubsection{Freedom of Experimentation}

Further evidence of the vigorousness of morphological freedom can be found in its conceptual prolificacy, its capability to reflect on and connect to other concepts, and its ability to help create multiple adjacent and peripheral concepts. Liberty is decontested as morphological freedom in the transhumanist conceptual arrangement, but another concept emerges logically from this decontestation. Freedom entails self-determination, which is further decoded as selfdevelopment combined with bodily self-determination. However, it logically entails an additional rights-related concept, the 'freedom of experimentation': applying technology without major constraints. The freedom to experiment should be accorded to both private or state-funded institutions in which research and development are practiced with as few regulations as possible, restricted mostly by the ethics of science. But such liberty refers also to the individual, who ought to be free to apply these developments.

Egalitarian critiques of morphological freedom hold that the allocation of funds to research into enhancement technologies will result in the reduction of funds for more essential research 
aimed at curing diseases that have more profound negative effects on society. 'The best reason of all not to press forward into the posthuman future [is] that the enormous resources required could be put to much better use helping the many people who do not now enjoy a human present', wrote George Scialabba (2002). Spending more money on brain-computer interface research may entail fewer funds for research on malaria vaccination given the scarcity of available resources. Since malaria causes more pain and suffering to more people than the absence of one's ability to directly download knowledge from the internet to one's mind, the latter has less social value than the former, so allocating more funds for the latter creates injustice. A plausible account of the problem is demonstrated by Steve Fuller (2013), and the following section provides an extended account of Fuller's line of thought.

Society approves of and values highly those who practice extreme sports such as solo climbing without a safety rope, wingsuit flying, base jumping, bungee jumping, or canyon swinging, just to name a few of such activities. The shared feature of these sports is the extreme level of risk which causes a high number of accidents. These accidents then have high costs for the whole society: the direct costs of the treatment of the injured and the loss of profit that stems from what society could have earned if the injured or deceased person had lived an average healthy life and contributed to sustaining society. However, society appreciates those who take extremely high risks to their life and health, and approves the social costs of treating those who suffer injuries or death due to their irrational leisure activities. It can thus be argued that the situation of those practicing their morphological freedom is similar to that of those practicing extreme sports: the two groups should be treated equally. In both cases, the central idea is the personal assumption of risk.

Chan et al. (2011) have conveyed the concept of 'scientific citizenship' in their argument for patients' participation in high-risk clinical research. Scientists and ethicists have long been debating the protocols through which patients with terminal illnesses are allowed to participate in different phases of clinical trials for new medicines and treatment methods. Many argue that it is unjust to deprive terminally ill patients, or those in extreme pain or suffering, of a possible cure even if the chances of success are low and the risks of the deterioration of their health condition are high. The debate gained further importance during the COVID-19 pandemic in 2020 when the whole scientific world was racing to find the vaccine to the SARS-2 virus as fast as possible, and many experimental or long-existing medications were allowed to enter the human trial phase as 
authorities suspended rigorous but slow protocols of clinical trials. Originally, the notion of 'scientific citizenship' referred to the participation and public engagement in health care policy decision-making procedures. Chan et al. suggested that the notion should be extended to direct participation in science:

If we view science as a social institution which helps to sustain us and is necessary for the flourishing of society, then it may be arguable that as members of society we should have the right to participate in this institution, in the same way that we have the right to participate in government and social policy, through voting, exercising our freedom of speech, and all the other forms familiar in a participatory democracy. (Ibid p. 95.)

The grounds upon which this right can be established are the same as in the case of extreme sports and morphological freedom: a person's ability to rationally value risks. Steve Fuller further developed the extended version of scientific citizenship (though he himself has not used the term) in his lottery analogy. If people are allowed to allocate money to buy tickets for a lottery in which they have a very minimal chance to win, it is logically implausible to limit one's right to spend resources on enhancement technology where the chances of success far exceed those of the lottery. It can be argued that such a distinction constitutes an unfair distribution of resources within society. Fuller's account of the problem is concisely summarised in this paragraph:

One might add to this case a sense of personal responsibility for the welfare of society as a whole: After all, even a treatment that fails to improve the lives of those who undergo it will have set a negative example to be avoided by others in the future. In contrast, one's failure to pick the winning lottery number is designed precisely not to allow for such a collective learning experience. (Fuller, 2013, p. 25)

The extended version of scientific citizenship and Fuller's lottery analogy demonstrate a plausible argument against the egalitarian objection. Morphological freedom can be defined as extended scientific citizenship, the practice of which creates lower costs (or losses) for society than socially 
approved activities such as extreme sports or playing the lottery. Thus, transhumanists may argue that the egalitarian objection lacks sufficient grounds and plausible rational arguments against the right to self-transformation.

\section{Figure 5. The decontestation chain of scientific citizenship}

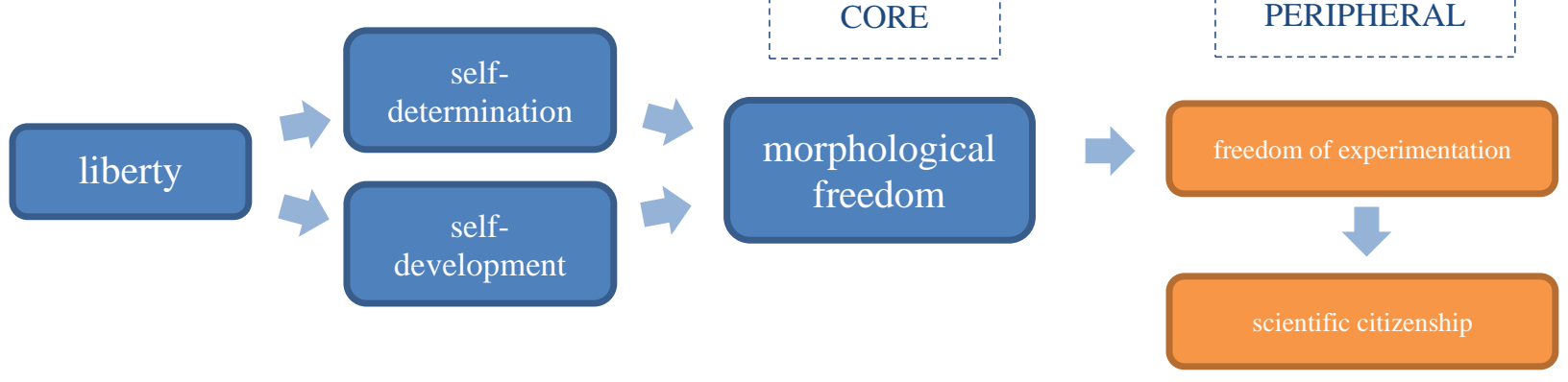

In sum, morphological freedom is exercised through technological and scientific experimentations mostly on one's body. It presupposes that there exist a great number of actors who perform the necessary research and development that leads to novel technologies and can be applied on the body. These actors must be relatively free to conduct their research with as few regulatory obstacles as possible so that the pace of advancement meets transhumanist expectations. Therefore, the logically adjacent concept of experimentation appears in early transhumanist theory. A novel right, the right to experimentation, is conceptualised, which is derived from morphological freedom as its conceptual host.

\subsubsection{Procreative Beneficence or Procreative Freedom}

As discussed earlier, it is genetic engineering where most of the fierce debate has occurred between transhumanists and their opponents. One of the most controversial and heavily contested transhumanist concepts is procreative beneficence, which was put forward by Julian Savulescu to defend the transhumanist advocacy for germline modification. ${ }^{14}$ According to this idea, parents (or single reproducers) with full personhood and risk-evaluating capabilities should be accorded the

\footnotetext{
${ }^{14}$ It is important to note here that Savulescu does not regard himself as transhumanist. However, transhumanists have adopted and widely used his concept of procreative beneficence.
} 
right to 'select the child, of the possible children they could have, who is expected to have the best life, or at least as good a life as the others, based on the relevant, available information', employing genetic tests (Savulescu, 2001, pp. 413-426; 2007, pp. 284-288). But such selection is not only a right, but also a moral obligation of parents, according to Savulescu, provided that safe and effective biomedical enhancement technologies are available. In practice, this means that parents are free to genetically screen their embryos and select freely the embryo which the parents think has the best chances for a good life.

Others moved even further, demanding the freedom of the parent(s) to apply inheritable alterations (germline modification) to their children in order to enhance the offspring's capabilities, provided they are entirely, or at least to the current state of scientific knowledge, aware of the risks and their consequences for the invasive procedure on their child. Genetic therapies that permanently change the reproductive cells of the embryo, thus their inheritable traits or their 'germline' are called 'germline therapies'. An alternative and equally contested possibility is the use of artificial chromosomes to modify someone's germline. People altered at the germline level would pass their modified genes to their offspring. Advocates of such procreative rights argue that sperm and egg selection, genetic screening, and germline engineering are based on rational choice (parents aim to provide their child with the best possible life), and the aggregate of such individual choices will eventually have indirect social advantages (Bailey, 2011), inadvertently using an argument borrowed from classical liberal theories. Transhumanists laid down the demarcation line for the debate:

a bio-progressive rights agenda doesn't have to mean that we're advocating an absolute free-for-all. There's plenty of room for complexity and discourse around legitimate limits to bio-liberty, once the essential premise - that individual autonomy in the bio-age resides in the body and brain (and possibly the intelligent external extensions) of the individual - is accepted. (Sirius, 2009, p. 9)

A novel and astounding narrative was opened up through attaching the active human agent to the cause of technological invention and scientific experimentation. Some immediately questioned the 
novelty and benevolence of the transhumanists' bent on shaping the world and associated their human enhancement project with nothing less than a new, upgraded version of eugenics.

The question concerning the connection between eugenics and transhumanism is an intricate one. Critics who equate transhumanism with eugenics evoke the horrific memories of the pre-World War II eugenics practice that aimed to purify humanity through the sterilisation of the genetically unfit and the selective breeding of people with preferred phenotypes. However, transhumanists strongly reject this accusation, claiming that this comparison is fundamentally flawed and unfair for two main reasons. First, transhumanist themselves made clear from the beginning their disapproval of the malign eugenicist practice. In the Transhumanist FAQ, Nick Bostrom definitively stated that eugenicist ideas 'are entirely contrary to the tolerant humanistic and scientific tenets of transhumanism'. Transhumanists deplore coercion, racism, and discrimination based on social class, but critics still continue to use these charges against its adherents. Second, critics neglect the fact that eugenics is itself a heterogeneous theoretical movement and most of its theorists would strongly denounce and distance themselves from the atrocities that were committed in the name of eugenics. Julien Huxley, who coined the term transhumanism, himself was a devoted eugenicist - he even served as the president of the British Eugenics Society - but in no way could be he associated with the despicable practice of the extremist racist branch of eugenics. When observing the conceptual interactions between eugenics and other ideologies, Freeden sharply pointed out that eugenics attracted not only extremist ideologies such as the Nazism, but it also exerted appeals to liberals and socialists in the late $19^{\text {th }}$ and early $20^{\text {th }}$ centuries:

efficiency has been linked in socialist thought to a fascination with eugenics. Personal efficiency - that is, physical health and flourishing - was the stipulated precondition for communal welfare. (Freeden, 1996, p. 454)

Jürgen Habermas strongly criticised the practice of genetic modification, presenting arguments grounded in moral philosophy. Habermas distinguished what he has called 'liberal' or 'positive eugenics' (Habermas, 2003, p. vii., 19) - capability-enhancing genetic interventions - from 'negative eugenics' - therapeutic interventions - approving the latter while raising strong 
objections to the former. In the focus of his criticism stands germline modification, particularly when parents irreversibly alter the inheritable traits of their offspring. It, according to Habermas, is regulated by market forces (supply and demand) and threatens to disrupt the symmetry of intergenerational relations insofar as it deprives later generations of their right to and opportunity for consent. Moreover, it eliminates responsibility, a key ethical constraint on freedom in social interactions, as descendants are unable to hold their ancestors to account for their decision to manipulate the organic disposition of subsequent generations. Consent and accountability are of particular importance in Habermas's perspective on genetic modification, a key transhumanist technology. The main question for Habermas, who approaches the problem from the postmetaphysical standpoint, is that whether the issue at stake is increased freedom that demand for regulation or human enhancement should rather be conceived as laissez-faire self-empowerment determined by individual preferences without self-limitation (2003, p. 12).

What constitutes self-realisation and self-empowerment for transhumanists is understood as self-instrumentalisation and self-optimisation by Habermas, in other words, it is the objectification of the human that infringes upon the moral imperative of the inviolability of the person. 'The ethically conscious conduct of life should not be understood as narrow-minded selfempowerment', wrote the German philosopher (Ibid., p. 10). Furthermore, Habermas warned that in a liberal society governed by transhumanist ideals,

eugenic decisions would be transferred, via markets governed by profit orientation and preferential demands, to the individual choice of parents and, on the whole, to the anarchic whims of consumers and clients. [...] This program, however, is compatible with political liberalism only if enhancing genetic interventions neither limit the opportunities to lead an autonomous life for the person genetically treated, nor constrain the conditions for her to interact with other persons on an egalitarian basis. (Ibid., p. 48)

In addition to the issue of irreversibility and the objectification of the 'designed' person, Habermas also cautioned that 'liberal eugenics', inheritable gene modification, also creates an asymmetrical 
relationship between the 'programmer' and the 'programmed' subject, a form of social dependence that is atypical of a community of morally and legally equal persons:

Up to now, only persons born, not persons made, have participated in social interaction. In the biopolitical future prophesied by liberal eugenicists, this horizontal connection would be superseded by an intergenerational stream of action and communication cutting vertically across the deliberately modified genome of future generations. (Ibid., p. 65)

Habermas's criticism is founded on the assumption that every generation sees themselves as the undivided author of their lives and liberal eugenics would deprive them of such authorship. $\mathrm{He}$ derived his arguments against germline modification from this simple claim. In response, transhumanists put forward a similarly plain initial argument in support of germline modification: current generations are entirely and uncontrollably exposed to the fallibility and languor of nature's random evolution and they are deprived of the authorship of the initial, genomic conditions of their lives that to a great extent determine one's quality of life (assuming that we accept that nature and nurture play an equal role in the formation of personhood). What difference does it make, ask transhumanists, whether it is nature or parents who decide the genetic traits of children? In both cases the authorship of life is independent from the offspring. Habermas's authorship argument was further criticised for his own approval of germline modification for therapeutic purposes while, according to transhumanists, he failed to propose a logically coherent, convincing answer as to where to draw the line between enhancement and therapy in normative terms:

I primarily concentrated on two possible consequences: first, that genetically programmed persons might no longer regard themselves as the sole authors of their own life history; and second, that they might no longer regard themselves as unconditionally equal-born persons in relation to previous generations. (Ibid., p. 79)

It is obvious that Habermas's critique greatly contributed to the ideological reconfiguration of transhumanism. The emphasis on individual liberty gradually shifted to a more nuanced 
articulation of transhumanist ideas and policy proposals, inviting and valorising new peripheral concepts such as diversity or the state as the main facilitator and guarantor of equal access to enhancement technologies. Transhumanist texts began to highlight that transhumanists do not deny the legitimacy of self-limitation or even normative regulation, and this gradual transformation was reflected in how these new peripheral concepts took up more central positions in the transhumanist conceptual arrangement.

It is fair to admit, however, that some transhumanists greatly contributed to the controversies by linking transhumanism to the progressive branch of eugenics, thus providing ground for further confusion. Some of them identified transhumanism as 'eugenics without the coercion', ${ }^{15}$ the soft eugenics of the bioliberal age that gives 'eugenics an ideological makeover, mainly by shifting the locus of normative concern from the population to the individual' (Fuller, 2013, p. 17), or simply approved of using the Habermasian term 'liberal eugenics' (Agar, 2004). However, those transhumanists who argue for accepting the strong connection between transhumanism and eugenics fail to properly address the problem that 'even the tamer idea of eugenics carries significant ethical questions concerning people's right to reproduce, and entails difficult determinations about what traits are "desirable" and which are "undesirable" to whom, and why' (Niman, 2012). This deficit indicates that some transhumanism concepts are still in a transitory state of development.

Another emblematic critic of germline modification and transhumanism, Francis Fukuyama, demanded in 2007 that the U.S. administration exert social control over reproduction by creating a regulatory agency that would oversee all forms of assisted reproduction techniques including IVF, ooplasm transfer, sex selection, and sperm sorting, as well as stem cell research. He also argued for the total ban on human reproductive cloning, germline genetic modification, and chimera creation (Bailey, 2007; Fukuyama and Furger, 2007). He identified three main movements that have raised objections to gene transforming enhancement interventions: religious groups that consider such intervention technological heresy, 'humans playing God'; advocates of a radical, techno-sceptic Green ideology, who disapprove of technologies overwriting nature; and moderate critics who raise moral concerns and claim that such alterations will infringe the moral autonomy of humans - and ultimately alter human nature - and will lead to social injustice without the

\footnotetext{
${ }^{15}$ https://amormundi.blogspot.com/2013/03/uh-good-luck-pushing-that-line.html
} 
influence of strong democratic state control. According to Fukuyama, the tenets of transhumanism represent intellectual and moral threats to the 'human essence' - the diversity and equal distribution of human intellectual and physical capabilities and phenotypical characteristics - on which the system of equal human rights is based. On the other hand, Fukuyama also admitted the upside of novel, safer, and more effective technologies in genetic engineering, as well as the fact that transhumanism does not involve coercion or restrictions on parents' rights. Instead, technological progress in the field will widen the reproductive choices of parents, reduce the risk of birth defects, and provide solutions to infertility. All these will likely result in less abortion. In Fukuyama's moral critique, the idea of human genetic enhancement is presented as a detrimental case: it is the negation of humanism, the transgression of established moral boundaries. He proposed a middle path between the two radical options:

Both approaches - a totally laissez-faire attitude toward biotech development, and the attempt to ban wide swaths of future technology - are misguided and unrealistic. Certain technologies, such as human cloning, deserve to be banned outright, for reasons both intrinsic and tactical. But for most other forms of biotechnology that we see emerging, a more nuanced regulatory approach will be needed. (Fukuyama, 2003, p. 183)

It is needless to say that transhumanists did not approve of Fukuyama's moderate stance towards genetic modification. Savulescu's concept of procreative beneficence and James Hughes's concept of procreative freedom were conveyed to present a theoretically solid, but at the same time effective and easily consumable - and in this respect ideological - counterargument in favour of germline modification. For Fukuyama, the integrity of the human body is sacrosanct, while transhumanists promote the sanctity of the freedom to enhance the human body.

The improvement of the ethical, cognitive, and physical self through experimentation in a proactive way using technology is not an original invention of transhumanism. Nonetheless, because of the haunting memory of eugenics in the late $19^{\text {th }}$ century and the horrific atrocities of human experiments by the Nazis during WWII, it took substantial courage to voice such an idea. Invoking the spirit of eugenics by its critics explains why transhumanist theorists have been 
struggling to defend their idea from constant - and sometimes unfair and demagogic - criticism, emphasising that the transhumanist enhancement concept shares no common ground with the distortions of eugenics. As Fuller summarised it, 'the history of eugenics always provides a cautionary tale to any automatic embrace of [the transhumanist] proposal, but that does not deny that the proposal itself is constitutive of the human project' $(2013$, p. 62). But this constant line of attack also helped the adjacent concepts of the freedom of experimentation and the procreative beneficence to strongly attach to the core concept of morphological freedom and cemented them in the centre of the ideational structure of the transhumanist ideology.

\subsection{From Welfare to Human Enhancement}

From drinking coffee or energy drinks to boost attention, through doping in professional sport, or the popular trend of using medication among students to sharpen concentration before examinations, to the social acceptance of cosmetic surgery, there are many tools that humans regularly use to improve our biological capacities. It is also a commonly held belief that we can and ought to aim to raise intelligence or strength through, for example, better education, nutrition, or training. These signal the emergence of what scholars call the 'enhancement society', in which almost any natural human capability is potentially open to improvement by science-based or technological bodily intervention (Coenen et al., 2009, p. 6). As a result, life itself came to be a locus of new and extensive forms of technological intervention starting from the second half of the $20^{\text {th }}$ century. Biochemical and medical interventions were added to the conventional methods of enhancement that aim to improve individual well-being and welfare: education, enriched environments, and general health conditions (Bostrom and Sandberg, 2009, p. 314). Ideologies always relate in some way or another to this issue, and one just needs to think of self-improvement in liberalism through education, or the importance of physical training in Nazi ideology. The idea of (conventional) enhancement is usually linked to the concept of welfare in almost every ideology.

The core concept of welfare is presented in transhumanist ideology through two components: human enhancement and longevity. Both components can be found in all 
transhumanist theoretical and political texts. Max More published the first version of his Principles of Extropy manifesto in 1988. He defined the term extropy as

affirming continual ethical, intellectual, and physical self-improvement, through critical and creative thinking, perpetual learning, personal responsibility, proactivity, and experimentation. Using technology - in the widest sense to seek physiological and neurological augmentation along with emotional and psychological refinement. (More, 2003)

Welfare is defined in short as the fulfilled 'desire for more life, more intelligence, more freedom' (More, 1990a, p. 4). In this early text, More presented the first articulation of the concept of human enhancement, described as continual self-improvement. The main reason that explains and justifies enhancement is that transhumanists view the human as a handicapped, faulty biological being, the unfinished project of nature. More further elaborated this view in his famous 'A Letter to Mother Nature':

Mother Nature, truly we are grateful for what you have made us. No doubt you did the best you could. However, with all due respect, we must say that you have in many ways done a poor job with the human constitution. You have made us vulnerable to disease and damage. You compel us to age and die - just as we're beginning to attain wisdom. You were miserly in the extent to which you gave us awareness of our somatic, cognitive, and emotional processes. You held out on us by giving the sharpest senses to other animals. You made us functional only under narrow environmental conditions. You gave us limited memory, poor impulse control, and tribalistic, xenophobic urges. And, you forgot to give us the operating manual for ourselves!

What you have made us is glorious, yet deeply flawed. You seem to have lost interest in our further evolution some 100,000 years ago. Or perhaps you have been biding your time, waiting for us to take the next step ourselves. Either way, we have reached our childhood's end. (More and Vita-More, 2013, p. 449) 
Max More's perspective on enhancement is rooted in the humanist and Enlightenment philosophical traditions and conceptualises a human being as a craftsman of self and sculptor of his own nature. James Hughes expanded More's description of human enhancement, defining eight layers where enhancement should be applied: curing disabilities, improving general health conditions, longevity, upgrading intelligence, exerting better emotional control, widening the opportunities for aesthetic expression, achieving spiritual goals, and ensuring better lives for our children (Hughes, 2010). Beyond the 'authorship' or 'craftmanship' arguments, other definitions were also presented by scholars (both transhumanists and critics) that led to the further ideological enrichment of the concept, systematically revealing the social determinants at play.

Sarah Chan and John Harris put forward a general definition of enhancement: 'a procedure that improves our functioning: any intervention which increases our general capabilities for human flourishing' (Chan and Harris, 2008, p. 1). In other words, a functional improvement on the human body leads to a general improvement in our conduct of life; interventions at the individual level result in a better society. In all transhumanist accounts, human enhancement stands on a firm individualist moral basis, as its purpose is to lead a good life. Perfecting the human condition is a prerequisite to pursuing a good life. The centrality of the concept is underpinned by the fact that it is one of the most frequently debated concepts of transhumanism in scholarly literature and political discussions. The emphasis is on the term 'enhancement' since the passionate debate revolves more around the methods, ethics, and consequences of improving the human condition rather than the legal-philosophical aspects of bodily self-determination.

In addition to the authorship and the functionalist arguments in favour of human enhancement, a third definition opened up another intriguing issue. A report produced for the U.S. National Science Foundation provided the so far most elaborated definition of enhancement as 'improving capabilities beyond the species-typical level or statistically-normal range of functioning for an individual' (Allhoff et al., 2009). As it was pointed out previously, there exists a certain level of consensus about the acceptance of bodily transformation, including even genetic engineering, as long as it aims to treat some sort of disease or disability to improve the condition to a normal level. However, two questions arise: what constitutes 'species-typical' normality and where should the line be drawn between treatment and enhancement as both result in a significant 
improvement in condition? The treatment-enhancement distinction differentiates between interventions and procedures aimed to prevent or cure conditions that are generally or in medical terms viewed as diseases or disabilities and interventions that improve a condition that is considered a normal function or capacity of members of the human species. There is an ongoing and unsettled debate among scholars about the scientific justification of such a distinction. Many scholars - not affiliated with or even opponents of the transhumanist movement - claim that such a distinction is socially constructed, tenuous, and scientifically unfounded (Daniels, 2000; McGee, 2000; Holtug, 2011). For transhumanists, human enhancement can definitely not be reduced to a mere medical issue. They endorse a welfarist position in which enhancement means improving one's chances of pursuing a good life, in the philosophical and political understandings of the term. For them, the treatment-enhancement distinction is pointless as both therapeutic treatment and enhancement are acceptable and desirable as means to increase welfare both at the individual level and in society as a whole, therefore, the line between the two is blurred.

In addition to external critics, even transhumanists are divided and lack a consensual understanding of enhancement. Stefan Sorgner differentiated between strong and weak transhumanist approaches to enhancement (Sorgner, 2016, p. 144). Representatives of the strong version claim that it is a moral - though not legal - obligation of the individual to apply the available enhancement technologies, and it is the political task of governments and the legislature to allocate financial resources to scientific research aiming to develop such technologies. Advocates of weak transhumanism decline any moral or legal obligation concerning enhancement, even if it may lead to many people living a good life. They argue that such a moral duty cannot be established and, consequently, policy action cannot be articulated because any theoretical consensus about the concept of good life does not exist and seems impossible to reach. To resolve the debate, Sorgner suggested a radically pluralistic account, which promotes the individual's pursuit of a good life according to their own idiosyncratic and diverse standards. Therefore, Sorgner pointed out the significance that transhumanists invite a peripheral concept of good life to cement the core concept of human enhancement in its central position in the transhumanist conceptual arrangement while utilising a further adjacent concept, diversity.

At the level of the individual, clearly separating it from therapeutic intervention, human enhancement is described by the proponents of transhumanism as a set of tools that improves a 
subsystem in some way other than repairing something that is broken or remedying a specific dysfunction' (Bostrom and Sandberg, 2009, p. 312). Human enhancement is the tool for humanity to transcend its biological limits, end the biological evolution based on random selection, and start a new era of technology- and science-driven directed evolution. The augmentation of cognitive, physical, and emotional capabilities will lead to a world with less or no pain and suffering, as the hedonistic principle of transhumanism promises. Additionally, human enhancement is an instrument that support individuals in leading a good life. The pluralistic approach to good life allows all-purpose goods to qualify as enhancements under all major philosophical accounts. As Savulescu has written:

I have not committed myself to any particular substantive conception of the good life. That is a complex question as old as philosophy itself. I believe the best life is a life of objectively worthwhile activity that provides pleasure and is desired. (Savulescu, 2007, p. 186)

This pluralistic approach and broad definition allow transhumanism to avoid ideological conflicts with other ideologies that offer a distinctive definition of a good life. When arguing with the proponents of other ideologies with a well-defined moral system of obligations, transhumanists are able to put forward suggestions of all-purpose means of human enhancement technologies that are difficult to denote on ideological grounds: for example, artificially improved memory, strengthened self-discipline, faster thinking, or expanded knowledge. Following similar logics makes it difficult to rationally argue why parents should be deprived of their right to enable their children to possess such enhanced capabilities through safe technological interventions (which takes us back to the issue of germline modification as the most controversial enhancement technology).

In addition to self-improvement, human enhancement is also supposed to better society as a whole. The original disadvantages for individuals lie in their being human, natural, and forced to continuously adapt to the externalities of nature. In its current biological forms, the human body and mind are unfit, archaic, and primitive, therefore, it is time for both to be upgraded, even partially, or totally replaced. But it is not only the biological form that needs to be ameliorated, according to transhumanists. What history teaches us foremost is that humans, with their current 
level of cognitive, intellectual, and psychological capabilities, are morally incompetent. Moreover, humans are a threat to human civilisation:

Even if human beings were psychologically and morally fit for life in those natural conditions in which they have lived during most of the time that the human species has existed, humans have now so radically affected their conditions of living that they might be less psychologically and morally fit for life in these new conditions. These new conditions consist in societies with an enormous population density and an advanced science and technology, which enable their citizens to exercise an influence that extends all over the world and far into the future. If human beings do not better adapt psychologically and morally to these new conditions, human civilization could be threatened. (Persson and Savulescu, 2012, p. 660)

What Persson and Savulescu have suggested is that moral enhancement is inevitable if we want to protect the human species from itself. Inherently human behaviours - such as the proliferation of nuclear weapons, terrorist attacks, or anthropogenic climate change - jeopardise human existence. Our current moral dispositions were designed for an archaic, primitive civilisation with rudimentary technologies, living in pastoral communities. Our natural, or 'species-specific', cognitive and psychological capabilities make us easily manipulable and in possession of conflicting moral dispositions. Consequently, we are unfit for the high-tech civilisation and the globalised world. Transhumanist enhancement technologies, however, offer a remedy to these moral disadvantages.

In this perspective, humans are morally unfit to handle not only existing social issues but also the upcoming conflicts that emerging technologies will inevitably create. Therefore, we need to develop new forms of social reflexivity concerning human enhancement technologies. The making of 'better humans', then, is not an idle utopian fantasy about the ideal future but an extensive social programme that requires the redistribution of resources; demands public deliberation concerning values, their interpretation, and prioritisation with regard to technological progress; and necessitates policy decisions. If the theoretical relevance of human enhancement relates to issues of more general philosophical significance, its practical implications concern 
issues such as how to increase societal acceptance of capability-enhancing developments, how to address the numerous ethical conflicts that exist among various policy actions, and how to forge public consensus that could direct general regulation and the control over new technologies. In this respect, 'human enhancement is a fundamentally political issue [...] that questions the values orienting collective action and establishing shared life' (Dévédec, 2018, p. 2).

The ideological decontestations of the concept of welfare in the forms of the concepts of morphological freedom and human enhancement stand at the centre of the ideological system of transhumanism just as binary stars revolving around each other hold together a solar system. Morphological freedom serves as the concept that is fundamental for the transhumanist ideological structure that philosophically and morally validates every other concept within the system. Human enhancement, then, provides transhumanism with its very own teleology, which is presented as an ideological tool to inspire policy action and economic, cultural, and societal restructuring. Transhumanists presented the authorship, functionalist, welfarist, and moral unfitness arguments in favour of human enhancement to theoretically underpin its relevance for future societies, while at the same time attempting to make transhumanism attractive to consumers of this futurist ideology. Thus, every other concept - core, adjacent, and peripheral alike - is within the gravitational pull of morphological freedom and human enhancement: they relate to them, reflect on them, and enrich them with specific ideational additions.

\subsection{From Welfare to Longevity}

According to transhumanists, the most important aim of practicing one's right to bodily self-determination and the proactive approach to scientific and technological advances is to extend the healthy lifespan far beyond the current human-specific life expectancy. A healthy life span is, at the same time, a core component of any transhumanist articulation of the peripheral concept of a 'good life'. Inheriting the convictions of the cryonic movement of the late $20^{\text {th }}$ century, most transhumanists believe that progress will eventually enable scientists to stop ageing, eliminate the suffering caused by age-related diseases, and offer a realistic prospect of living forever. Longevity - defined as the expansion of healthy life as long as possible - has been immanent to transhumanist 
culture from the beginning, and today many transhumanists participate in anti-ageing projects, scientific research programmes, or for-profit enterprises, while transhumanist groups urge governments to allocate more funds to 'cure aging' (Bostrom, 2003b; Kostick, 2017). Thus, 'living forever' is not a utopian policy goal, but a fundamental idea backed by serious science (The Lancet Diabetes \& Endocrinology, 2018) and lavish research funds provided by Silicon Valley tech giants (Friend, 2017; Gray, 2017).

Longevity is the morphological decontestation of the central concept of welfare utilised by other mature ideologies and is bound together with the concept of autonomy. As Habermas posited, 'the wish to be autonomous in the conduct of one's own life is always connected with the collective goals of health and the prolongation of lifespan' (2003, p. 24). Max More also linked the issue to the philosophical concept of autonomy in his 'A Letter to Mother Nature':

We will no longer tolerate the tyranny of aging and death. Through genetic alterations, cellular manipulations, synthetic organs, and any necessary means, we will endow ourselves with enduring vitality and remove our expiration date. We will each decide for ourselves how long we shall live. (More and Vita-More, 2013)

But transhumanists prefer deriving longevity from the concept of welfare by claiming that without the expansion of the healthy lifespan or, even more explicitly, without immortality, human welfare cannot be significantly improved. Death is the most salient limit to the realisation of human potential, which dwarfs poverty and wealth in comparison. Additionally, the death of our loved ones - parents, children, spouses, friends - is the most terrifying source of emotional suffering that puts human psychological capabilities to the test.

The most prominent advocate, theorist, and active researcher among transhumanist immortalists is the British biogerontologist Aubrey de Grey. He launched the Strategies for Engineered Negligible Senescence Research Foundation, one of the most acknowledged research centres in the field, which is, not surprisingly, based in California, a few miles from Google's headquarters. Using his own multimillion-dollar inheritance, boosted by Silicon Valley investors and Hollywood celebrities, de Grey devoted his life to developing, promoting, and providing widespread access to therapies that cure and prevent ageing-related diseases and disabilities, and 
finally defeat death. As such, he has become a true evangelist of immortality. De Grey was among the first to promote the theory that the most common causes of death - heart disease, cancer, Alzheimer's - are ageing's side effects (de Grey, 2007). If that is the case, he concluded, ageing itself is also a disease that can be cured. He frequently appears in mass media, has published several popular books on the topic, and remains a well-respected scientist. His most famous prediction is that the first human to live for over 1,000 years is probably already alive (Cox, 2017).

Although longevity may in the first place seem to serve as a policy goal and not an ideational component, its central role and omnipresence in all manifestations of transhumanism in every theoretical text irrespective of time of publication and political position, as well as in party manifestos and public debates - suggests that it has been upgraded to the conceptual level within the ideational arrangement of transhumanism. Such an upgrade is not only permitted in the Freedenian framework, but also is listed as a typicality of ideologies. Longevity may also appear as a rhetorical hyperbole, a propaganda tool in the hands of transhumanists to make their perspective more attractive and easier to consume for wider audiences. But Freeden, when advising on how to distinguish ideological assertions from vote-maximising, or attention-seeking, rhetorical catch-phrases, emphasised that

...ideologies are not only produced but consumed. If the audiences towards whom rhetoric is directed find it indistinguishable from genuine political beliefs, it will have the same effect on the formation of their opinions, on their judgements and actions. Rhetoric will then enter the plural world of ideological debate as a serious contender for the legitimacy of its utterances. The mass consumption of ideologies is of equal importance when analysing fields of social meaning as is their production - to a large extent - by social and cultural elites. (Freeden, 1996, pp. 35-36)

Consequently, the concept of longevity serves as an effective tool designed for mass consumption and to popularise the transhumanist ideology. As such, it is tantamount to the concept of ecoconsciousness in Green ideology or the decontestation of the concept of sovereignty in the populist ideology. In addition to evoking the most archaic and fundamental human psychological trait - the fear of death and the lament over the finiteness of life - a welfarist argument was also 
put forward in favour of longevity through the introduction of the idea of the longevity dividend (Bailey, 2007; Sandberg, 2007; Olshansky, 2013). It encompasses the assumed economic benefits of extending the healthy lifespan indefinitely and reducing the health care costs associated with ageing. It is based on scientific and economic research that showed that the increase in the average life span since the early $20^{\text {th }}$ century has produced enormous net economic benefits globally (Nordhaus, 2002; Murphy and Topel, 2005). By extrapolating from these quantitative studies, transhumanists concluded that 1 ) it is scientifically and technologically possible to extend life far beyond what we currently find possible, and 2) such extension will present net economic gains on individual, national, and global levels alike.

Freeden's morphological approach explains how such a utopian idea could become a core concept within an ideology. Transhumanism, just like other ideologies, assigns emotional importance to their key values. As Freeden pointed out when describing the main characteristics of ideologies, the role of the concept of longevity is to increase the effectiveness of the consumption of the transhumanist ideology through a desire-fulfilling, easily consumable, emotion-evoking core concept that is buttressed by a peripheral concept, the longevity dividend, which provides a rational argument to fine tune its logical and cultural decontestation from its original concept, welfare. Thus, longevity stands as a prime example of a concept that encompasses emotion and rationality at the same time, which explains why it took a central position inside the conceptual arrangement of transhumanism.

Without human enhancement and longevity, human welfare loses its meaning and value, according to transhumanists. Death and ageing are the most salient obstacles to the maximisation of human well-being. 'The abolition of aging and, finally, all causes of death, is essential to any philosophy of optimism and transcendence relevant to the individual', wrote Max More (1990e, p. 10). In its activist role, longevity inspires two types of policy action: the acceptance of aging as a disease by medical science, allocating the necessary funding and focusing medical research on the expansion of healthy lifespan. In this respect, transhumanists celebrated minor progress when in 2018 the World Health Organization added an extension code for 'ageing-related' disease to its 
revision of the International Classification of Diseases for Mortality and Morbidity Statistics, ${ }^{16}$ a move seen by many as the first step towards the classification of ageing as a disease.

As centrally ineliminable components, the presence of longevity and human enhancement are cultural preconditions to any conceptualisation of welfare in transhumanism. In the transhumanist perspective, the ultimate aim of human enhancement is to achieve the power to upgrade human bodies with superior physical, emotional, mental, and moral traits; the ability to live a longer and happier life; and to postpone death indefinitely. At the same time, they allocate a distinctive character to the concept of human welfare that cannot be found in any other ideology.

\subsection{Progress Driven by the Proactionary Principle}

The concept of progress also has an eliminable role within transhumanism. As Freeden observed in terms of its purpose in mature ideologies,

[t]he concept of progress ... both interprets reality as the march of human and social improvement, and reacts on other adjacent concepts to fashion a particular understanding of welfare, liberty, or rationality. A conservative view of slowly changing phenomena affects adjacent concepts that will either be halted in their development or construed through the prism of organic change. Theories of development or evolution thus allow for change within ideologies, either on the macrolevel of an ideology directed at attaining teleological or open-ended goals, or on the microlevel of patterned change within the structure of an ideology. In the latter case the concepts interact and co-ordinate their reinterpretation until an internal balance, or a continuous dynamic equilibrium, is achieved. (Freeden, 1996, p. 98)

\footnotetext{
${ }^{16}$ World Health Organization, '11th International Classification of Diseases for Mortality and Morbidity Statistics', 2018, https://www.who.int/classifications/icd/en/.
} 
Progress is assigned a similar objective in transhumanism: adding further argument for its distinctness as an ideology; the ideational uniqueness of transhumanism is underpinned by how it articulates its approach to progress. Theories of history fundamentally shape the conceptual arrangements of ideologies. The belief in exponential progress, an indeterministic view of history, and the promotion of disruptive mechanisms conducive to change formulate the context in which concepts are decontested in transhumanism: the construction and arrangement of concepts are constrained by an ideational environment in which (morphological) freedom, choice, and rationality play an ineluctable role, which is a direct consequence of the transhumanist theory of history.

Transhumanism belongs to the family of ideologies that conceives of progress as a 'boundless expansion' (More, 1990b, p. 17), a perpetual and endless process. It adopts the theory of evolution and hypothesises that science and technology will enable humanity not only to take control over the fallible, nature-driven evolution, but also to accelerate its pace and define its direction. More's notion of self-transformation redefines the main character of evolution as continual and exponential progress replacing Darwinian random selection, considers technology the main drive of this perpetual improvement, and ascribes the ultimate aim of capability and capacity augmentation. Humanity will be able to take control over evolution, and our obligation is to proactively pursue this endeavour. Our human existence is conceptualised as 'a temporary stage along the evolutionary pathway. [...] Life and intelligence must re-order, transform and transcend its limits in an unlimited progressive process’ (More, 1990c, p. 11).

Max More defined progress as 'taking personal charges of creating better futures rather than hoping or praying for them' (More, 2013, p. 4). Progress is not only a desirable process, but also is the open-ended goal of (political) action through which the end-state, the posthuman condition, ought to be reached as soon as possible. Progress is the meaning of life according to transhumanists, or as More wrote, 'Transhumanists seek neither utopia nor dystopia. They seek perpetual progress - a never-ending movement toward the ever-distant goal of extropia' (More, 2011, p. 140). Therefore, any obstacle to progress is unfavourable and harmful. The main driving force of progress is science and then technology. It plays the same role as class struggle in Marxism or education in liberalism. 
Transhumanists demand that all individuals should support and proactively act according to the cause of progress. Morphological freedom allows the individual to voluntarily apply enhancement technologies, and these individual endeavours accumulate, thus contributing to the progress of all humanity. The demand and advocacy for proactivity is reflected in the adoption of the proactionary principle in transhumanism. This principle was first formulated by Max More as the baseline for human enhancement and the right and morally justified approach to practicing one's morphological freedom:

The Proactionary Principle stands for the proactive pursuit of progress. Being proactive involves not only anticipating before acting, but learning by acting. When technological progress is halted, people lose an essential freedom and the accompanying opportunities to learn through diverse experiments. We already suffer from an undeveloped capacity for rational decision making. Prohibiting technological change will only stunt that capacity further. Continuing needs to alleviate global human suffering and desires to achieve human flourishing should make obvious the folly of stifling our freedom to learn. (More, 2004)

The proactionary principle is advanced as an alternative approach to evaluating the effects of technological innovation to challenge the intellectual dominance of the popular precautionary principle. The precautionary principle was initially endorsed by the proponents of the emerging Green movement of the 1980s to promote eco-conscious policies, and gradually became incorporated into the statutes of numerous national and supranational institutions. The precautionary principle suggests that, in the case of an assumed health risk or a potential threat to the environment, measures should be taken to restrict or to fully suspend corporate activities or technological innovation, even if the causal relationship between the activity and the negative effect cannot be established scientifically (Barrieu and Sinclair-Desgagné, 2006, pp. 1146, 1150-1152). As opposed to the restrictive approach of the precautionary principle (Epstein, 1980; Foster, 2000; Gollier, Jullien and Treich, 2000; Martuzzi and Tickner, 2004), the proactionary principle - or proactionary imperative (Fuller and Lipińska, 2014b) - proposes decision-making based on transparent risk evaluation and an objective cost-benefit analysis that considers not only the 
potential dangers, but also the opportunity costs of inaction. The proactionary principle supports minimal regulations on technological innovation and scientific research ('the liberation of science') as well as the unrestricted practice of morphological freedom to experiment with one's own body. Thus, it stands in close proximity to the peripheral concept of the freedom of experimentation. Also, the proactionary principle reflects activist impulses at the core of transhumanism and suggests profound ways of surpassing the fringe status of the contemporary movement, especially from a political context. This activist impulse demonstrates another ideological property of transhumanism.

Fuller and Lipińska described the conflict between the precautionary and proactionary approaches as 'the twenty-first-century's defining ideological polarity' (2014a, p. 12). Belligerent critics attacked transhumanist thinkers based on their alleged neglect of the potential ramifications of technological progress. Transhumanist 'techno-optimism' was denounced and confronted with the possibility of a dystopian future and the extinction that unregulated, uncontrolled advancement would cause to humanity. Fuller and Lipińska turned this accusation backwards against the critiques:

Precautionaries aspire to a 'sustainable' humanity, which invariably means bringing fewer of us into existence, with each of us making less of an impact on the planet. In contrast, proactionaries are happy to increase the planet's human population indefinitely as nothing more or less than a series of experiments in living, regardless of out-comes. Whereas precautionaries would reacquaint us with our humble animal origins, from which we have strayed for much too long, proactionaries would expedite our departure from our evolutionary past - in some versions, the Earth itself, if we succeed in colonizing other planets. At the very least, proactionaries would re-engineer our biology, if not replace it altogether with some intellectually superior and more durable substratum. (Fuller and Lipińska, 2014a, p. 63)

In this argument, transhumanism is presented as the ideology of human expansion, while other ideologies (especially Green and conservative ideologies) that oppose the proactionary imperative are reductionist ideologies that narrow the opportunities for the progress of humankind and human 
existence in general. This ideological division suggests that future ideological conflicts will differ from the current left-right divide. Fuller and Lipińska borrow the terms introduced by FM-2030 some 40 years earlier: up-wingers and down-wingers replace the commonly held left-right 'wing' perspective of ideologies. Up-wingers are identified with those approving of the proactionary principle, while down-wingers are identified with supporters of the precautionary approach. Consequently, the attitude towards caution profoundly reshapes the ideological landscape as depicted in Table 5.

Table 5. The reorientation of the wings of the ideological axis

\section{Left wing Right wing}

\begin{tabular}{l|l|l|}
\hline Up wing & Technocrat & Libertarian \\
\hline Down wing & Communitarian & Traditionalist
\end{tabular}

Source: Fuller and Lipińska (2014a, p. 43)

Table 5 also explains how and why the strange coalition of religious orthodoxy, Green communitarians, and ideological conservatives could have been formed against transhumanism, and, on the other hand, how left-leaning egalitarians and state-denier libertarians could gather under one ideological umbrella. The answer lies, according to FM-2030 and Fuller and Lipińska, in that the main ideological cleavage shifted 90 degrees, from left-right to up-down, and the traditional political left and right

By all means, the proactionary principle is a disruptive idea in itself that challenges a dominant perspective approved by the majority of scientists. But its true agitative power becomes comprehensible when it appears alongside other transhumanist core constituents. The concept of the proactionary principle is attached to morphological freedom in the ideological arrangement and the two together logically imbue the concept of freedom of experimentation, which, then, develops further into the concept of human enhancement to create an explanatory framework for the latter (see Figure 6). What we see here is a well-structured, logical, and culturally coherent set-up, where the proximity of four core and adjacent concepts provide transhumanism with exceptionally strong conceptual cohesion. 
Figure 6. The decontestation of the concept 'human enhancement'

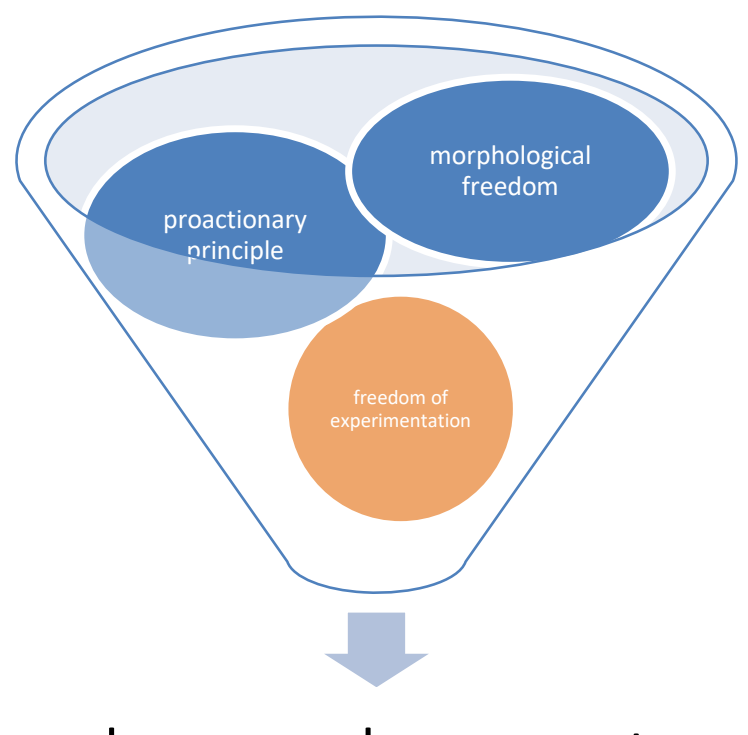

human enhancement

\subsection{From Individuality to Post-Anthropocentric Rights}

Freeden dismissed enumerating rights among core concepts and ascribed an instrumental status to it:

the concept of rights cannot be part of an ideological core, being definitionally attached to any political value or concept it is designed to protect and prioritize. A right is a prioritizing concept which deliberately secures a specific configuration of the core concepts of a given ideology... On the micro-level, the concept of rights has a specific impact on decontesting the concepts to which it is proximate. Thus, its attachment to the concept of liberty entails specific conduct on the part of others towards the subject of liberty. (Freeden, 1996, p. 162)

However, the issue of rights has gained such significance in the transhumanist ideology that it is imperative to investigate its status within the conceptual arrangement. Transhumanists propose a new rights framework, which is unique among ideologies and can only be understood by 'zooming 
out' of the anthropocentric view of other belief systems. In this new framework, the subject of the legal system is not required to necessarily belong to the human species. 'Just as human rights have become independent of race, gender, and property, rights will become independent of being a breathing human being', wrote Hughes (2001), the creator of the new transhumanist rights system. As technology continues to develop at an accelerated rate, transhumanists predict that soon new conscious and sentient life forms, intelligent machines, and their hybrids will emerge. Transhumanists envision chimeras, cyborgs, enhanced animals, super-intelligent hive minds 'collective super-intelligence' (Bostrom, 2016) - self-aware robots - things that until recently appertained to the realm of ancient mythology or science fiction literature.

What then could be the precondition to becoming the subject of a right in a world full of such diverse forms of existence? Transhumanists suggest that sapience, sentience, and most importantly non-anthropocentric personhood serve as the new standard of rights (More, 2013). What was once a peripheral idea in early transhumanism is now in a central position within the transhumanist ideological arrangement: the articulation of personhood exemplifies the rapid morphologies of concepts within young ideologies. Historically, the addition of animal rights to the rights framework in various ideologies (liberalism, ecologism) reflected cultural adjacency. However, moving beyond the anthropocentric perspective in transhumanism reflects to a lesser extent a cultural rather than a logical relationship. If enhanced biological and synthetic life forms and their hybrids with various levels of sentience are possible, it can logically be inferred that the rights system must be expanded to such personhood-possessing forms of existence. Not doing so would risk the coherence of any transhumanist rights system to collapse. In this case, logical adjacency overwrites the culturally accepted anthropocentric perspective to rights, which is permitted in the Freedenian analysis, as 'logical adjacency may ... override cultural adjacency when attempting to reorder sets of values in line with agreed rational procedures or ends' (Freeden, 1996, p. 72). 
Table 6. System of rights proposed by James Hughes

\section{Example Types of Life}

Level of
Consciousness

- Enhanced or unenhanced adult humans and their

Mature
personhood, with
reason

Rights Status

Example Rights cognitive equals

- Human children

- Demented and \begin{tabular}{c|c} 
Personhood (self- \\
awareness)
\end{tabular} Full citizens Right and ability to selfdetermination, to vote, and to make contracts mentally disabled human adults

- Great apes

- Most animals

- Foetuses

- Permanently (pleasure and Sentient property

Right to life and to assistance to achieve full self-determination vegetative humans

- Brain-dead humans

- Embryos

- Plants

- Toasters

In his seminal work, Hughes proposed a rights system based on the personhood model (Hughes, 2004). He distinguished property-level and citizen-level rights statuses based on the cognitive capabilities of the rights bearer (see Table 6). In the former group belong those life forms who possess sentience but are not self-aware (e.g. most animals, embryos, brain-dead humans), while the second, self-aware group is bestowed with two types of citizenship: disabled and full. Children, mentally constrained human adults, and great apes would possess disabled citizenship with a limited set of rights, such as the right to life and the right to assistance to achieve full selfdetermination, while full citizenship would entitle its bearer to all the rights available in the current rights system, extended with the right to morphological freedom. But the rights-bearer of full citizenship can be any intelligent life form - be they carbon-based, synthetic, or their hybrids - that possesses mature personhood with the capacity to reason.

Hence, the transhumanist rights system rejects the current universal human rights system, and offers instead a new model that incorporates the legal consequences of what transhumanist core concepts, human enhancement, morphological freedom, and the proactionary principle entail 
as well as adopting a feminist perspective on the legal status of embryos and the recent developments in the acceptance of animal rights. Within transhumanism, human rights are decontested in an expansive fashion: the Right of Man evolves to the Right of the Conscious, Sentient Being.

Not surprisingly, opponents of the idea have raised several objections. Fukuyama questioned the technological and scientific possibility of self-aware robots:

It is the stuff of science fiction for an android, robot, or computer to suddenly start experiencing emotions like fear, hope, even sexual desire, but no one has come remotely close to positing how this might come about. The problem is not simply that, like the rest of consciousness, no one understands what emotions are ontologically; no one understands why they came to exist in human biology. (Fukuyama, 2003, p. 168)

Habermas, on the other hand, accepted that science and technology will sooner or later achieve the knowledge level that will enable humans to fundamentally transform our existence. In response to this possibility, he put forward a counterproposal to the transhumanist rights expansion, especially against procreative freedom: he offered instead the legal protection of the human genetic inheritance through the introduction of a fundamental right to unmanipulated hereditary factors (2003, p. 27).

Whether or not we may see ourselves as the responsible authors of our own life history and recognize one another as persons of 'equal birth', that is of equal dignity, is also dependent on how we see ourselves anthropologically as members of the species. May we consider the genetic self-transformation and self-optimization of the species as a way of increasing the autonomy of the individual? Or will it undermine our normative self-understanding as persons leading their own lives and showing one another equal respect? (Habermas, 2003, p. 29) 
Steve Fuller has argued in defence of the transhumanist concept of extending human rights that historically what we call human rights were mostly understood as civil rights attached to the practicalities (entitlements and duties) of citizenship that have never applied to every member of the human species. Right bearers have always had to show and prove some sort of competence that they are eligible to certain rights. To decide on eligibility to 'human citizenship', or full citizenship as Hughes calls it - Fuller proposes a cognitive test similar to the well-known Turing test that is a theoretical device to decide whether a computer or a robot with developed AI has reached humanlevel consciousness (Fuller, 2015a). This 'Turing test 2.0' would accord 'humanity', the full range of rights to all forms of existence that pass it irrespective of their biological, non-biological, or hybrid origins. For transhumanists this is a logical next step in the social process that ended discrimination based on race, gender, or age, the end of 'human racism' (Hughes, 2004, p. 78). This emancipatory perspective also spawned the machine rights movement (which membership to a great extent overlaps with that of the transhumanist movement), whose proponents demand a new legal framework that recognises rights to robots (Goertzel, 2002). They promote a permissive approach to what Hilary Putnam, the famous philosopher and computer scientist, described as the 'problem of the civil rights of robots' in a seminal essay:

I have referred to this problem [whether robots possess human-level consciousness or not] as the problem of the 'civil rights of robots' because that is what it may become, and much faster than any of us now expect. Given the ever-accelerating rate of both technological and social change, it is entirely possible that robots will one day exist, and argue 'we are alive; we are conscious!' In that event, what are today only philosophical prejudices of a traditional anthropocentric and mentalistic kind would all too likely develop into conservative political attitudes. (Putman, 1964, p. 678)

Transhumanists are spearheading not only the philosophical and ideological discussion but also the political debate. They are demanding that legal theory and practice should prepare for the imminent disruption that science and technology will create: law-making should prepare for nonhuman life forms with human-grade cognitive capacities. Thus, personhood-based rights within the 
transhumanist ideology became a 'scientifically viable concept of the human fit for the future' (Fuller, 2015a) and occupied a central position within the conceptual arrangement within proximity of other core concepts. Nonetheless, the personhood standard of rights raises several ethical problems in addition to the fact that the age-old philosophical conundrum 'what is consciousness' remains unresolved, and the notions of personhood and identity still demand proper clarification. But it is important to emphasise that despite the unresolved scientific and ethical issues with nonanthropocentric personhood, this concept emerged into a key position inside the transhumanist conceptual system and the new rights system became an intrinsic part of the transhumanist ideological core and its policy demands.

Furthermore, the advocacy of post-anthropocentrism clearly separates transhumanism from any contemporary mature or immature ideologies that privilege the human species when articulating their ideas, rights frameworks, moral beliefs, or policy proposals. For transhumanists, this human-centredness equals human short-sightedness and reflects exclusionary practices similar to racism, xenophobia, or chauvinism. ${ }^{17}$ As Dinorah Delfin, a provocative transhumanist fine artist, futurist, and the editor-in-chief of Immortalist Magazine, an important transhumanist media outlet, summarises,

[w] can think of anthropocentrism, as a social construct of the human, another example of limiting beliefs which need to be dissolved. Transhumanists wish to not only foster a climate of tolerance and acceptance but to abolish all forms of discrimination: ethnicity, class, gender, creed, and at its root, speciesism, by establishing policies and value systems that can facilitate peaceful and harmonious relationships, not just with fellow humans and nature, but with future intelligent species, including our machine descendants. (Delfin, 2019, p. 601)

The post-anthropocentric perspective does not only distinguish transhumanism from other ideologies, but also confronts it with them as we have seen in the counterarguments of Habermas and Fukuyama. The bioconservative perspective, from which all contemporary ideologies derive

\footnotetext{
${ }^{17}$ The emergence of animal rights in the second half of the $20^{\text {th }}$ century marked the beginning of the end of humancentrism, according to transhumanists.
} 
their respective conceptualisations of the ideal social order, is fundamental for their selfarticulation. As a result, the idea to replace this perspective with a broader one is necessarily received with disapproval and hostility. Thus, post-anthropocentrism entails a previously unseen level of confrontation between ideologies, and in this conflict, transhumanism stands alone as the newcomer challenger to established ideologies. At the same time, the potential ramifications of losing the ideological competition explains why the followers of the contested ideologies were so keen on forming an ad hoc coalition to suppress the challenger.

\subsection{Adjacent Concepts}

Transhumanism utilises a great variety of adjacent concepts also present in other mature ideologies, but it creates peculiar ideational morphologies. In general, these adjacent concepts serve two fundamental goals. First, they provide unique decontestations of meaning that strengthen the particularity and distinctiveness of the transhumanist ideological core. Second, transhumanism borrows familiar concepts and decontestations from other ideologies to follow the intellectual enrichment and political expansion of the transhumanist movement, as well as addressing major criticism against transhumanist ideas and policy proposals. The following section will outline the main adjacent concepts of transhumanism.

\subsubsection{Rationality}

Transhumanism is deeply rooted in the philosophical tradition of humanism:

Transhumanism can be viewed as an extension of humanism, from which it is partially derived. Humanists believe that humans matter, that individuals matter. We might not be perfect, but we can make things better by promoting rational thinking, freedom, tolerance, democracy, and concern for our fellow human beings. Transhumanists agree with this but also emphasize what we have the potential to become. Just as we use rational means to improve the human condition and the 
external world, we can also use such means to improve ourselves, the human organism. In doing so, we are not limited to traditional humanistic methods, such as education and cultural development. We can also use technological means that will eventually enable us to move beyond what some would think of as <human>. (Bostrom, 2003a, p. 4)

The concept of self-development was further expanded by the Enlightenment's epistemic maximalism: the eternal desire of humanity to understand the world and itself, the strong belief in progress, and the assertion that it is a moral obligation to act to improve the human condition. 'Transhumanism is humanism and humanism is transhumanism', wrote Micha Brumlik (2016). The only constraints that transhumanism deploys is that any actions must be justified by reason and must not harm others.

\section{Figure 7. Concepts attached to rationality in transhumanism}

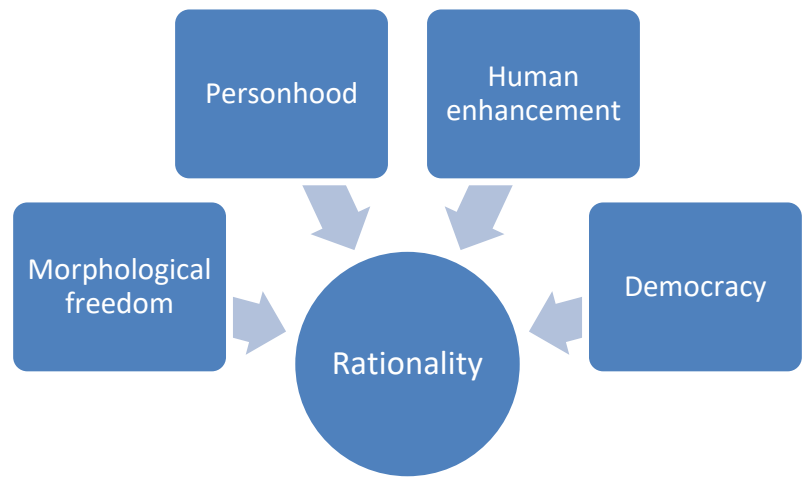

Rationality has an adjacent role in transhumanism. As mentioned before, it is decontested as 'informed wish' or 'informed consent' and attached to the core concepts of morphological freedom, human enhancement, and personhood. The agent is free to exercise morphological freedom irrespective of the community's reaction, any form of peer group pressure, or implications for the society as a whole, provided that the consequences of their action do not harm others. However, the subject of bodily transformation must possess all available information in an unbiased fashion about the risks and consequences of such action and must be in possession of their full mental capacities to make judgements and decisions. If that is the case, the subject is free 
to take any risk and bear the consequences. Simultaneously, if one is to endorse transhumanism on the basis of reason, it must be intelligible. Individuals are free to modify their bodies to enhance their physical or cognitive capabilities - for example to implant a device in the eye that allows for night vision but reduces sharp vision - even if it is considered irrational or too risky by social conventions or the majority of society.

Rationality is also at the centre of the transhumanist argument in favour of allocating an increasing role to artificial intelligence in policy decision-making. As current human intelligence is vulnerable to manipulation - one of the main causes of the contemporary phenomenon of democratic backsliding and the loss of public trust in politicians and democratic institutions artificial intelligence provides the means to correct the abuse of this human fallibility. In January 2020, the Transpolitica think-tank led by David Wood presented a novel roadmap for the renewal of the transhumanist political offer. The so-called RAFT 2035 document, which is a draft text made available for public discussion at the time of writing this thesis, proposes that tools run by artificial intelligence should be extensively used in policy-making. As stated in the document:

AI and other decision support tools should be able to provide very useful analysis and validation of political statements, including legislative changes that politicians are proposing. AI could identify potential problems with legislation sooner, and suggest creative new adaptations and syntheses of earlier ideas. AI can also alert us when we are becoming tired, bigoted, or selective in our use of evidence, and can recommend more fruitful ways to continue a discussion. This AI, therefore, could help us to become, not only cleverer, but also kinder and more considerate. (Wood, 2020)

In this respect, technology is presented as a tool to support and expand the limited human capability for making rational decisions. In this role, the concept of rationality is attached to another adjacent concept in the transhumanist ideological structure: democracy. 


\subsubsection{Abundance}

As critics of transhumanism often have accused transhumanists of neglecting contemporary social problems, transhumanism developed a new decontestation to enrich its welfare concept. The idea of abundance first appeared in an opinion piece written by Esfendiary to the New York Times in 1975 . He wrote:

The world is moving toward an age of limitless abundance - abundant energy, food, raw materials. Decades from now this late $20^{\text {th }}$ century will be remembered as a period in which the world shifted from age-old scarcity to a new era of plenty. (Esfendiary, 1975)

In this early articulation of the adjacent concept, Esfendiary outlined his vision of a world that was in sharp contrast to the popular negative visions of the mid-1980s: the fear of depleting the earth's natural resources, the energy crisis, famine caused by overpopulation, rising poverty, and the demand for ending consumerism. Instead, he argued that the main problem was not scarcity, but the flawed system of redistribution. He demanded political action to reduce public funding for the military or the fossil fuel industry and allocate funds instead to develop solar and nuclear energy to provide for infinite energy, a computer-supported Green revolution in food production to feed the growing population, and securing natural resources through recycling and space expansion. Although Esfendiary's article may seem at first sight as a Green manifesto, he made it very clear that he put forward his vision against what the emerging Green ideology was offering at that time:

How short-sighted the exhortations to no-growth at precisely the time when we urgently need more and more growth - growth not within but beyond industrialism.

This article positioned the two young ideologies, ecologism and transhumanism, as ideological opponents, and a bitter conflict began between the proponents of the two movements that lasted until the early $21^{\text {st }}$ century when the progressive wing of the transhumanist movement introduced new versions of the concept of abundance to reconcile and neutralise ecologist criticism. 
But the concept of abundance started its ideological career in 2012 thanks to a bestselling book that popularised the idea of ending scarcity with the help of technology:

Humanity is now entering a period of radical transformation in which technology has the potential to significantly raise the basic standards of living for every man, woman, and child on the planet. Within a generation, we will be able to provide goods and services, once reserved for the wealthy few, to any and all who need them. Or desire them. Abundance for all is actually within our grasp. (Diamandis and Kotler, 2012)

This articulation of the concept of abundance, however, is slightly different from what Esfendiary put forward several decades earlier. Esfendiary equated abundance with the unlimited availability of basic natural resources that would enable mankind to create wealth at an historically unprecedented level. To achieve this required the redistribution of available funds to maximise access to those natural resources. Diamandis's perspective on abundance, on the other hand, shifted away from this restricted, materialist view of the concept. His version of abundance included not only the unlimited access to resources that are fundamental to human survival (food, clean water, shelter, etc.), but also two further components. Among the 'catalysts of growth', he listed access to energy, education, and information or communication. These are essential to specialisation and exchange, the two prerequisites to what Hayek called catallaxy. Then, Diamandis added freedom and health as indispensable components that strengthen the ability of individuals to create wealth. Unsurprisingly, this enriched version of the concept was more suitable for incorporation into the transhumanist ideological structure, as it could be easily attached to other transhumanist concepts such as morphological freedom or longevity.

Transhumanist theorists and activists adopted the concept of abundance rapidly. Technological abundance, or as it was reconfigured later, sustainable abundance, produced by the future, robot-driven economy was added to the conceptual structure of transhumanism to fill an ideational gap, address theoretical criticism, and make the ideology more intelligible and consumable for wider audiences. With the emergence of the peripheral concept of sustainability (Trans Vision2017, 2017), transhumanism borrowed a concept from another ideology, which is a 
proof of its conceptual flexibility and responsiveness. Furthermore, by attaching sustainability to the concept of abundance, it became rationally comprehensible and consumable for those who sympathise with the Green ideology as coherence grew between transhumanism and their ideological preferences. It was David Wood who presented the most developed articulation of the concept, which he renamed sustainable superabundance (Wood, 2019b). According to Wood, there are seven spheres of human flourishing which are presented as the seven manifestations of sustainable superabundance:

1. Abundance of clean energy (replacing fossil fuels with solar energy)

2. Healthy food and clean water to counterweight the effects of growing population (using vertical farming, synthetic biology, agriculture in the sea, lab-grown meat, desalination of sea water)

3. Adequate material goods (atomic-scale manufacturing using nanotechnology and 3D and $4 \mathrm{D}$ printing)

4. Abundance of health and longevity (the abolition of the deceases of ageing using rejuvenation biotechnology)

5. Abundance of intelligence (collective smartness using artificial intelligence and connected minds and enhancing cognitive and psychological capabilities)

6. Abundance of creativity and exploration by ending 'boring labour'

7. Abundance of collaboration and democracy to improve decision-making and interhuman relations

These seven components are interconnected, and human flourishing requires progress in all seven spheres simultaneously. The conceptualisation of abundance is not restricted to material wealth, ending the scarcity of essential resources, but it is extended to the intellectual sphere, which is a unique characteristic of transhumanism. It allocates equal importance to physical, cognitive, and emotional well-being. Additionally, transhumanism does not only borrow and adopt the concept of sustainability from the Green ideology, it also enriches it. Sustainability is described as the continual replacement of natural resources that we use to prevent deprivation, as well as 
maintaining a good relationship with the environment and with each other to support effective collaboration.

Figure 8. The morphology of the concept 'abundance'

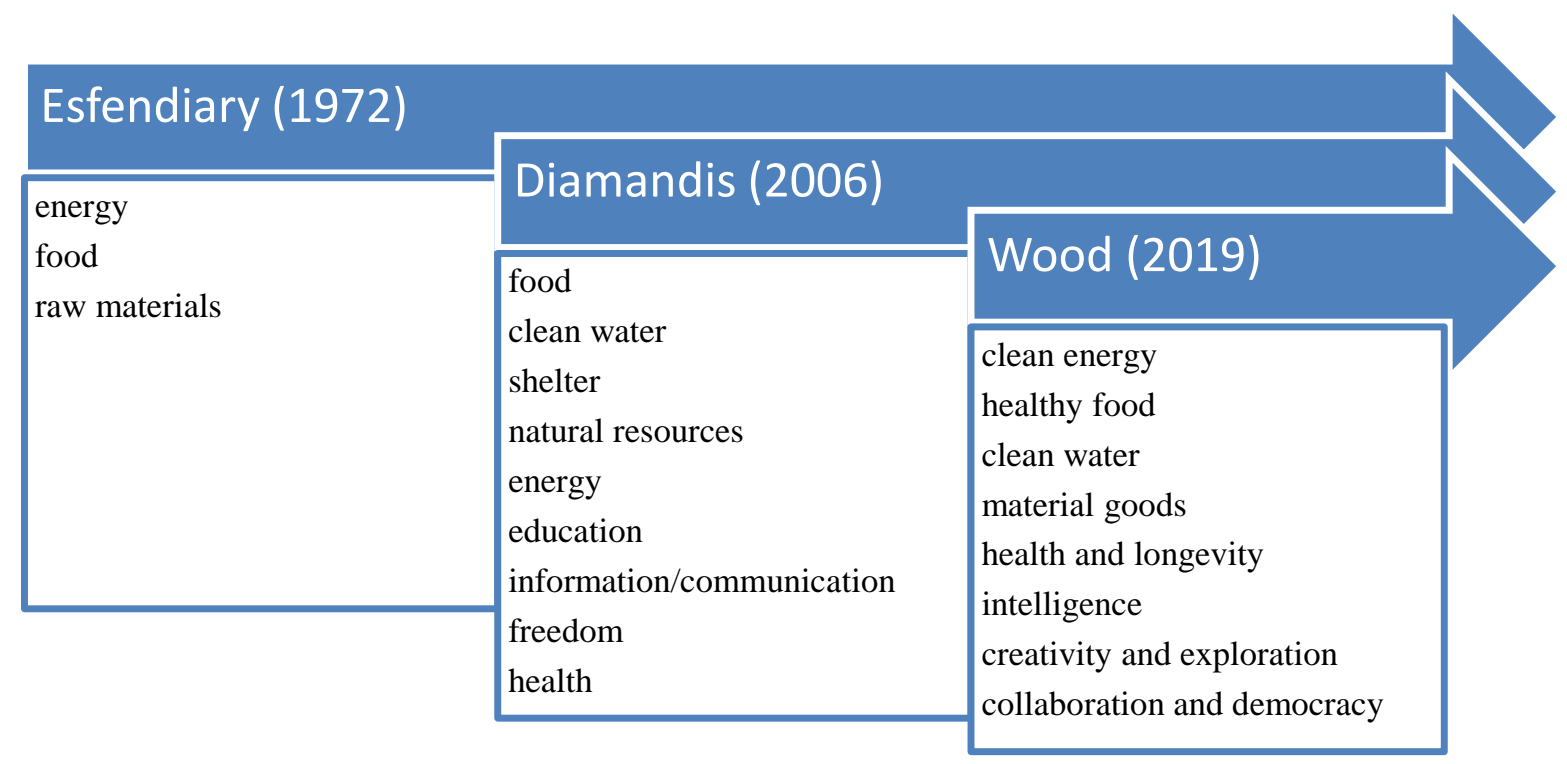

The concept of abundance presents a unique morphology within the transhumanist ideology (see Figure 8). In its early articulation it referred merely to the need for the redistribution of funds to secure infinite basic natural resources and create material wealth. Several decades later it morphed into an enriched concept that incorporated other ideas such as self-development (through education) or freedom, and further, more specific components, for instance, access to adequate health care and information technologies. Then it borrowed a concept from another ideology to stimulate the imaginary of new audiences who otherwise had concerns about the consequences of unrestricted and permanent technological development. When it reached its current format attached to the peripheral concept of sustainability, its maturity and shift to adjacency entailed that it incorporate other core, adjacent, and peripheral concepts as its main components and took a new position within the transhumanist conceptual arrangement: it shifted slightly further from welfare and progress and relocated in proximity to the concept of equality. This morphology also enabled transhumanism to reframe and re-contextualise long-existing policy proposals present in other 
mature ideologies - for example universal basic income or environmental protection - and put them into the service of the transhumanist ideology.

\subsubsection{Democracy}

According to Freeden, democracy is one of the most indeterminate concepts, a 'superconcept' (Freeden, 2015, p. 122). Its manifestation is determined by the position, logical arrangement, and significance of five main internal components: liberty (as self-determination), equality (one person, one vote), community (practiced in groups, by individuals), participation (requires active members), and a certain level of accountability (limits and monitors the power of the executive). These components may be arranged in countless ways and can take different relative significance, thus creating many variants of democracy in actual practice. This super-concept holds a core position in almost every contemporary ideology: conservativism, liberalism, socialism, ecologism, feminism, or populism. This was not the case for transhumanism, where it has only recently gained such significance that it can be listed among the adjacent concepts.

Democracy is decontested as a radically extended version of deliberative democracy in almost all transhumanist morphologies of the concept. Again, technology has a crucial role in articulating the transhumanist version of democracy. Direct democracy, conceptualised as the uttermost egalitarian and participatory form of partaking in shaping policy and politics, should be practiced through applying the latest digital technologies to extend knowledge and electoral participation and garner collective intelligence.

Transhumanist theorists agree that the contemporary functioning of democracy is utterly flawed; it needs to be reformed to better serve societies. FM-2030 predicted that the technologydriven future society would be neither capitalist nor socialist (or communist) and a transhumanist model of direct democracy based on issue-centred electronic voting supervised by randomly selected 'referendum committees' would render the leadership-dependent, 'mired and rotten' representative democracy obsolete, as well as its authoritarian alternatives (FM-2030, 1984). To ameliorate the shortcomings of voter behaviour, the short-sightedness of politicians, and the fraudulent campaign financing systems in contemporary democracies, the technoprogressive David Wood proposed a new political system predicated on a mixture of plebiscitary democracy and technology-driven, knowledge-based policy decision-making in which well-informed, engaged 
voters enabled by new technologies would participate in frequent referendums while elected and accountable politicians decide on complex policy issues and consult a group of technocrats (Wood, 2018, pp. 233-252). Wood coined the notion superdemocracy to present his understanding of this new social arrangement (Wood, 2019b, p. 101). He defined the main features of superdemocracy as follows:

- informed deliberation among the electors

- $\quad$ respect for expertise and scientific principles

- $\quad$ support for technocracy: respect for decisions by domain experts, but expert opinions are subject to thorough analysis

- pluralism: respect for the plurality of views, no priority should be given to any ideology, theory, idea, or person

- inclusion: respect for minority opinion to invite a wider number of perspectives to participate in the deliberation

- objectivity: reliance on objective data to establish effective decision-making

- use of artificial intelligence technologies to reveal hidden knowledge

- the creation of virtual worlds with the help of technology to test the potential outcomes of policy decisions

- transparent, intelligible, and accessible decision-making processes

- preference for decentralisation

- redistribution through common ownership and public dividends: companies are managed by private individuals but are regarded as partially owned by the citizenry

- refusal of full public ownership or other forms of full state ownership

- delegated voting

- more freedom of expression and more secularism: laws on blasphemy should be removed from statute books

- $\quad$ sanctions against the deliberate distribution of misleading information

- limits of funds that political organisations spend on political campaigns

- 'more informed and more engaged' voters less exposed to political manipulation

- a comprehending community: key decisions should be communicated openly and collectively understood 
Importantly, in every transhumanist version of democracy, the ultimate goals are to guarantee access to enhancement technologies and to secure the right to exercise one's morphological freedom in addition to the traditional aims of such a political system:

Good politics can enable and encourage patient long-term investment in beneficial technological developments. Bad politics prevents or discourages such investments from taking place. Good politics can ensure technological products serve the needs of all members of society. Bad politics acquiesces when such products serve only a narrow portion of society. (Wood, 2019b, p. 12)

As far as participation and elections are concerned, there is no particular transhumanist offer, however, recently a growing number of transhumanists have started promoting the model of liquid democracy (Schiener, 2015; Rutt, 2018, 2019; Wood, 2019b).

As an important by-product of her analysis of the thin-centred ideology of populism, Margaret Canovan put forward an original and convincing understanding of a key feature of democracy. She suggested that democracy has two faces: pragmatic and redemptive (Canovan, 1999). The pragmatic face is responsible for effective conflict management within society that guarantees peaceful and smooth system operation 'by means of a highly contingent collection of rules and practices' and institutions (Ibid., p. 10). The redemptive face of democracy, on the other hand, is articulated in its 'promise of a better world through action' (p. 11) that mobilises and emotionally engages the people. The two faces are not only opposed, but also interdependent: the pragmatic perspective serves as a constraint on the popular desire for (secular and/or religious) redemption, while the redemptive aspect legitimises pragmatic political actions, rules, and institutions, contributing to the stabilisation of the democratic system.

From this point of view, the transhumanist approach to democracy is fundamentally 'redemptivist', yet lacks a full-fledged pragmatic face. The redemptive promise of transhumanist democracy is that it will bring back rationality into policy-making and will replace the corrupt and emptied liberal democracy (in this respect transhumanism is similar to populism, but the resemblance ends here, as Zoltan Istvan wrote (Hewitt, 2016)). To do so, it will utilise 
transhumanist technologies, such as artificial intelligence, big data, computational science, and cognitive enhancement, to mend human fallibilities and vulnerabilities that stem from the lack of immunity from manipulation and the tendency for irrational behaviour immanent in human nature. These are supposed to enable the electorate to ameliorate executive accountability and to fact-check the validity and adequacy of political claims. This technophile vision of democracy, however, raises concerns of a totalitarian dystopia, of losing control and succumbing to 'machine overlords'. The totalitarian potential of transhumanist ideas creates ample room for criticism, but also explains the eagerness of transhumanist proponents to elaborate and enrich the transhumanist concept of democracy and offer a comprehensive description of transhumanist politics.

For example, transhumanists strongly refute any form of technological authoritarianism. They are among the strongest opponents to algogracy, the emerging form of contemporary authoritarianism that exerts control over society through algorithm-based evaluations of systemcritical individual and group behaviour, pattern recognition by artificial intelligence, and high-tech surveillance as represented by some current governments, for example in China.

In response to such criticism, theorists of the left-leaning wing of the transhumanist movement, technoprogressives, adopted the idea of the need to democratise technology. For them, transhumanism is the democratisation of technology and the technologisation of democracy. Thus, democracy presented a unique morphology in which two components - participation and equality - have particular importance, and the concept itself was attached to the concept of abundance to become its essential component. As such, the concept of democracy is decontested from the concept of welfare. Although it has recently gained growing significance within the transhumanist conceptual arrangement, the concept of democracy still has a reduced, functionalist role. It is an 'enabler', a societal arrangement that is supposed to support the achievement of the ultimate transhumanist goal: moving as quickly as possible towards the posthuman era.

\subsubsection{Equality}

The concept of equality is first associated with the equality of opportunity as a distinguishing component. Then, it is further contextualised from the socio-economic perspective as the equality of opportunity to access enhancement technologies. Hence, the transhumanist decontestation concerning the concept of equality is formed. But the process does not end there. 
Access to enhancement technologies has much greater significance in the transhumanist conceptual structure compared with the position that, for example, the concept of equal opportunity adopts within liberal ideology. In liberal ideology, equal opportunity is raised in the context of wealth acquisition, education, health care, gender, or professional career. Equality of opportunity is prioritised as an important but not the most important feature. Equality before the law, equality of basic human rights, or equality of political representation take higher positions within the conceptual hierarchy of mature ideologies. Contrarily, within transhumanism, the equality of opportunity to access enhancement technologies is a fundamental component of the concept of equality, while other components are secondary.

Ideologies not only allocate a particular meaning to a concept, but also accredit value to them during the decontestation process:

political concepts are not merely appraisive [...] Concepts may have empirically describable and observable components that may in addition be conceived of as desirable and thus become values. (Freeden, 1996, p. 56)

Such valorisation is reflected in the transhumanist preference for equal access to enhancement technologies over other forms of equality of opportunity. In this case, the accessibility is an addition, an appraisive component that accredits positive value to the concept of equality of opportunity as well as defining the concept's proximity to other core concepts within the transhumanist ideational hierarchy such as human enhancement or morphological freedom.

Another transhumanism-specific decontestation is put forward through the concept of biological equality, a peripheral concept closely attached to the concepts of enhancement and morphological freedom and connected with the concept of equality. Contrary to the popular (bio)conservative view that each member of the human species is biologically equal, transhumanists claim that a major source of inequality derives from the natural randomness of genetic variations, which is responsible for massive differences in physical, cognitive, and psychological capacities among individuals. Consequently, transhumanists claim that 'democratically regulated, and distributed ... enhancement technology makes it possible to redress that source of inequality' (Hughes, 2004, p. 195). The peripheral concept of biological equality 
provides another prime example of the strong logical and cultural coherence within the transhumanist ideology in which each core concept is interconnected through a variety of adjacent and peripheral concepts that cement the position of the ideological core and allocate transhumanism with a distinctive, easily recognisable structure.

Further peripheral concepts emerge in transhumanism with regards to the equality issue and reveal the semantic aspects of ideology formation: accessibility. It is present in two distinguished manifestations. The first emphasises free access to enhancement technologies, while the other accentuates the access to free enhancement technologies. The order of the words reveals a deep ideological distinction that gave birth to the two main political branches within the transhumanist movement. The 'free access' branch stresses freedom and neglects the social equality aspects while the 'access to free' branch emphasises the need for a redistributive scheme to guarantee social equality and prevent exclusion based on wealth. Hence, the adjacent concept of equality is further decontested in two distinct forms in the transhumanist conceptual arrangements. Libertarian techno-optimists emphasise the importance of free access to new technologies while left-leaning democratic transhumanists (technoprogressives) focus on equal access to free technologies (see Figure 9). The first prefers the Hayekian free market as the main organising mechanism of the economy and the allocation of wealth while the latter demands extensive state interference and controlled redistribution mechanisms to guarantee that each member of the society can benefit from the opportunities provided by new technologies and scientific inventions. However, both equality interpretations are based on the precondition that the future socio-economic environment will secure technological abundance and scarcity will disappear from the economy.

It is important to note, again, that to address the equality-based criticism and the dystopic forecast of a future where society is divided along enhanced and non-enhanced members with hierarchical power-relations between the two, transhumanists always add to morphological freedom the protection of those who decide to abstain from enhancement, who thus become entitled to compensation for their inevitable competitive disadvantages. To prevent the emergence of a new social cleavage between a powerful class of 'superhumans' who benefit from the enhancement technologies and an underclass who are excluded from the fruits of progress, techno-optimists recommend more freedom while technoprogressives urge the controlled redistribution of transhumanist technologies. 


\section{Figure 9. Transhumanist decontestation of the concept of equality}

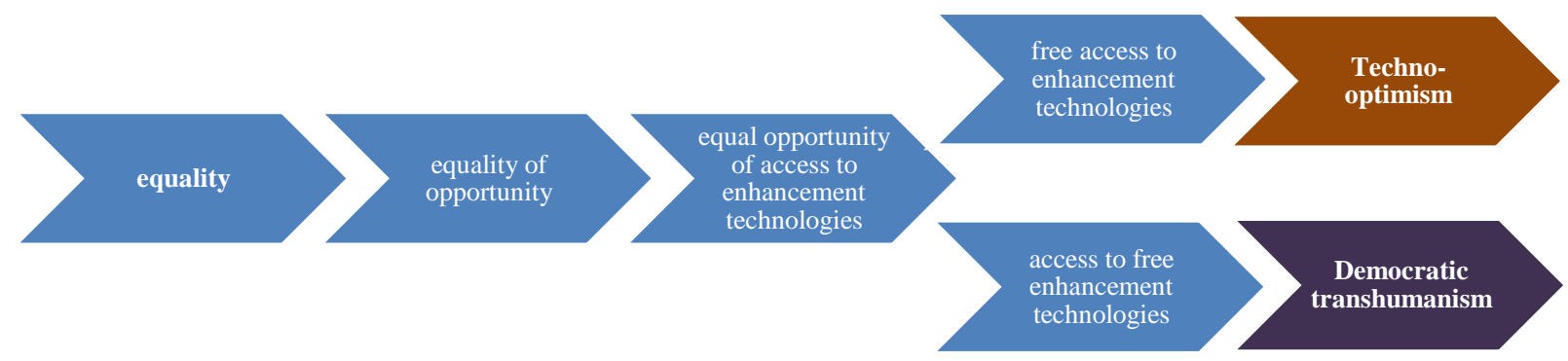

\subsubsection{Diversity}

Many critics of transhumanism suggest that human enhancement technologies and morphological freedom threaten diversity (Buchanan et al., 2002; Buchanan, 2017; Hall, 2017). Though the risks are widely acknowledged and discussed, transhumanist theorists claim that the opposite is true, and diversity occupies an important position within the conceptual structure of transhumanism. The argument is three-fold. First, as has been discussed earlier, morphological freedom will allow a great variety of new technological tools for expressing individuality and uniqueness while contributing to the decrease of peer pressure, prejudices, and societal pressure endemic in contemporary communities (Sandberg, 2013, p. 59). Second, germline modification and controlled evolution will produce physically and cognitively more diverse humans as well as new living beings, synthetic intelligence, enhanced animals, cyborgs, and interspecies life forms (Sorgner and Ranisch, 2015, p. 210; Hauskeller, 2016, p. 18). Third, the right to abstention is inherent to morphological freedom: those who choose to remain 'natural' are not only free to do so, but also entitled to special protection. It is the moral duty of enhanced beings to protect those members of the human species who decline augmentation. This situation will result in a greater variety of people living together. As the Transhumanist FAQ says:

Racism, sexism, speciesism, belligerent nationalism and religious intolerance are unacceptable. In addition to the usual grounds for finding such practices morally objectionable, there is an additional specifically transhumanist motivation for this. In order to prepare a time when the human species may start branching out in various 
directions, we need to start now to strongly encourage the development of moral sentiments that are broad enough to encompass within the sphere of moral concern sentiences that are different from current selves. (Humanity+, no date)

\subsubsection{The Role of the State}

The distinguishing mark of transhumanism is its claim of state neutrality concerning the use of enhancement technologies. As long as no other entity (person, property, or the environment) is harmed, people should be free to use these technologies for self-realisation and to pursue their own ideal of the good life.

The position of the state within the transhumanist conceptual configuration has undergone significant diachronic changes similar to what occurred in liberalism, where, in the beginning, the role of the state was limited to defending individuals from physical aggression by other individuals or power holders. Later, as more sophisticated theories of social operation emerged in response to profound changes in the socio-economic environment, the protector of physical immunity role expanded 'to cover the kind of qualitative existence that wealthy and humane societies are expected to promote and guarantee' (Freeden, 1996, p. 269). The concept of the state has undergone a similar development within transhumanism. In the theory's early articulations, the state was invisible. Reflecting its libertarian origins, early transhumanist literature rarely mentions the state (if it does, it is limited to negative context with reference to the disadvantages of the hierarchical world order built on nation states), instead focusing exclusively on the individual and its minimally constrained free choice. Later, as new ideological mutations emerged in response to criticism and as other ideologies impregnated transhumanism with novel and fashionable concepts, the state appeared first in a peripheral position (as the guarantor of an open society) then shifted gradually to adjacency in those versions of transhumanism that critically reconsidered the strong individualistic and freedom-centred character of early transhumanism.

Today the position of the state in the conceptual structure clearly separates major political branches of transhumanism. Libertarian techno-optimists remain sceptical and suspicious of state intervention and regulations while democratic transhumanists (technoprogressives) allocate a key redistributive role to the state in their political and theoretical arguments, investing the adjacent concept of the state with the role of 'servicing the particular decontestation of the core principles' 
(Freeden, 1996, p. 269). Technoprogressivism upgrades the concept of the state to adjacency together with the peripheral concept of redistribution. Technoprogressives envision an activist state as the guarantor of equal and free access to enhancement technologies as well as preventing and repairing injustice that may arise from the wide diversity of forms of existence. It is the state's legal obligation to halt the rise of a new, privileged ruling class from those with improved cognitive and physical capabilities (the enhanced elite) and to protect the rights and interests of those who opt out of enhancement and choose instead to live a natural life. The technolibertariantechnoprogressive divide within the transhumanist movement proves that Hughes was right when claiming that 'transhumanists have inherited all the arguments about the value and meaning of liberty, equality and solidarity that divided their Enlightenment forebears' (Hughes, 2015, p. 139).

\subsection{Peripheral Concepts}

The ideational thickening process of transhumanism occurred partly in response to egalitarian criticism and partly due to the enrichment of the original, mostly libertarian approach with left-leaning, feminist, ecologist, and other accounts of transhumanism. This conceptual morphology helped solidify the ideational centre of transhumanism, as well as clearly separate the core, decontested concepts from the adjacent and peripheral symbolic environment, resulting in a conceptually sturdier ideology.

Today, transhumanism can be considered an 'umbrella ideology' under which advocates of distinctive policy agendas, issues, and subcultures gather and construct ideological subvariants of transhumanism. Ecoconsciousness is reflected in technogaianism, a feminist evaluation of technological progress is discussed among cyberfeminists, advocates of decentralised data-sharing and secured privacy on computer networks form the cryptoanarchist movement, believers in exponential scientific and technological progress resulting in an intelligence explosion and the emergence of a new form of non-biological existence are called singularitarians - just to name a few among the plethora of ideological branches. Ideological convergence and divergence are taking place at the same time among these various groups, making transhumanism a vivid, dynamic ideology and intellectual movement. Consequently, the emergence of peripheral concepts is closely 
linked to this ideological variegation. Peripheral concepts are mostly borrowed from other established or less-developed ideologies: reconciliation ecology from environmentalism (Rosenzweig, 2003, p. 1), blockchain-backed digital privacy from cryptoanarchism, and technological gender neutrality from feminism (Haraway, 1987, 1991) are prime examples of this ideational expansion.

In previous sections some of the major peripheral concepts were presented. Their significance is manifold. First, they change the position and proportion of core and adjacent concepts within the transhumanist conceptual structure. The role of such relocation is to enable the transhumanist ideology to overcome existing cultural constraints or create new ones, as well as responding to logical constraints that emerge from moving closer to other concepts. For example, the appearance of the peripheral concepts of redistribution and accessibility allows the adjacent concept of equality to occupy a greater space and gain higher ranking within the conceptual arrangement proposed by technoprogressivist transhumanism.

Second, they create new bonds with other concepts, and thus, just as thoughts are born as neurons and then establish new connections inside the human brain, they generate novel policy actions that otherwise the original concept would not necessarily entail. For example, the adjacent concept of abundance alone does not necessarily demand ecological considerations in policymaking. It supports finding new resources (for instance through asteroid mining), utilising existing resources more effectively (more efficient nuclear plants), or creating new materials with scientific means (nanomaterials) to boost economic growth and consumption. However, when the peripheral concept of sustainability is attached to abundance, it validates novel policy actions such as recycling or the promotion of the circular economy that otherwise are not logical inferences from the pure concept of abundance. Finally, peripheral concepts spawn new ideological versions. It was shown how the peripheral concepts of accessibility and redistribution presented in two distinguished manifestations have led to the creation of the two main ideological branches of transhumanism. Another example is the creation of technogaianism when sustainability is allocated with a more central role. The emergence of the concepts of privacy and decentralisation may (but not necessarily) lead to anarcho-transhumanism and/or inspire policy actions such as the extensive application of blockchain technologies or regulatory measures to protect individual online privacy from profit-oriented corporate activities. 
The common feature of these peripheral concepts is that, unlike the core concepts of transhumanism, they are neither new creations nor unique decontestations. They are simply borrowed or adopted from other ideologies. It comes as no surprise as permeability is listed among the main characteristics of concepts, neither is it transhumanism-specific. Every ideology borrows from other ideologies. On the other hand, peripheral concepts enable transhumanism to create unique decontestations and form ideology-specific novel concepts. Also, these peripheral concepts greatly contribute to the ideological thickening of transhumanism, as it becomes capable of expanding to greater semantic fields and occupying symbolic territories to capture the public imaginary. 


\section{An Ideological Map of Transhumanism}

The relationship of the core concepts that emerged from the investigation presented in this dissertation - progress (proactionary principle), welfare (human enhancement, longevity), individualism (personhood-based rights framework), and liberty (morphological freedom) - is one of mutual dependence. Leaving out any single aspect will result in a completely different ideological perspective. Each manifests an ineliminable component: for liberty, it is the notion of non-constraint (of bodily self-determination); for individualism, the notion of the person conceptualised beyond the Anthropocene as a separate entity possessing unique attributes and capable of choice; and for progress, the notion of movement from less desirable (human condition) to more desirable states (posthuman condition). These ineliminable concepts are decontested in unique ways and the result is a hallmark conceptual configuration of transhumanism. Table 7 presents some prime examples of the main decontestations of the transhumanist ideology.

Table 7. Main decontestations of core concepts in transhumanism

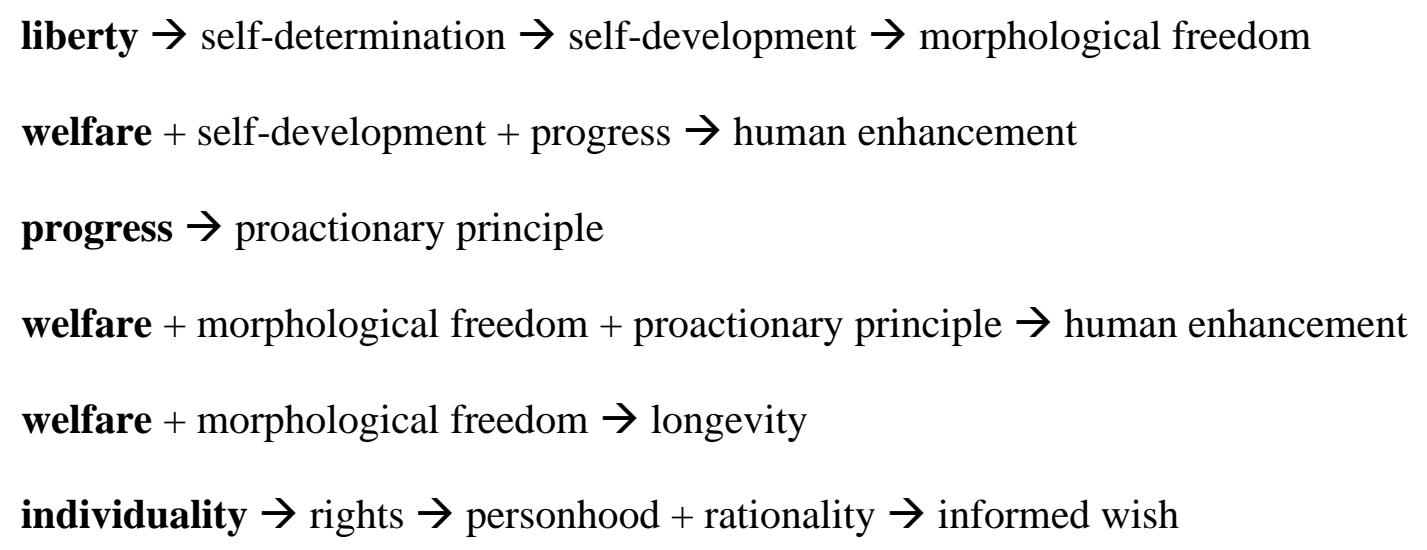

During this morphological analysis, four core concepts and a number of adjacent concepts were revealed that mutually reinforce each other. These key concepts form the conceptual architect of transhumanism - a distinct arrangement to evince the solidifying ideational cluster of transhumanism. Figure 10 shows a possible conceptual map of the transhumanist ideology based 
on Freeden's two-dimensional spatial map, in which the position of the concept reflects priority, proximity, and permeability.

Figure 10. The conceptual map of transhumanism

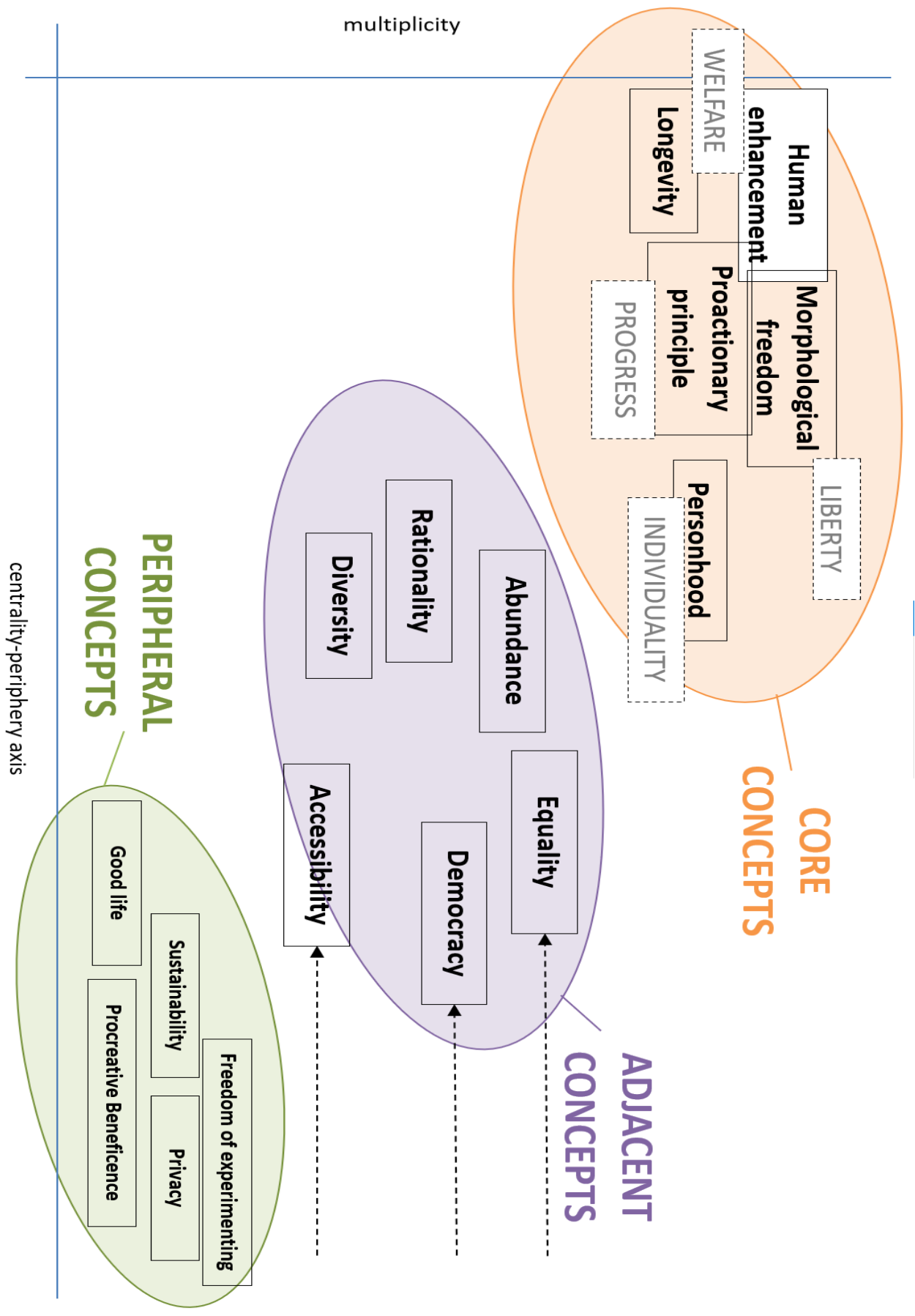


It has now been proven that transhumanism is capable of producing effective decontestations and arranging its core concepts to build a distinct conceptual map of transhumanist ideology. This map also reveals a high degree of shared ideational alignment around constituent concepts that reflect deep-seated norms and values. Inspired by libertarian or egalitarian aspirations, transhumanism rearranges and recombines these values, endows them with new meanings, and invigorates new value-laden concepts such as morphological freedom. The result is a fundamentally new ideological morphology reconfigured around a rising global technoawareness against the regressive counterculture of bioconservativism.

Another sign of the ideological strengthening of a premature ideology is when it becomes capable of assimilating concepts taken from other ideologies, then injecting them with novel or modified meanings and achieving discursive dominance over its political usage. Such concepts lose their original conceptual role and position in their host ideology and gradually become inherent parts of their new ideational home. A prime example of such a process is provided in the case of UBI. Basic income was originally put forward as a policy proposal by utopian socialist thinkers in the $19^{\text {th }}$ century to provide a minimal level of welfare to the lowest strata of society. The idea then re-emerged from time to time and faded out of political discourse in the $20^{\text {th }}$ century. Eventually, it developed into a universal allowance irrespective of need to which each citizen of the state is entitled, with the aim to reduce welfare inequality. Whatever form it took, every instance of the idea was rooted in the concepts of equality, solidarity, and welfare - the key components of socialism.

However, at the beginning of the $21^{\text {st }}$ century, arguments in favour of the introduction of UBI started to concentrate on the issues surrounding automatisation. As the use of robots grew in many industrial sectors, particularly in labour-intensive manufacturing, more and more analysts warned of the consequences on employment. Machines replacing humans will obviously have serious social impacts on the most developed nations, therefore, the topic unsurprisingly re-entered public discourse. Logically, UBI re-emerged as a possible policy solution to the problem of technological unemployment and numerous political parties started openly to advocate the idea. The original aim of UBI as an instrument to alleviate social inequality and narrow the wealth gap gradually faded out and was replaced by the technological argument - something that transhumanists have for a long time been discussing. As robotisation has a central role in political 
transhumanism as the precondition to achieving sustainable abundance, the transhumanist version of the welfare state, transhumanist parties, as well as two presidential candidates in the U.S., the Democrat Andrew Yang and the independent transhumanist Zoltan Istvan, incorporated the idea into their political programmes. Today, transhumanists argue in favour of expediting automatisation and, at the same time, advocate the introduction of UBI (or negative income tax) as the appropriate solution to the challenges it entails.

Other political movements with different ideological backgrounds are either cautious or openly hostile toward the phenomenon. Although voters rarely identify UBI with transhumanism, it is now inseparably linked to a truly transhumanist topic: the inevitable spread of robots in all segments of the economy. Nevertheless, transhumanists succeeded in decoupling an idea from a core concept of another ideology and deployed a novel and unique decontestation that allocated it with a distinct argumentative power in the political arena. As UBI is thus 'reframed', it also helps transhumanists to promote a novel concept (abundance) over which they have issue ownership, and which occupies an adjacent position in the conceptual arrangement of the transhumanist ideology.

In addition to the obvious ideational thickening, the ideological analysis also reveals deficiencies of this ideological architect. Transhumanism lacks a comprehensive and distinct set of adjacent and peripheral concepts, the presence of which is a key attribute of every mature ideology. Instead, it mostly borrows from other ideologies to fill the gaps. As a result, transhumanism fails to put forward a political programme that contains policy proposals in every area. Let us take a simple case to show this deficiency: public transportation. For the follower of the socialist ideology, the operation of an extensive and high-quality public transportation system is the responsibility of the state and must be financed through redistributive channels. This solution can be logically deducted from the core concepts of the socialist ideology. On the other hand, for a proponent of the conservative ideology, public transportation should ideally be financed completely by the users and must be operated by private subcontractors. The state's role is limited to the supervision and quality control of the service. However, there is no distinct transhumanist proposal for financing and operating a public transportation system that can be logically construed and argued on behalf of core transhumanist ideational concepts. Transhumanists may envision that in the era of technological superabundance or sustainable abundance, robots will provide such services. But the concept of abundance seems more like a 'jolly joker' answer to all policy issues than a profound 
solution. Further, the question of public transportation is not the only policy topic where transhumanism fails to provide an adequate proposal, similar examples are countless. One major difference between mature and less-developed ideologies is that the former is capable of advancing a comprehensive and distinct system of policy solutions. Therefore, transhumanism cannot be considered a fully-developed ideology.

According to Freeden, ideological concepts inspire political action. Table 8 presents some examples of policy proposals put forward by transhumanist theorists and parties that derive from the core, adjacent, and peripheral concepts and combinations of concepts of the transhumanist ideology. These further validate the hypothesis that transhumanism is eligible to be defined as an ideology.

Table 8. Transhumanist concepts and policy proposal derivations

Concepts Policy proposals

Freedom of experimenting

Human enhancement

Personhood-based rights system

Democracy

Sustainable abundance

Post-genderism
- Simplifying the regulations and processes of clinical trials

- Allowing voluntary participation for individuals in somatic and psychological scientific and technological experiments

- Revision of current regulatory framework with regards to unconventional enhancement methods (e.g. germline modification)

- $\quad$ Turing test 2.0

- AI-driven, extended accountability of the executive

- Universal basic income

- Circular economy

- Introduction of permissive regulations to use artificial wombs 


\section{The Thin-centredness of Transhumanism}

Transhumanism has been steadily growing in popularity in recent decades, moving beyond the 'theoretical phase' of ideological thickening. It is supported by not only a closed group of theorists, but also a relatively wide audience with various intellectual backgrounds and social statuses as well as political organisations and other political actors. Fitting into Freeden's description of ideologies, its language is easily consumable: the main ideas are present in scholarly literature and political discourse, popular culture, and mainstream media. The other side of the coin is that the outreach of transhumanism is still restricted as its political organisations have not yet managed to play a transformational role in party competition and transhumanist themes have a limited - though increasing role - in policy debates. Their significance is determined not by the influence of the intellectual appeal of transhumanism or the awareness-raising activities of the transhumanist movement, but by an exogenous factor: rapid scientific and technological progress.

It is not the attractiveness of a new emerging ideology that shapes public discussions, policy debates, and party systems. Transhumanism benefits from the spectacular techno-scientific progress that invites topics into the political arena such as robot rights, autonomous weapons run by artificial intelligence, or genetic modifications. The added value of transhumanism is that it articulates its distinct theoretical and practical (political programmatic) answers to these issues. In this respect, the emergence of transhumanism is a result of an ideological turmoil that characterised

the late $20^{\text {th }}$ and early $21^{\text {st }}$ centuries, during which new thin ideologies were born and began to challenge the ideological status quo, such as ecologism, feminism, and identitarianism. As Freeden described this phenomenon:

a number of groupings of political thought...attempt to escape from the morphological and interpretative constraints of the older established ideologies. One way of effecting this has been through the processes of redefining the domain of the political, reconceptualizing the ideational elements of the contending ideologies, renaming the components of political vocabulary, and revalorizing marginal political concepts. (Freeden, 1996, p. 485) 
These changes brought to life a group of new thin-centred ideologies that either challenge the dominant belief systems or enrich them with novel ideas and perspectives. Transhumanism was one of them, but its emergence was a much slower process than the case of ecologism or feminism.

Freeden defined thin-centred ideology as a less-developed ideology with a restricted, but identifiable, morphology that deliberately removes or replaces many concepts that an ideology would otherwise include and is limited in its ambitions and scope (Freeden, 2003, p. 98; 2005a, pp. 141-142). He identified ideologies like nationalism, feminism, and ecologism as thin on the basis of their 'decreased internal integration', 'restricted core attached to a narrower range of political concepts', and the inability to provide a 'reasonably broad, if not comprehensive, range of answers to the political questions that societies generate' (Freeden, 1996, p. 485; 1998, p. 750). Thin ideologies focus on certain areas of ideological contestation, but otherwise borrow concepts from other ideologies to fill the gaps in areas on which they put less emphasis.

\subsection{Three Arguments}

The argument to define transhumanism as a thin-centred ideology is three-fold. First, its ability to distinguish itself from other ideologies through distinct core concepts and the postanthropocentric perspective is properly verified within the Freedenian theoretical framework, as shown in the ideological analysis of this dissertation. As in the cases of feminism and ecologism, transhumanism also has a coherent and easily recognisable ideational structure that essentially distinguishes it from other mature ideologies. In addition, transhumanism has undergone a restricted thickening process, when theorists equipped it with distinct ideological functions that outlined, justified, and demanded an entirely new social, political, and economic system that, according to the transhumanist promise, would better serve the requirements created by technoscientific progress.

Second, despite the recent thickening, transhumanism still exhibits limited responsiveness

due partly to its reduced capacity to respond to a broad range of policy areas without borrowing ideas and solutions from other, mature ideologies, and because it addresses only a specific (mostly technology- and science-related) group of political issues. Whenever transhumanists attempt to 
provide answers to policy issues unaffected by the techno-science revolution, they struggle to find or create original, decontested concepts typical of transhumanism. For example, there is no unique transhumanist response to the problem of party financing or the proper ratio of public and private financing of mass transportation. There is some evidence of transhumanists putting forward unique ideas for solving certain policy issues (for example the usage of blockchain technology to support the accountability of the executive power; Wood, 2018, pp. 364-367) as well as reformulating existing ideas, such as universal basic income ('Platform of the United States Transhumanist Party', no date; Matthews, 2019), but the quantity of such initiatives is not sufficient to allow us to claim that transhumanism has met the requirements of responsiveness.

This limited responsiveness is also visible in that, unlike mature ideologies, transhumanism has so far been unable to incorporate apolitical concepts into its ideological architecture. As Freeden pointed out:

thick ideologies should contain, at least in part, a different set of concepts, including care, nurturing, empathy, and altruism. The ideological struggle over the control of language is not just that of competing over the meanings of prevalent political concepts such as liberty and justice, but one that endeavours to endow concepts customarily held to be apolitical with political import. (Freeden, 2003, p. 98)

Such notions are very rare in transhumanist texts, and even if they appear, their role is not to buttress the conceptualisations and decontestations of core, adjacent, or peripheral concepts. Thus, their importance with regards to our ideological analysis is negligible.

Table 9 summarises the main ideological attributes of transhumanism and their manifestations and evaluates them with respect to their presence, significance, and prevalence according to Freeden's description of ideologies. It illustrates that some key attributes are missing or have restricted significance in transhumanism which buttresses the thin-centredness hypothesis. 
Table 9. Ideological maturity of transhumanism based on Freeden's description

\begin{tabular}{|c|c|c|c|}
\hline Attribute & Manifestation & Evaluation & Example or comment \\
\hline \multirow{2}{*}{ Distinctiveness } & $\begin{array}{l}\text { distinctive configuration of } \\
\text { concepts }\end{array}$ & yes & $\begin{array}{l}\text { presents a unique ideological } \\
\text { core }\end{array}$ \\
\hline & unique decontestations & yes & $\begin{array}{l}\text { morphological freedom } \\
\text { human enhancement }\end{array}$ \\
\hline \multirow{4}{*}{ Relevance } & raising novel issues & yes & $\begin{array}{l}\text { procreative freedom } \\
\text { longevity }\end{array}$ \\
\hline & $\begin{array}{l}\text { proposing novel and } \\
\text { distinct solutions to } \\
\text { existing issues }\end{array}$ & yes & $\begin{array}{l}\text { liquid democracy } \\
\text { freedom of experimentation }\end{array}$ \\
\hline & $\begin{array}{l}\text { offering solutions to a } \\
\text { wide range of policy issues }\end{array}$ & no & $\begin{array}{l}\text { it needs to borrow concepts from } \\
\text { other ideologies to fill the gaps }\end{array}$ \\
\hline & $\begin{array}{l}\text { aiming to challenge the } \\
\text { existing status quo }\end{array}$ & yes & $\begin{array}{l}\text { post-Anthropocene } \\
\text { Hughes's 3D model of politics } \\
\text { Fuller's 90-degree shift of } \\
\text { politics }\end{array}$ \\
\hline \multirow[b]{2}{*}{ Coherence } & $\begin{array}{l}\text { diachronic and synchronic } \\
\text { stability of the conceptual } \\
\text { core }\end{array}$ & yes & $\begin{array}{l}\text { the five core concepts have been } \\
\text { present since the beginning of } \\
\text { the transhumanist movement }\end{array}$ \\
\hline & adaptability & yes & $\begin{array}{l}\text { the ability to internalise concepts } \\
\text { or ideas from contested } \\
\text { ideologies: for example, } \\
\text { sustainability }\end{array}$ \\
\hline \multirow{6}{*}{$\begin{array}{l}\text { Influence and } \\
\text { efficiency }\end{array}$} & $\begin{array}{l}\text { shared by significant } \\
\text { groups }\end{array}$ & no & $\begin{array}{l}\text { the current membership of the } \\
\text { movement is estimated at } 50 \mathrm{k}\end{array}$ \\
\hline & broad circulation & restricted & $\begin{array}{l}\text { pop culture contributes to } \\
\text { popularising transhumanist ideas }\end{array}$ \\
\hline & inspiring policy action & restricted & $\begin{array}{l}\text { some public discussion, but not } \\
\text { mainstream }\end{array}$ \\
\hline & control of language & no & $\begin{array}{l}\text { it has so far been unable to } \\
\text { modify the language of politics }\end{array}$ \\
\hline & group product & yes & \\
\hline & mobilisation potential & restricted & low membership \\
\hline \multirow[t]{2}{*}{ Consumability } & language & yes & $\begin{array}{l}\text { simple, comprehensible } \\
\text { language }\end{array}$ \\
\hline & visuality & yes & globally unified logo \\
\hline
\end{tabular}




\begin{tabular}{|c|c|c|c|}
\hline Attribute & Manifestation & Evaluation & Example or comment \\
\hline \multirow{3}{*}{$\begin{array}{l}\text { Consumability } \\
\text { (continued) }\end{array}$} & emotions & restricted & $\begin{array}{l}\text { it does not assign emotional } \\
\text { importance to its key values, nor } \\
\text { recognises it the centrality of } \\
\text { emotion in socio-political } \\
\text { interactions }\end{array}$ \\
\hline & overt and coded messages & no & $\begin{array}{l}\text { not yet developed such } \\
\text { ambiguity to allow for various } \\
\text { interpretations }\end{array}$ \\
\hline & creativity & yes & $\begin{array}{l}\text { it is able to stimulate public } \\
\text { imaginary }\end{array}$ \\
\hline \multirow{4}{*}{$\begin{array}{l}\text { Institutionali- } \\
\text { sation }\end{array}$} & political representation & restricted & niche proto-parties \\
\hline & elections & no & very few candidates \\
\hline & elected officials & no & $\begin{array}{l}\text { only some rare and insignificant } \\
\text { cases }\end{array}$ \\
\hline & NGOs, think-tanks & yes & $\begin{array}{l}\text { very active organisations, WTO } \\
\text { IEET, Transpolitica }\end{array}$ \\
\hline
\end{tabular}

Finally, it is justified to assert that to a limited extent transhumanism can present effective conceptual decontestations; put differently, decontested explanations of the current reality of our world. Moreover, it seems that it is the main comparative advantage of transhumanism against other, established ideologies that it is the first ideology to comprehend, valorise, and ingest the already present consequences and future challenges of disruptive scientific and technological changes. As it was pointed out in earlier chapters, transhumanism is not restricted to conveying random ideas and concrete policy initiatives to transform prevailing political and social arrangements. It also intends to disrupt the semantic field of politics and, in this respect, has two strong supporters: science and technology. Other, mature ideologies are either unable or reluctant to address the new social, economic, and political issues continuously emerging as the result of exponential progress or they are outright dismissive of transhumanist ideas and amend their conceptual offer to enable them to prevent a dystopian outcome for humanity. Transhumanism has not yet developed a full-fledged policy offer for all aspects of life, but its decontested explanations provide new and thought-provoking alternatives to the policy proposals of mature ideologies.

Much of the transhumanist mainstream discourse of the late $20^{\text {th }}$ and early $21^{\text {st }}$ centuries has reflected the issues that techno-scientific progress created from a historical and sociological perspective as well as its philosophical and policy implications. But in recent decades the focus of 
transhumanist theorising shifted from futurist visions to solving immanent problems such as climate change, famine, or poverty. Encompassing a broader perspective greatly contributed to the conceptual enrichment of transhumanism, which, then, helped it grow ideologically more mature.

Even though transhumanism, following the humanist and Enlightenment traditions, praises reason as the ultimate guiding principle for humanity, strong emotive aspects are also present in at least two types of transhumanist arguments. First, techno-scientific progress is seen as benevolent, omnipresent, and irreversible - though not risk-free. Actively supporting, adopting, and adapting to new technologies is the moral duty of each individual, as technology is good. It is the tool for achieving a good life for the individual and the greater good for the whole human race. The main goal and ultimate benefit are the elimination of pain and suffering from life. This is a startingly naïve, idealised, almost romanticised picture of the future, but without a doubt something that we all desire. Second, transhumanism relates the argument that individuals, all sentient beings, may one day unite in a hive mind. Liberated from the burdens of self-sustenance, individuals will be able to unleash their cognitive capabilities and focus on maximising their creative capacities. The world will be inhabited by billions of Mozarts, Einsteins, and Picassos who may connect with each other through their brain-computer interfaces and create a super-intelligent entity. These visions of the future are inherent in transhumanist discourse. Belief in progress in not only rational for transhumanists, but also there is an emotional attachment to it that overwrites other, mostly rational, dystopian criticism. Critics subtly claim that the transhumanists' unconditional belief in rationalism is irrational.

Additionally, with the development of the concept of morphological freedom, transhumanism acquired a distinctively ethical and emotive character. Transhumanism is not a cold, unemotional, pro-science theory designed only for nerds and Silicon Valley entrepreneurs, nor is it the worship of unleashing the full potential of technological progress to overstep humanity's boundaries. It is articulated as a means for enabling full-scale individual flourishing, the maximisation of the interior life of individuals who become real agents with free choice, unbound from the constraints of the externality of nature, capable of using a broader toolkit made available by science to improve their lives and lessen pain and suffering. Moreover, it is an ideology that celebrates the absolute distinctiveness of the individual and emphasises the necessity of fullfledged self-realisation, a pursuit of interior authenticity. It is a celebration of the inner freedom of 
the individual and the acknowledgement of humanity's final victory over nature, a realisation of its telos. Such a teleological addition to transhumanist theory suggests that transhumanism has shifted from a radical individualistic idea to one that can offer a universal vision. It promises to become an ideology that societies may turn to as they progress technologically. In sum, the reconciliation of the social and the individual is a key milestone in the process of the ideological thickening of transhumanism.

\subsection{A Brief Comparison}

Though it is beyond the scope of this dissertation to conduct a comprehensive comparative analysis of transhumanism and other thin-centred ideologies, it is important to emphasise a few observations that may help us understand why transhumanism managed to develop thin-centred ideological status and comprehend its conceptual thickening potential. The emergence of new ideologies is in most cases linked to disruptive socio-economic changes and the aim of any theorist is to resolve issues that they hold unjust or detrimental. In this respect, transhumanism's role is similar to that of feminism: both at least intend to equalise and emancipate a suppressed social group. But the difference between the two is that feminism focuses on women, who have suffered from exploitation, oppression, and patriarchal dominance throughout human history, and therefore the issue it attempts to resolve has long been present, ubiquitous, and neglected by male-dominated societies. On the other hand, the subjects of transhumanist emancipation do not yet exist. Robots with human-level intelligence, genetically modified chimeras, enhanced superhumans, and upgraded animals are examples of technological potentials, not current affairs. While feminism is enmeshed in a burning social issue of our times, transhumanism attempts to inject new features into the political practice and concepts into the ideological discourse in order to shift policy priorities and create a new semantic field so that humanity might not make the same mistakes in the future as it did with women's rights in the past. In this regard, feminism is protective and transformative while transhumanism is preventive and preparatory. But unlike feminism, transhumanism does not assault and challenge the current political vocabulary with the intention 
to replace it; rather it allocates new meanings to old terms, introduces new concepts to the dominant political language, and enriches existing thought-behaviours with new dimensions.

Similarities can also be observed between transhumanism and ecologism. Both introduce a new type of interspecies communality among various forms of existence surpassing the anthropocentric restrictions of existing belief systems. A major difference is present, however, in that Green ideology limits its scope to nature-created life forms while transhumanism expands the definition of species to include artificially created, non- or semi-organic new life forms that technology may create in the (near) future. These life forms are invested with the same rights and duties as current predominant ideologies apply to humans (and in the case of Green ideologies, species created by nature through the process of the organic evolution) provided they possess the required level of sentience.

Another resemblance is that action is central to both ecologism and transhumanism. Importantly, however, action is not ascribed in transhumanism because of other core concepts being under constant threat like in Green ideologies, but because of the teleological character of transhumanism that sets the ultimate goal of humanity to transcend its biological limits and take control over its own evolution to reach the posthuman era as fast as possible. This actioncentredness is well demonstrated in the fact that the proactionary principle holds a core conceptual position in transhumanist ideology. The aim of activism for ecologists is to protect and conserve while transhumanists desire to disrupt and challenge. Both demand radical methods but for different reasons.

As mentioned previously, early transhumanists were attached intellectually to the libertarian philosophical tradition, but it is important to clarify their conceptual differences. Libertarianism and early transhumanism are similar in that both reduce progress to the level of technical and scientific advancement - though, as it was previously noted, contemporary transhumanists put equal emphasis on moral enhancement (Bostrom, 2005a; Caldera, 2008; Tennison, 2012; Fuller, 2015b) - but they differ greatly in how the concept of development and improvement are interpreted. Libertarians identify development with the growth of personal wealth. Transhumanists, on the other hand, while acknowledging the importance of material prosperity, focus more on the maximisation of intelligence and other cognitive and psychological attributes. For transhumanists, wealth is of secondary importance simply because techno-scientific 
progress, in the transhumanist narrative, will create a new socio-economic system characterised by technological (or as the latest wave of transhumanist terminology infused with ecologist views put it, sustainable) abundance, in which hard labour and a scarcity of resources are absent and wealth is guaranteed for everyone. The liberty concept of libertarianism is strongly attached to economic theories whereas individuals are conceived primarily as material wealth creators. In transhumanism, individuals are detached from the economic aspects of human nature. The libertarian view of humans as self-seeking, rivalry-driven quantitative maximisers of material conditions is, thus, replaced by the transhumanist idealisation of the individual being driven first and foremost by self-realisation and self-development in cognitive, physical (health), and psychological terms. Consequently, transhumanists set a higher importance on immaterial parameters when articulating the notion of wealth maximisation. Moreover, self-development became not only an individual option, as in libertarianism (Freeden, 1996, p. 289), but also an obtainable and desired universal end.

\subsection{The Success of Thin-centred Ideologies}

When examining thin-centred ideologies, it is inevitable to contemplate their future potential, especially with regards to their quest for dominance and electoral success - the fundamental goal of every ideology. Consensus exists among political scientists about which belief systems can be listed among thin ideologies. These include ecologism, feminism, nationalism, fascism, and most recently, populism. Thin-centred ideologies attempt at 'redefining the domain of the political, reconceptualizing the ideational elements of the contending ideologies, renaming the components of political vocabulary, and revalorizing marginal political concepts' (Freeden, 1996, p. 485). Based on these criteria, a historical assessment of the evolution of existing thin ideologies may conclude that, thus far, thin ideologies can undoubtedly be considered successful in ideological terms.

A parallel synchronic and diachronic analysis of performance can be conducted along three dimensions: electoral, semantic, and conceptual. First, many of the aforementioned thin ideologies spawned political parties that performed well in elections and became part of democratically 
elected governments either as dominant governing parties or minority members in coalition governments. Prime examples are the fascist governments of Italy and Germany in the 1930s; the nationalist Front National party reaching the top in several municipal, presidential, and European Parliamentary elections in France since the 1990s (Stockemer, 2017); the steadily improving electoral support for Green parties in Western Europe (Delwit and Close, 2016; Grant and Tilley, 2019) - especially the surprising success and high polling rates of Green parties in Germany and the Netherlands today; and the contemporary populist governments of Hungary, Poland, Slovenia, and the U.S. (Kyle and Gultchin, 2018). The global rise of populist parties even led some political scientists to call this phenomenon the Populist Zeitgeist (Mudde, 2004). It is important to note here, however, that describing as successful the performance of political parties representing thin ideologies by no means should be understood as a positive evaluation of governments bearing these ideologies. On the contrary, the political output and historical legacy of fascist and populist governments are among the most devastating in human history: they either committed the most horrific atrocities against humankind in the $20^{\text {th }}$ century or are generally held responsible for the democratic backsliding in the $21^{\text {st }}$ century.

The second dimension of the assessment of success is the ideology's capability to exert influence over political language. In this respect, Green and feminist ideologies achieved spectacular results in transforming the semantic field that has been dominated for over a century by the language of the three mainstream ideologies: conservativism, liberalism, and socialism. The feminist contribution to the enrichment of the semantic fields of ideologies and to political thought in general was

to discover domains of surplus meaning and to suggest that, by reading the surplus back into the employment of words and arguments by past and current mainstream users of political theory, a significant new interpretation of political conduct and its purposes. (Freeden, 1996, p. 488)

Words such as 'women' and 'gender' became ineliminable parts of the political discourse thanks to feminist interpretations, while the emancipatory efforts of feminist activism resulted in a revised vocabulary and grammar of political and business language deprived of its patriarchal bias. The 
success of the feminist thin ideology can also be observed in how the depiction of women changed incrementally in popular culture, indicating that the feminist ideological discourse has become mainstream since the 2010s (Anderson, 2018).

Ecologism exerted a similar semantic influence on political discourse. First and foremost, it enriched the political and everyday language with terms such as preservation, sustainability, climate catastrophe, and recycling. In this process, mass media was of great help for the Green movement as it ensured the dissemination of environmentalist terms and transmitted a new type of worldview to wider audiences. Secondly, further reinforced by the manipulative power of social media, Green ideology managed to transform human and social interactions, and shape the lifestyle of generations (Madden, 2019).

Populism also exhibits capabilities of discourse transformation. The re-interpretation of terms such as migration and national sovereignty, the use of the 'us and them' dichotomy, the disparaging of elites, and excessive utilisation of these tools to change the political agenda explain to a great extent the recent electoral success of populist parties.

Finally, thin ideologies that present a narrow range of owned concepts are capable of penetrating the ideational structure of other mature ideologies. The ideational core of thin ideologies produces a diverse range of both logical and cultural decontestations. These decontestations create or invite novel adjacent and peripheral concepts and dismiss or neglect other concepts that for a long time have been ineliminable parts of mainstream ideologies. Then, with the help of these new ideological components, thin ideologies assault the ideological convention fixed by the dominant mainstream ideologies. The result is that robust, mainstream ideologies were forced to create modified decontestations of their own core concepts in response to the challenges of thin ideologies. For instance, socialism responded to feminism by incorporating genderist instances into its own conceptual architecture, conservativism established shared ideas with the Green ideology based on their common scepticism towards change, and liberalism struggles with establishing a common ground with the political implications of the concept of sustainability.

The outcome of these hostile interactions among mature and thin ideologies are still unsettled. One of two possible scenarios is that mainstream ideologies will be able to cannibalise contested thin ideologies by incorporating their conceptual innovations without fundamentally altering their own conceptual core. The product of this process is a hybrid ideology such as feminist 
socialism or eco-libertarianism. Otherwise, thin ideologies move forward with their ideological thickening and finally themselves become full-fledged platforms replacing old ideologies. A similar process resulted in the appearance, emergence, and then dominance of socialism in the $19^{\text {th }}$ and $20^{\text {th }}$ centuries.

Taking into consideration these scenarios, it comes as no surprise that the reaction of established ideologies to the emergence of thin-centred ideologies is always defensive and hostile. These inferences are also important to understand the intellectual and political reception of transhumanism. Followers of established ideologies are always suspicious of the new contender, whereby proponents of new ideologies are prone to provoke. They follow the rule of Stendhal, who famously said that the most impactful entry into a society is a duel.

\subsection{The Main Ideological Conflict of the $21^{\text {st }}$ Century?}

As an ideological newcomer, transhumanism set an ambitious goal for itself: to disrupt the whole ideological space. The main transhumanist claim in this respect was presented by James Hughes in his seminal book Citizen Cyborg, in which he stated that the ideological space of the $21^{\text {st }}$ century would be determined by biopolitics. At the centre of biopolitics lies the irreconcilable ideological conflict between transhumanists and bioconservatives. The following section will examine the details and implications of this claim.

The starting point of Hughes's line of thought is the attitude of society towards scientific progress. In this respect, he distinguished optimistic and pessimistic attitudes. Those who exhibit the former disposition are descendants of the Enlightenment who believe in progress, which is mostly driven by advances of science and technology. The main early representatives of these distant stances were John Burden Sanderson Haldane and Aldous Huxley. Haldane published a bestselling short book in 1923 in which he envisioned abundant clean energy produced by windmills and hydrogen plants, the synthetic production of food, extended healthy human lifespan, and widespread use of ectogenesis (reproduction without 'sexual love making'), selective breeding, biomedical control, and the amelioration of psychological capabilities - all these realised by science before the end of the $20^{\text {th }}$ century. He also predicted that the international order would 
transcend the nation as a building block, and sooner or later humanity would unite under a single global organisation. Then, he gave an account of his optimistic view on the role of science in bettering the world:

We must regard science then from three points of view. First it is the free activity of man's divine faculties of reason and imagination. Secondly it is the answer of the few to the demands of the many for wealth, comfort and victory, [...], gifts which it will grant only in exchange for peace, security and stagnation. Finally it is man's gradual conquest, first of space and time, then of matter as such, then of his own body and those of other living beings, and finally the subjugation of the dark and evil elements in his own soul. None of these conquests will ever be complete but all, I believe will be progressive. (Haldane, 1924)

Disturbed and inspired by Haldane's enthusiasm, the writer Aldous Huxley wrote his famous novel Brave New World to refute the optimistic vision of science and offered a dystopian presentation of what science is capable of when it is driven by malign intentions. Ever since, the pessimistic group has evoked the phrase 'brave new world' when optimists predict or promise fundamental social changes because of revolutionary scientific advances.

The dispositional dichotomy towards scientific progress continued to determine visions of the future until the present. However, attitudes towards various scientific achievements vary greatly. Hughes quotes public opinion polls from 2002, but more up-to-date studies are also available (U.S. Public Wary of Biomedical Technologies to 'Enhance' Human Abilities, 2016; Masci, 2016). These studies have come to similar conclusions that the public is more inclined to approve of disruptive technological inventions and therapeutic biomedical and genetic interventions, whereas they are prone to disapprove of human enhancement technologies.

Unsurprisingly, it was genetic modification that became the main frontline of the conflict between the optimistic and pessimistic camps. According to Hughes, the academic discipline of bioethics turned into a propaganda tool in the hands of those intellectuals who demanded strict regulations on various forms of reproductive interventions ranging from stem cell research through in vitro fertilisation and human cloning to germline modification. The bioethics advisory 
committee appointed by President George W. Bush in the U.S. presented its report in 2003, in which the committee raised ethical, social, and economic concerns against enhancement technologies. The report echoed Leon Kass's idea of the 'wisdom of repugnance' outlined in his 1997 article, as well as another committee member, Francis Fukuyama's argument against human enhancement to protect 'human dignity'. Kass stressed that

in this age in which everything is held to be permissible so long as it is freely done, in which our given human nature no longer commands respect, in which our bodies are regarded as mere instruments of our autonomous rational wills, repugnance may be the only voice left that speaks up to defend the central core of our humanity. (Kass, 1997)

He added in his subsequent book on bioethics that

repugnance is the emotional expression of deep wisdom, beyond reason's power completely to articulate it [...] We are repelled by the prospect of cloning human beings not because of strangeness or novelty of the undertaking, but because we intuit and feel, immediately and without argument, the violation of things we rightfully hold dear. (Kass, 2002, p. 150)

At the same time, Fukuyama demanded strict regulation of genetic research:

Congress must identify the ethical principles to guide a new regulatory institution, as well as identify which activities should be taken off the table up front and which can be performed with suitable regulatory oversight. (Fukuyama and Furger, 2007)

The bioconservative camp - or as Hughes labelled them ironically: the bioLuddites consisted partly of religious conservatives (evangelical theologians, pastors, and Republican politicians) and political conservatives (like Fukuyama), but they soon found an unexpected ally from the political left. It was Jeremy Rifkin, an anti-war socialist activist and promoter of the idea 
of the 'zero marginal cost society' who recognised the shared goals of ideologically different groups to defeat a common enemy:

Rarely do political groups on the opposite ends of the spectrum come together in pursuit of shared goals. But the current debate over embryo stem cell research as well as the debates over patents on life, genetically modified foods and 'designer babies' are fundamentally reshaping our political landscape. Social conservatives and left activists are beginning to find common ground on a range of biotech concerns. If this continues, conventional politics could be torn asunder in the Biotech Era. (Rifkin, 2001)

Rifkin was among the first who advanced the idea that biotechnology will be the main cause of ideological rupture in the future - an idea that Hughes adopted and developed further. But Freeden also came to a similar conclusion when analysing the conceptual arrangements of conservative and Green ideologies. The decontestation of the concept of preservation and the intrinsic prejudice against progress in Green ideological variants indicated that ecologism deployed strong cultural constraints on possible human acts - including scientific experimentation - that have potential detrimental effects on nature and human future. The protection of the natural human genome became the common set that united those with otherwise distant ideological backgrounds. As Freeden wrote:

Progress becomes a manifestation of the replacement of 'true' human and natural values with artificial ones generated by the industrialist-modernist project. [...] Conservatives utilize the human-nature relationship, or the transgenerational bond, or the small community - all elements of Green vocabulary - for the Burkean purpose of controlling the pace of change and resisting destructive innovation. They revere nature as an extra-human force underpinning human force underpinning human life. Here Green core and adjacent concepts are to be found at strategic locations in conservative morphology. (Freeden, 1996, pp. 536-537) 
This unexpected conceptual family resemblance explains the emergence of the strange umbrella coalition against transhumanism and proves that this phenomenon cannot be reduced to the formulation of ad hoc political alliances, but instead defines the cleavage along which the techooptimist and techno-pessimist ideological camps clash.

\subsection{Hughs's Cube - The Three Dimensions of $21^{\text {st }}$ Century Ideological Space}

As noted in the previous section, Hughes adopted Rifkin's idea that the conflict over biotechnology will determine political allegiance in the coming age of unprecedented scientific and technological progress. According to his account of $20^{\text {th }}$-century politics, ideologies were positioned along the left-right economic axis, and the main determinants were distinct approaches to welfare, equality, redistribution, the role of the state, and taxation, among others. In addition to the traditional left-right economic axis, he added a second dimension that describes the branches of ideologies (and their representative parties) based on their cultural orientation toward issues of race, gender, and civil liberties. In this dimension right-wing radicals, ethnicists, and left-wing populists are closer to the 'cultural conservative' end, while seculars, cosmopolitans, and human

rights and diversity advocates occupy the 'cultural progressive' end. According to Hughes, this two-dimensional map of politics characterised $20^{\text {th }}$-century politics, in which the interactions among ideologies and parties could be visualised as movements along the cultural or economic axis.

Nevertheless, in the $21^{\text {st }}$ century, a new type of division has emerged that separates society and politics based on attitudes toward enhancement technologies. Hughes calls this new dimension biopolitics. At one end of the biopolitical axis stand those who reject enhancement technologies, while those who accept the proactionary principle and the use of enhancement technologies lean toward the other end. If this third, biopolitical axis is added to the two previous dimensions, the result is a cube - 'Hughes's cube' - that maps out the exact positions of different versions of transhumanist ideologies (see Figure 11). In Hughes's cube, the positions of distinct ideologies and their mutations can be visualised based on the distance of an ideology's position from the cube's centre point. 
Figure 11. Hughes's cube - The ideological space in the $21^{\text {st }}$ century

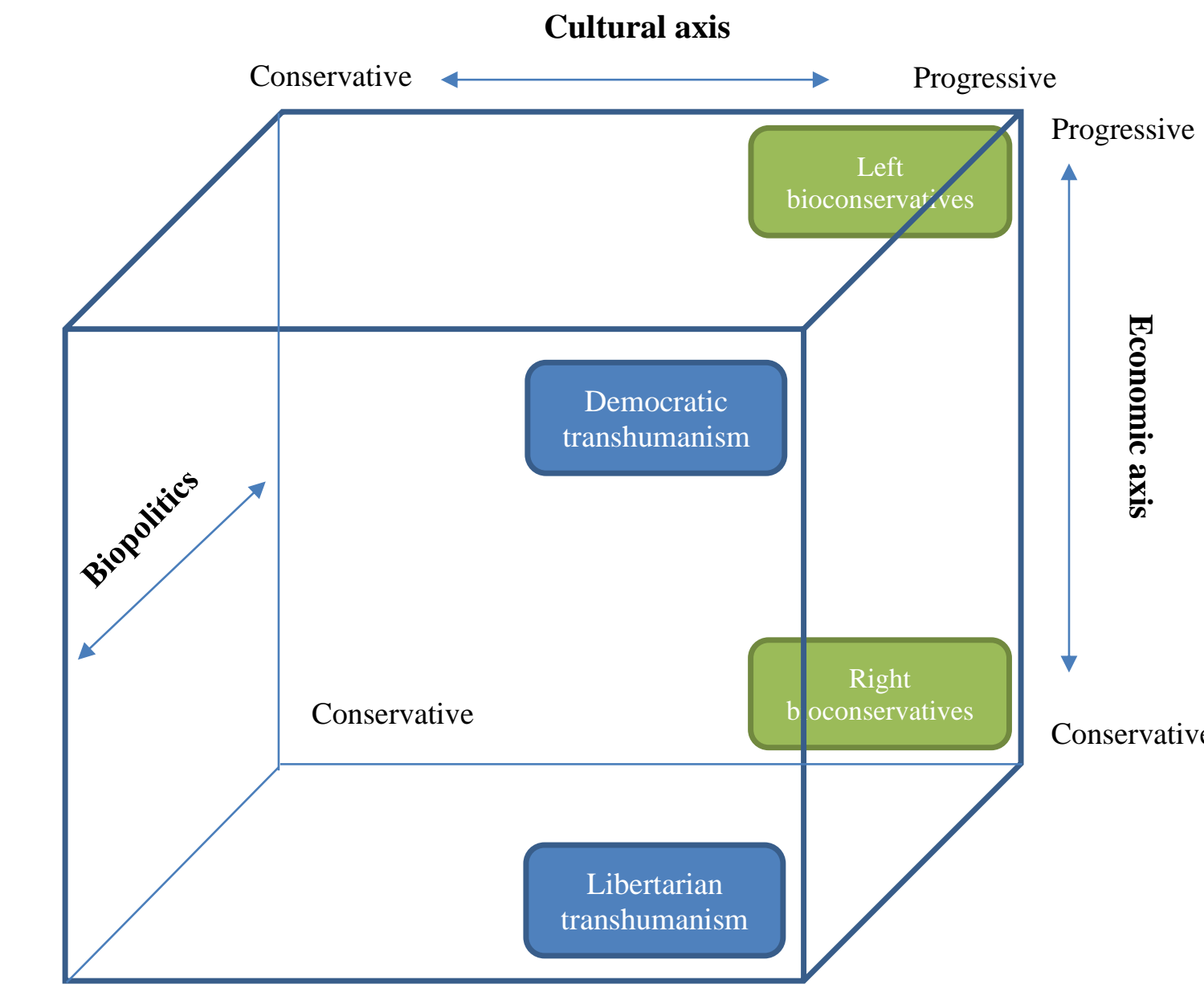

Progressive

Source: Hughes (2004, p. 72)

What is the relevance of Hughes's cube for the understanding of the thin-centredness of transhumanism? Less-developed ideologies aspire to challenge the political status quo. Such an ambitious endeavour requires the ability to exert influence on the political discourse. Ideological newcomers need to communicate their ideas effectively, present their visions in a creative, consumable way, and stimulate the imagination of their target audiences. The fastest way to stand out from the ideological noise is to provoke and challenge contested ideologies to a duel. Transhumanism acted exactly according to this simple rule. First, it articulated its utopic and controversial visions about immortality, the end of scarcity, the liberation of mankind from hard 
labour, and space colonisation. Transhumanists buttressed their arguments with scientific evidence and technological achievements to appeal to secularist audiences. They offered reason instead of mysticism, but their vision was as attractive as the promise of heaven in some religions. Transhumanism presented a unique and exceptionally coherent set of concepts and its ideational core remained almost unchanged in the subsequent four decades. At the same time, Esfendiary pinpointed the main ideological opponent of transhumanism, another thin ideology, ecologism. The choice was not arbitrary. Only a few visionaries understood at that time that an external factor the accelerating techno-scientific progress - would have a decisive role in shaping the future ideological space.

Building on this externality, transhumanism set an even greater ambition: it aimed at disrupting the whole ideological space to make established, mature ideologies obsolete. Hughes's cube represents this ambition: a novel explanatory framework designed for the near future. In the 1980s, only a handful of transhumanists and some radical environmentalists foresaw the emerging conflict between two young ideologies, and that this split would have a disruptive effect on established ideologies. Decades later, full-fledged ideologies have continued to neglect the transhumanist challenge. But time is on the transhumanists' side: the progress in science and technology continues at an unprecedented pace, and every new invention underpins the validity of the transhumanist argument (and the ecologists' fear). In the meantime, more and more intellectuals and activists on the ideological fringes have realised the risks that transhumanism poses to their own religious or conservative worldviews. A countermovement was formed and began to alert the followers of mainstream ideologies.

Parallel to this, the ideological thickening of transhumanism began through its interaction with other ideologies to respond to the ideological assault coming from other established ideologies. Hughes posed a relevant question:

Why are so many contemporary social democrats, feminists and Greens suspicious and hostile to biotechnologies, computers and science in general? [...] The ecological movement suggested that industrial activity was threatening all life on the planet, while the anti-nuclear-power movement inspired calls for technology bans. The counterculture attacked positivism, and lauded pre-industrial ways of life. 
Deconstructionists and post-modernists cast doubt on the 'master narratives' of political and scientific progress, while cultural relativists attacked the idea that industrialized secular liberal democracies were in fact superior to pre-industrial and authoritarian societies. (Hughes, 2004, p. 129)

The relevance of Hughes's cube lies in that it visualises how transhumanism created novel decontestations and produced unique morphologies though adopting other concepts from contested belief systems and reacted to critiques of the advocates of contested ideologies. It also demonstrates how transhumanism provokes reactions from among these challenged ideologies. A further advantage of Hughes's cube is that it is suitable to describe the expected position shifting of ideologies as they choose to engage in either accommodative or adversarial strategies toward transhumanist topics.

From the above inferences, a further question arises: is the conflict between ecologism and transhumanism irreconcilable? Transhumanists consider themselves successors of the humanist and modernist philosophical traditions, hence, they adamantly oppose any postmodernist philosophies. They do not hide their disrespect for radical, neo-primitive Green ideologies, but they do exhibit awareness of environmental risks and propose their own progress-compatible solutions to ecological problems. The conflict is of different nature, with postmodernism at the centre. As Natasha Vita-More wrote:

contrary to journalistic hyperbole and postmodernist hegemony, the aim of transhumanism has been and continues to be to establish a platform for critical thinking and visionary foresight that can and will have significant impact on people. This impact is to educate society and to offer platforms for discussion and take the conversation out of the postmodernist rhetoric, journalistic sensationalism, and fearmongering of bioethicists, into the public arena. (Vita-More, 2019, p. 52) 


\section{Conclusion}

This final chapter will revisit the themes of this dissertation, returning to reflect upon the relevance of the ideological analysis conducted on transhumanism. In so doing it will seek to reappraise the substantive findings of the ideological examination and evaluate the theoretical implications of studying transhumanism from the ideological perspective for political science. Such an inquiry is essential for drawing together and reflecting upon the different inferences of these findings and contemplating possible ways of extrapolating them to other ideologies. For these reasons, the chapter re-examines the analytical and methodological insights advanced to assert the pertinence of this form of inquiry for future research.

Transhumanism is set of ideas, the main claim of which is that it is possible and desirable to transcend human biological limits with the help of science and technology and improve human cognitive, physical, psychological, and moral capabilities beyond what is deemed possible with our current level of knowledge. Such transcendence entails profound social, economic, and political changes and has the potential to significantly improve the human condition. Transhumanist ideas have been rapidly gaining in popularity during the last half a century among future-oriented thinkers, tech-savvy audiences, and zealous advocates of scientific progress. The dynamics and mutually reinforcing character of scientific and technological advances prompted theorists and scholars from various disciplines to analyse the impact of this progress on human civilisation in its philosophical, social, economic, cultural, and political aspects. Transhumanism is based on a strong belief in perpetual and accelerating scientific and technological progress, and that science and technology will improve the quality of life and help humanity realise its telos: to reach a posthuman condition, an age of sustainable superabundance and controlled evolution. Thus, transhumanism grew into a worldwide movement, with the spread of transhumanist themes occurring at the same time as debates over the disruptive changes induced by technology penetrated public discourse and popular culture.

It has recently grown political branches that exert influence on policy-making by inviting topics such as the modification of inheritable genetic traits, robot rights, post-Anthropocene, or the freedom of bodily transformation into the political arena. The latest development is the emergence of transhumanist political representation in the form of niche proto-parties worldwide. These 
changes signal an ideational thickening of transhumanism, which makes it an adequate subject for ideological scrutiny.

This dissertation presented the first ideological analysis of political transhumanism applying Michael Freeden's morphological approach. Its hypothesis was that transhumanism is a thin ideology. To test this hypothesis, this dissertation conducted a qualitative content analysis of key transhumanist political texts and defined the core, adjacent, and peripheral concepts of the transhumanist ideology as well as presenting how transhumanism decontests its main concepts and what ideological components it utilises.

This dissertation has sought to explore the following main research question: is transhumanism a distinct ideology?

Freeden described ideologies as structural arrangements that attribute decontested meanings to a range of mutually defining political concepts; ideologies compete over the control of political language and inspire policy action to achieve semantic dominance. At the core of Freeden's approach lies the process of decontestation. As the main feature of concepts is their essential contestability, decontestation is necessary to allocate them with ideology-specific meaning, attach satellite concepts, and finally, to place them inside the conceptual space. When pursuing the morphological analysis, the main tasks are to find the exact location of these concepts inside the ideological architecture, reveal how the given ideology prioritises its concepts, defines their interrelations in the political space, and reveals their synchronic and diachronic morphologies. Therefore, the key outputs of the morphological analysis - and accordingly, of this dissertation are decontestation chains that uncover the process of concepts' acquisition of ideology-specific meaning, a temporal investigation of their transformations, and a map of their spatial distribution according to their proximity to each other, priority ranking, proportionality inside the conceptual space, and permeability (Freeden, 2003, pp. 60-65).

This dissertation conveyed four secondary research questions that are logically inferred from Freeden's methodology and provide further insights to properly answer the main research question. Does transhumanism possess a coherent ideology? What are the core ideas, key values, and claims (decontestation chains) that make up transhumanism? How can the conceptual structure of transhumanism be described? Finally, what is the extent to which these concepts and claims are distinct from other ideologies? 


\subsection{The Question of Eligibility}

Before embarking on the morphological analysis, this dissertation investigated the eligibility of transhumanism as an adequate subject of ideological analysis. Transhumanism has many definitions: some describe it as an intellectual and cultural movement, others hold that it is a class of philosophies, a perspective, a world view, a theory, a cultural ecology, a social narrative, or a scientific study. This definitional ambiguity is well demonstrated in that the Wikipedia entry about transhumanism classifies it among ideologies, whereas in the text body of the entry it is defined as a 'philosophical movement'. ${ }^{18}$ To clarify, this dissertation gauged the presence of main ideological attributes, following Freeden's methodological guidelines. Transhumanist texts were examined to test the eligibility along six key attributes: distinctiveness, relevance, coherence, influence-efficiency, consumability, and the level of institutionalisation.

It is striking that even a quick glance through various transhumanist texts picked randomly at any time from the last 50 years reveals that the themes, ideas, and concepts present in these books, journals, printed magazines, or blog posts are nearly identical. The same ideas and topics appear in every transhumanist theoretical text irrespective of their date of publication. This hints at an exceptionally strong ideational coherence. Furthermore, the distinctiveness of transhumanist proposals is beyond a doubt vindicated as none of the transhumanist core ideational claims can be found in any other ideology. This distinctiveness is connected to the unique perspective based on which transhumanism interprets reality and proposes changes to the contemporary social order: the techno-scientific perspective. Transhumanism is the only ideology that conveys the advances of science and technology to the realm of politics and derives its concepts and policy offers strictly from the techno-scientific field. Exponential progress is viewed as a categorical externality to individual existence and social reality that will have disruptive consequences on the human condition, and the main task of politics is to help society prepare and adapt to these changes. Moreover, transhumanism suggests more than improved receptivity and positive accommodation: it urges proactivity from individuals and society to fasten the techno-scientific advance, as progress is viewed as the only way to overcome the existential issues of our time and lead to a better future.

\footnotetext{
${ }^{18}$ https://en.wikipedia.org/wiki/Transhumanism
} 
The relevance of transhumanist ideological claims is further buttressed by the fact that its utopian or visionary proposals conjured many decades ago have become scientific possibilities and technological realities by the year 2020 .

Transhumanist ideas, such as enhancing human capacities or extending a healthy lifespan, are of high consumption-value. They are not only easily intelligible for the public as recognisable and distinct thought-behaviours and cultural speech, but also inspire a wide selection of policy actions such as increased funding for scientific research for transhumanist technologies, a permissive regulatory environment for genetic engineering, and the post-anthropocentric extension of the rights system. Furthermore, transhumanist ideas are presented in simplified, comprehensible language. Also, transhumanism developed its unique visuality due to the fact that the transhumanist movement attracts a great number of artists, performers (Vita-More, 1983) and its advocates are greatly inspired by superhero comic books and science fiction literature. The linguistic and visual creativity greatly improves the attractiveness of this young ideology.

However, some key attributes of mature ideologies are either missing from transhumanism, or their presence is hardly observable. Its use of emotive arguments is limited as it does not assign particularly outstanding emotional importance to its main values, nor recognises the centrality of emotion in socio-political interactions. Transhumanism has not yet developed overt or coded messages: it allocates concepts with fixed meanings. This may be explained by the transhumanist respect for science. Evidence-based, clearly articulated arguments demanded by science characterise the transhumanist language. Thus, transhumanism is unable to generate semantic ambiguity that allows for various interpretations as in the case with other, full-fledged ideologies. On the other hand, transhumanist topics successfully penetrated pop culture, which is now the major distributor of transhumanist ideas. This indicates that transhumanism has a great potential to reach the public more effectively.

When transhumanists aim to shape public discourse and policy, the transformation of the transhumanist philosophy into a consumable, interpretative belief system is a logical and costeffective option as well as a necessity for political success. As Ben Stanley has written:

[i]deologies do not simply reflect possible pathways through the political; they also play a role in shaping them. Having new ideas is not a costless enterprise, and extant 
ideologies are invaluable heuristics for individuals wishing to access the political world and build links with others. (Stanley, 2008b, p. 99)

But the eligibility test revealed that transhumanism is unable to exert significant influence on politics. Albeit it attracts a highly influential and affluent audience, it has so far failed to mobilise as many followers as other new ideologies, such as ecologism or feminism. This partly explains why the transhumanist movement is unable to directly exert influence on policy decisions. However, it is important to note that transhumanist topics have successfully penetrated political discourse and are constantly being discussed at various policy levels. Most importantly, transhumanism has so far failed to develop its effective political representation conducive to the thickening of ideologies. Transhumanist political parties have emerged worldwide, but these are mostly niche proto-parties that do not play an important role in party competition, and their electoral performance is negligible. On the other hand, transhumanist think-tanks and organisations are active in proposing distinct ideas to intellectuals and policy-makers.

The conclusion was that while transhumanism is eligible for ideological analysis, it clearly lacks some key attributes of ideologies implying that the ideological maturity of transhumanism can and should also be properly investigated.

\subsection{The Conceptual Arrangement}

As part of the morphological analysis, three distinct types of concept were revealed. Core concepts are ineliminable, ubiquitous components that are the essential building blocks of an ideology to provide it with the necessary ideational coherence. Four core concepts of transhumanism emerged from the investigation presented in this dissertation: liberty, welfare, progress, and individuality. This finding suggests a shared conceptual core with liberalism, but a thorough examination uncovered the unique decontestations that transhumanism deployed on these four host-concepts and the result is a distinct set of core concepts that clearly separates transhumanism from liberalism. Liberty is decontested as morphological freedom - the right to bodily self-transformation; welfare is decontested as human enhancement - the need for and moral 
duty of ameliorating human cognitive, psychological, and physical capabilities beyond speciesspecific biological limits - and longevity - the infinite extension of healthy lifespan; individuality is decontested as personhood - the base for a novel inclusive rights system; and progress is decontested as the proactionary principle - the individual's active experimentation with enhancement technologies applied freely on their own body.

Morphological freedom can inhabit several conceptual fields: liberty as self-determination, as an elevating power, a release from the constraints of nature; equality of opportunity, as the emancipatory right to ameliorate individual capability defects; and self-realisation, as the expansion of choice available for individuals to exercise or augment one's abilities, fulfil desires, and maximise happiness. As such, morphological freedom is logically associated with other peripheral concepts: freedom to experiment, freedom of partaking in clinical trials, or procreative beneficence - the parents' right to apply inheritable genetic modifications on their unborn children.

From the transhumanist point of view, human enhancement will lead to more individual freedom and take responsibility for and gain more control over our lives and technological and societal development. These technologies are presented as a means to increase the plurality of social life and human existence in the upcoming era that will be determined by exponential technoscientific progress. Furthermore, transhumanists maintain that perpetual self-development is an essential human characteristic, an intrinsic part of human nature, which justifies their progressive aspirations and proactive approach to bodily self-transformation. But practicing morphological freedom is not arbitrary. Applying enhancement technologies will have cumulative benefits to society through more intelligent, happier individuals and a world with less suffering and pain. Welfare is equated with enhancement and immortality.

Morphological freedom and human enhancement will allow for the creation of novel, conscious forms of existence: biological, synthetic, and hybrid life forms will coexist, which renders anthropocentrism outdated. We will need to rethink our current legal framework with regards to citizenship to adopt this existential diversity. James Hughes, one of the most influential transhumanist thinkers, proposed a new, personhood-based rights system in which citizenship is granted not based on species-membership, but on personhood - the capacity of sentience.

The transhumanist conceptual core is surrounded by a host of other, less important concepts. Adjacent and peripheral concepts create the mutations of core concepts, whereby 
combinations of peripheral and core concepts create different versions of transhumanism. Adjacency can be determined by logical inferences as well as cultural variables within the Freedenian analytical framework.

The ideological analysis uncovered six adjacent and a plethora of peripheral concepts within the transhumanist conceptual arrangement. As a descendant of the Enlightenment, transhumanism applies the concept of reason in various articulations of its ideological claims as well as attaching it to a multitude of core and adjacent concepts. For example, rationality is decontested as informed wish or informed consent in the transhumanist argument in favour of human enhancement. The individual's informed consent is a precondition to the application of enhancement technologies, which entails that transhumanism refutes any forms of coercion physical, psychological, or peer pressure - and respects the individual's right to remain 'natural'. Coercion and authoritarianism are off the transhumanist table.

An important step towards becoming an ideology was when transhumanism identified the idea of technological progress with political progress and embarked on articulating its distinct account of democracy. A similar development took place among $19^{\text {th }}$-century socialists and $20^{\text {th }}$ century feminists, who both championed reason and science as means for greater democracy. The transhumanist articulation of the concept of democracy is a mixture of the models of deliberative and participatory democracy. It is aimed at maximising cumulative intelligence through deliberation and inclusion, promoting higher participation, and improving the quality of decisionmaking and the accountability of the executive power through the extensive usage of technology, especially artificial intelligence.

A unique morphology was revealed during the examination of the concept of abundance. It is attached to the host concept of welfare, but its decontestation has developed significantly over time. In its early, rudimentary version it referred to ending the scarcity of natural resources, but by now it is conceptualised as a super-concept, incorporating various components and rebranded as sustainable superabundance. Borrowing and adopting the concept of sustainability from the Green ideology enriched it conceptually, and relocated its position within the transhumanist conceptual arrangement, further from welfare and progress and closer to the concept of equality.

Equality is the rising star among the concepts as its prominence has continuously increased during recent decades. However, it is appropriate to assert that transhumanism presents a unique 
decontestation even in the case of the concept of equality. The decontestation chain demonstrates how adjacent concepts create distinct variants of an ideology. Equality is first decontested as equality of opportunity - as in liberalism or socialism - then it is attached to the concept of human enhancement as equality of opportunity for capability enhancement. In a further move, it borrows the peripheral concept of accessibility to create two mutations of the original concept in the forms of 'free access to enhancement technologies' and 'equal access to free enhancement technologies'. The former creates the freedom-centred, libertarian version of transhumanism, whereas the latter spawns the egalitarianist technoprogressive branch. While diversity is in an adjacent position in every transhumanist account, the role of the state differs along the libertarian-technoprogressive line of division.

Finally, the investigation of morphologies identified several peripheral concepts that create ideological variants. Above was presented the concept of accessibility and its combination with the concept of equality being the main driving force behind the creation of the two main ideological branches of transhumanism. Further peripheral concepts create more variants.

\subsection{Thin-centredness and the Transhumanist Potential}

The findings of the morphological analysis verified the original hypothesis of this dissertation that transhumanism is a thin-centred ideology. Three arguments were presented. First, it was demonstrated that transhumanism possesses an exceptionally coherent and unique ideational structure that essentially distinguishes it from other mature ideologies. In addition, transhumanism outlined, justified, and demanded an entirely new social, political, and economic system that, according to the transhumanist promise, would better serve the requirements created by technoscientific progress. On the other hand, transhumanism still exhibits limited responsiveness, a reduced capacity to respond to a broad range of policy issues without borrowing ideas and solutions from other, contested ideologies, and because of its focus on a constrained set of political issues and its limited outreach to the public. But the conceptual investigation convincingly proved that to a limited extent transhumanism can present effective conceptual decontestations to offer a unique interpretation of social reality. 
It was argued that transhumanism has a great potential for ideological thickening. The borrowing and exchange of explanatory paradigms among ideologies is one of the most fertile ways of developing new thinking, ideas, political offers, and policy solutions, and they pave alternative paths forward for transhumanism, giving its conceptualisation a much-needed boost.

Influential thinkers of transhumanism, like Istvan, Bostrom, Goertzl, or Hughes, provided intellectual inputs that gradually increased the conceptual density and ideational sophistication of transhumanism. The various decontestation chains constructed by the ideologues of transhumanism then were applied in various policy areas and offered unique answers to a wide array of salient political issues. They were not hesitant to borrow parts of other mature or thin ideologies like socialism, ecologism, or feminism only to rearrange them or allocate them with different meanings as is the case with self-determination or self-development which were transformed into morphological freedom and human enhancement in the transhumanist perspective. Reformulating old conceptualisations of abundance, welfare, rights, and liberties and presenting them in an accessible language, these ideological decontestations strengthened transhumanism's appeal to broader segments of the population, creating new opportunities for improving its political attractiveness.

The chances of thickening for the transhumanist ideology are further supported by its ability to gain control over language. The language of the $21^{\text {st }}$ century is enriched by new terms previously used only in science and academia or science fiction literature, which are now entering public discourse. Transhumanism is the only or at least the fastest ideology to adopt the new language. Gene editing, human enhancement, mind uploading, robot rights, privacy of algorithms - these are examples of phrases that transhumanists were the first to use in social and political discourse. Moreover, transhumanism proactively decontests the core ideological concepts and invests them with technology- and science-compatible new meanings. The transhumanist potential for semantic hegemony and its capability to build specific programmatic content to answer new policy issues opens up the path of ideological thickening.

The transhumanist ideology is neither doctrinaire nor dogmatic. It is an 'open ideology' (Freeden, 1996, p. 81) which borrows and incorporates ideas not only to fill gaps in its ideational structure, but also to articulate the transhumanist response to social problems and policy issues. The selection of borrowed ideas is not arbitrary: they do not put into peril the coherence of the 
transhumanist ideological core. For example, the choice of free market or state redistribution in two separate ideological branches of transhumanism as the main organisational mechanism is explained as the best tool to guarantee the access to enhancement technologies, not as the right mechanism to create the posthuman social order. Also, borrowing the peripheral concept of sustainability from ecologism and attaching it to the concept of abundance, a unique transhumanist invention, does not throw into disorder its conceptual coherence. Abundance keeps its adjacent position, and although it shifts a bit further from the core concept of a proactionary principle (deploying new cultural constraints - ecoconsciousness), it climbs the conceptual hierarchical ranking and achieves greater proportion, relative space among adjacent concepts. Considering the recent popularity of the concept of sustainable superabundance among transhumanists, it has the greatest potential to emerge in a core position within the ideological architecture.

As Freeden pointed out, the morphology of an ideology can be temporal or spatial. Sustainable superabundance is a prime example of spatial morphology as it invited numerous components to enrich its meaning, increase its proportion, and rise in importance among transhumanist concepts. Another poignant example of temporal morphology is that the concept of equality has migrated from a peripheral position to adjacency over a period of two decades and will likely become part of the core conceptual cluster within the technoprogressive branch of transhumanism. This retraction was a result of substantial reflection on the equality criticism by the opponents of transhumanism, which led to the creation of an ideological variant of transhumanism.

Transhumanism has a clear comparative advantage to other ideologies: it is the only belief system that realised the salience of rapid advances in science and technology and their implications on politics. Other mature and thin ideologies are still preoccupied with $20^{\text {th }}$-century issues. Transhumanism was neither born out of societal discontent (like populism and feminism) nor in response to an existential problem (like ecologism), but emerged as a reaction to exogenies in the socio-economic environment. In this respect, transhumanism is more similar to the thick ideologies born after the industrial revolution: socialism and liberalism. The rise of transhumanism was preceded by and coincides with disruptive changes in science and technology (the fourth industrial revolution) and the core ideas of transhumanism respond to the new philosophical, economic, 
cultural, and social issues that have arisen as a result of these disruptive exogenies. The intellectual conception of transhumanism took place outside the realm of politics.

Furthermore, the emergence of transhumanism evinces the limits of the internal flexibility of other mature ideologies. The constraints to adopting new perspectives have so far failed to ensure continuity amid disruptive socio-economic, scientific, and philosophical changes long envisioned and forecast by theorists, futurists, and even popular artists without any substantial reaction from mainstream ideologies. Geertz subtly observed that:

It is when neither a society's most general cultural orientations nor its most downto-earth, 'pragmatic' ones suffice any longer to provide an adequate image of political process that ideologies begin to become crucial as sources of sociopolitical meanings and attitudes. (Geertz, 1973, p. 219)

However, transhumanism sparked fierce criticism from three influential groups: activists affiliated with the religious orthodoxy of the Christian right, radical left bioconservatives, and social liberal or conservative philosophers (such as Habermas and Fukuyama) who strongly oppose certain - but not all - transhumanist technologies. These powerful groups agree that transhumanism poses a major new type of challenge (or in their view, threat) to their belief systems. But otherwise, mainstream liberal, socialist, and conservative political actors have mostly neglected the transhumanist challenge to date. Consequently, those thinkers dissatisfied with the inelasticity of the available ideational supply of existing mature ideologies started to develop new ideas, concepts, and conceptual components as well as propose new policy actions. Had full-fledged ideologies adapted to these techno-scientific advances, transhumanism today would be considered a subgenre of liberalism, libertarianism, or socialism, or would not exist at all. The fact that the contrary is true means that the techno-scientific disruption demands a new ideological configuration that can provide answers to issues raised by these rapid changes in a similar fashion as socialism, liberalism, and their co-variants did during and after the industrial revolution.

Scientific achievements in the fields of genetic engineering, neuroscience, or artificial intelligence research provide ample evidence that transhumanism is an intellectual project far more substantive, complex, and encompassing than its frequent reduction to dystopic fiction by 
mainstream political actors. On the contrary, such disparaging views or the negligence of transhumanism reflect the misunderstanding of reality by advocates of other ideologies and mainstream political actors. Transhumanist policy proposals are often portrayed as the perilous reemergence of the long-discredited views of eugenics, or as the expressions of a techno-totalitarian political agenda: an anti-egalitarian response to scientific and technological disruption that is nonetheless better understood as an assault on the current world order led by the new elite of Big Tech corporations, rather than a systematic ideological vision.

Further support for ideological thickening is the issue ownership of transhumanism. Political transhumanism aims to define the future through putting forward intentionally controversial policy proposals, while the transhumanist ideology strikes for hegemony over the language of politics introducing novel topics, terms, and notions that other mature ideologies have so far neglected, or only moderately criticised or challenged. The only other political ideology (if we do not consider the various forms of religious orthodoxy, such as political Islam, ideologies) with a similar agenda is ecologism. It seems that at the beginning of the $21^{\text {st }}$ century transhumanism and ecologism are competing over the issue ownership of the future.

The common feature of transhumanism and ecologism is their global outreach. 'No one is in charge', wrote Thomas L. Friedman about globalisation (Friedman, 2000, p. 113), referring to the fact that under globalism, it is not nations, peoples, or politicians that decide: it is the market and technology that determine what is happening in the world. Further, no one can escape it or decouple or separate itself from its effects. Transhumanism further reduces this type of inexorability of integration and determination: 'Technology is in charge'. It does not matter what politicians, ideologues, or different levels of groups (communities, nations, regions, alliances) think the future should look like: it is the unstoppable spread of technological advancements that determines the future. Any ideologies, political, social, or economic entities that do not put technology in the centre of their thinking are doomed. Technology even determines the market. Thus, transhumanism is a reduced or simplified global imaginary, a globalist thin ideology.

As such, transhumanism presents a radical rapture from the logic of the existing world order and its dominant ideologies. It has so far been successful in offering innovative and unique responses as well as claiming exclusivity over specific issues neglected by other ideologies. However, it is fair to admit that transhumanist issue ownership is limited in its extent. The 
ideological thinness of transhumanism invokes two possible scenarios: transhumanism may either develop into a full-fledged ideology or dissolve in the ideational space of other ideologies, enriching them with novel and original adjacent and peripheral concepts while expanding their spatial perspective and increasing their dominance-potential in the ideological contest. Nonetheless, transhumanism deserves to be accorded equal ranking with feminism or nationalism based on its ideological thin-centredness, not on its influence in shaping political practice.

These findings also lend support to the argument that transhumanism is a thin-centred ideology. However, this thickening process has not reached the point from which one can claim within the Freedenian framework that transhumanism is a thick ideology. Instead of 'thickening', it is more appropriate to call this process ideational reconfiguration.

\subsection{Future Research and Closing Remarks}

The ideational approach to the study of transhumanism as an ideology had various benefits for political science. First, it provided insightful explanations of the growing popularity of proscience transhumanist ideas and illuminated the reasons for its attractiveness among specific social groups. Second, it helped follow and gauge the development of transhumanist thought as presented by various transhumanist theorists since the 1980s. Only by showing its interactions with other competing ideologies can we understand the articulation of the transhumanist political offerings and policy initiatives put forward by transhumanist political parties in recent years. Finally, bringing ideology into the analysis of transhumanism allowed us to look at the current trends in political theories from a valuable and new perspective.

The morphological analysis presented in this dissertation is far from complete. Further exploration is required to uncover more details of the ideological architecture of transhumanism: unique decontestation chains, emerging peripheral concepts, and most importantly, the interactions with other ideologies. This latter issue deserves further elaboration.

The question can be reformulated as 'which ideology can be the partner of transhumanism?' Unlike nationalism or populism, which are 'diffuse in [their] lack of a programmatic centre of 
gravity, and open in [their] ability to cohabit with other, more comprehensive, ideologies' (Stanley, 2008b, pp. 99-100), the focused and easily-identifiable conceptual core of transhumanism serves as a gravitational centre around which original and unique decontestations can create distinctive adjacent and peripheral concepts, which open up the path to two main directions of further development. This constellation of structured and patterned concepts may lay the foundation for the ideological thickening for transhumanism and result in the emergence of a robust and comprehensive new ideology. Alternately, it can attach to an existing, mature ideology, diffusing into it, and transforming it to better adapt to techno-scientific externalities.

However, transhumanism is not fully free to choose which mature ideology to attach. The history of the theory proves that it hardly can be associated with conservativism or ecologism. There has been continuous experimenting with mixing transhumanism with religious views by interpreting Christian eschatology in transhumanist terms, which brought to life the Christian Transhumanist branch or the Mormon Transhumanist Party. Also, technoprogressives have made enormous intellectual efforts to reconcile transhumanism with Green ideals. For this purpose, they created the concept of sustainable abundance, a form of technology-created abundance of resources that takes into consideration environmental protection and natural diversity. Some transhumanists even went further, suggesting a more radical approach to Green issues. They call themselves technogaianists. But these attempts so far have not been convincing for adversaries: ecologists and religious zealots still form the fiercest opposition groups against transhumanism.

On the other hand, socialism, liberalism, and libertarianism - among the mature ideologies - and the thin ideology of feminism seem to be natural and conducive partners for transhumanism. Nationalism and populism are off limits to transhumanists. There is no shared set of concepts, policy offers, or values between them and transhumanism. Communism presents an interesting case. Some identify the communist utopia with the phase of technological superabundance, the liberation of mankind from boring labour that transhumanists envision. At first sight it is strange to find connections between a belief system that is strongly attached to individual freedom and one that is marred by the horrific memories of the totalitarianism of historical communism. Apart from rudimentary attempts to reconciliate transhumanism and communism (Bastani, 2019; Wood, 2019a), such proposals are rejected by transhumanists. 
Another question is: what future lies ahead for transhumanism? Transhumanism attracts heterogenous audiences - heterogenous with regards to philosophical background, political stance, social status, demography, and geographical location. Sketching the history, criticism, and contemporary perspective of transhumanism allows for the provision of a detailed map of transhumanist ideology that shows its complexity while also illuminating its common ideational core, programmatic commitments, and potential to transform the future ideological landscape as well as the global political discourse. Transhumanism was able to create a distinctive conceptual arrangement, but its structure is far from complete, making it a thin-centred ideology according to the Freedenian terminology. Ideologies solidify, resist change, and become dogma. But those thought systems that challenge the ideational status quo, the hegemony of the dominant ideologies are not necessarily utopias. Populism, nationalism, and feminism are thin-centred ideologies as well as challengers to mature belief systems without utopic attributes.

In the $21^{\text {st }}$ century, thin-centred, immature ideologies are tools in the hands of those who initiate change in society and politics. Albeit utopias and thin-centred ideologies fundamentally differ, their role is similar: to contest dominant ideologies and dogma. Among the newcomers, transhumanism has great potential for ideological thickening as the process is supported by disruptive technological and scientific progress. 


\section{References}

Agar, N. (2004) Liberal Eugenics: In Defence of Human Enhancement. Wiley-Blackwell.

'Agile organisations for agile politics' (2016). UK Transhumanist Party. Available at: https://dw2blog.com/2016/11/08/agile-organisations-for-agile-politics/.

Allhoff, F. et al. (2009) Ethics of Human Enhancement: 25 Questions \& Answers. Available at: http://ethics.calpoly.edu/NSF_report.pdf.

Anderson, K. V. (ed.) (2018) Women, Feminism, and Pop Politics. New York, NY: Peter Lang. doi: $10.3726 / \mathrm{b} 13150$.

Bailey, R. (2007) 'Medievalizing Biotech Regulation', Reason. Available at: https://reason.com/2007/03/09/medievalizing-biotech-regulati/ (Accessed: 30 March 2020).

Bailey, R. (2011) 'The Case for Enhancing People', The New Atlantis, 32(Summer), pp. 16-38. Available at: http://www.thenewatlantis.com/publications/the-case-for-enhancing-people.

Barrieu, P. and Sinclair-Desgagné, B. (2006) 'On Precautionary Policies', Management Science, 52(8), pp. 1145-1154. doi: 10.1287/mnsc.1060.0527.

Bartlett, J. (2014) 'Meet the transhumanist Party: "Want To live Forever? Vote For Me", The Telegraph, 23 December. Available at: https://www.telegraph.co.uk/technology/11310031/Meet-the-Transhumanist-Party-Wantto-live-forever-Vote-for-me.html.

Bastani, A. (2019) Fully Automated Luxury Communism: A Manifesto. London, New York: Verso.

Begley, S. (2018) 'Amid uproar, Chinese scientist defends creating gene-edited babies', STAT, November. Available at: https://www.statnews.com/2018/11/28/chinese-scientist-defendscreating-gene-edited-babies/.

Benedikter, R. and Siepmann, K. (2016) “"Transhumanism”: A New Global Political Trend?', Challenge, 59(1), pp. 47-59. doi: 10.1080/05775132.2015.1123574.

Bostrom, N. (2003a) 'The Transhumanist FAQ: A General Introduction'. World Transhumanist Association, p. 66. Available at: https://nickbostrom.com/views/transhumanist.pdf.

Bostrom, N. (2003b) 'Transhumanist Values', in Adams, F. (ed.) Ethical Issues for the 21st Century. Charlottesville, VA: Philosophical Documentation Center Press, pp. 3-14. Bostrom, N. (2005a) 'Ethical Issues for the Twenty-First Century: Transhumanist Values', Journal 
of Philosophical Research. Edited by F. Adams, 30(Special Issue), pp. 3-14.

Bostrom, N. (2005b) 'The History of Transhumanist Thought', Journal of Evolution and Technology, 14. Available at: http://jetpress.org/volume14/freitas.html (Accessed: 18 January 2017).

Bostrom, N. (2016) Superintelligence. Reprint. Oxford: Oxford University Press.

Bostrom, N. and Sandberg, A. (2009) 'Cognitive Enhancement: Methods, Ethics, Regulatory Challenges', Science and Engineering Ethics, 15(3), pp. 311-341. doi: 10.1007/s11948-0099142-5.

Branwyn, G. (1991) 'Cyberpunk Manifesto'. Available at: https://www.digitalmanifesto.net/manifestos/135/.

Brumlik, M. (2016) 'Transhumanism Is Humanism, and Humanism Is Transhumanism', in Hurlbut, B. J. and Tirosh-Samuelson, H. (eds) Perfecting Human Futures. Transhuman Visions and Technological Imaginations. Wiesbaden: Springer, pp. 121-140.

Buchanan, A. et al. (2002) From Chance To Choice: Genetics And Justice. Cambridge University Press.

Buchanan, A. (2017) Better Than Human? The Promise and Perils of Biomedical Enhancement. Reprint. Oxford University Press.

Caldera, E. O. (2008) 'Cognitive Enhancement and Theories of Justice: Contemplating the Malleability of Nature and Self', Journal of Evolution and Technology, 18(1), pp. 116-123.

Campbell, A. et al. (1960) The American Voter. Midway Rep. The University of Chicago Press.

Canovan, M. (1999) 'Trust the People! Populism and the Two Faces of Democracy', Political Studies, 47(1), pp. 2-16. doi: 10.1111/1467-9248.00184.

Carmines, E. G. and D’Amico, N. J. (2015) 'The New Look in Political Ideology Research', Annual Review of Political Science, 18(1), pp. 205-216. doi: 10.1146/annurev-polisci-060314115422.

Chan, S. et al. (2011) "'Risky" research and participants' interests: the ethics of phase 2C clinical trials', Clinical Ethics, 6(2), pp. 91-96. doi: 10.1258/ce.2011.011019.

Chan, S. and Harris, J. (2008) 'In Support of Human Enhancement', Studies in Ethics, Law, and Technology, 1(1). doi: 10.2202/1941-6008.1007.

Coenen, C. et al. (2009) Human Enhancement. Available at: 
http://www.europarl.europa.eu/RegData/etudes/etudes/join/2009/417483/IPOLJOIN_ET(2009)417483_EN.pdf.

Cohen, J. (2018) "“I feel an obligation to be balanced." Noted biologist comes to defense of gene editing babies', Science, November. Available at: https://www.sciencemag.org/news/2018/11/i-feel-obligation-be-balanced-noted-biologistcomes-defense-gene-editing-babies\#.

Converse, P. E. (2006) 'The nature of belief systems in mass publics (1964)', Critical Review, 18(1-3), pp. 1-74. doi: 10.1080/08913810608443650.

Cox, H. (2017) 'Aubrey de Grey: scientist who says humans can live for 1,000 years', Financial Times. Available at: https://www.ft.com/content/238cc916-e935-11e6-967b-c88452263daf.

Daniels, N. (2000) 'Normal Functioning and the Treatment-Enhancement Distinction', Cambridge Quarterly of Healthcare Ethics, 9(3), pp. 309-322. doi: 10.1017/S0963180100903037.

Delfin, D. (2019) 'An Artist's Creative Process: A Model for Conscious Evolution', in Lee, N. (ed.) The Transhumanism Handbook. Cham: Springer, pp. 587-602.

Delwit, P. and Close, C. (2016) 'Green Parties and elections', in van Haute, E. (ed.) Green Parties in Europe. London: Routledge, pp. 241-264.

Denzau, A. T. and North, D. C. (1994) 'Shared Mental Models: Ideologies and Institutions', Kyklos, 47(1), pp. 3-31. doi: 10.1111/j.1467-6435.1994.tb02246.x.

Dévédec, N. Le (2018) 'Unfit for the future? The depoliticization of human perfectibility, from the Enlightenment to transhumanism', European Journal of Social Theory. SAGE PublicationsSage UK: London, England, p. 136843101775097. doi: $10.1177 / 1368431017750974$.

Diamandis, P. H. and Kotler, S. (2012) Abundance: The Future Is Better Than You Think. New York, NY: Free Press (Exponential Technology Series).

Van Dijk, T. A. (1998) Ideology. London: SAGE Publications.

Van Dijk, T. A. (2006) 'Ideology and discourse analysis', Journal of Political Ideologies, 11(2), pp. 115-140. doi: 10.1080/13569310600687908.

Donahue, M. (2017) 'How a Color-Blind Artist Became the World's First Cyborg', National Geographic. Available at: https:/www.nationalgeographic.com/news/2017/04/worlds-firstcyborg-human-evolution-science/. 
Dvorsky, G. and Hughes, J. (2008) Postgenderism: Beyond the Gender Binary. Available at: https://ieet.org/archive/IEET-03-PostGender.pdf.

Epstein, L. G. (1980) 'Decision Making and the Temporal Resolution of Uncertainty', International Economic Review, 21(2), p. 269. doi: 10.2307/2526180.

Esfandiary, F. M. (1973) Up-Wingers: A Futurist Manifesto. John Day Co.

Esfendiary, F. M. (1975) 'Homo Sapiens, the Manna Maker', The New York Times, p. 12. Available at: https://www.nytimes.com/1975/08/09/archives/homo-sapiens-the-manna-maker.html.

Ettinger, R. (1964) The Prospect of Immortality. New York, NY: Doubleday.

Ettinger, R. (2005) Man into Superman: The Startling Potential of Human Evolution -- And How To Be Part of It. Edited by C. Tandy. Ann Arbor: Ria University Press.

Fagerholm, A. (2016) 'Ideology: A proposal for a conceptual typology', Social Science Information, 55(2), pp. 137-160. doi: 10.1177/0539018416629229.

FM-2030 (1984) 'What is the future of democracy?' Available at: https://youtu.be/C-WB6dVkETI. FM-2030 (1989) Are You a Transhuman?: Monitoring and Stimulating Your Personal Rate of Growth in a Rapidly Changing World. New York: Warner Books.

Foster, K. R. (2000) 'Science and the Precautionary Principle', Science, 288(5468), pp. 979-981. doi: 10.1126/science.288.5468.979.

Freeden, M. (1996) Ideologies and Political Theory: A Conceptual Approach. Oxford: Oxford University Press.

Freeden, M. (1997) 'Ideologies and Conceptual History', Journal of Political Ideologies, 2(1), pp. 3-11. doi: 10.1080/13569319708420747.

Freeden, M. (1998) 'Is Nationalism a Distinct Ideology?', Political Studies, 46(4), pp. 748-765. doi: 10.1111/1467-9248.00165.

Freeden, M. (2003) Ideology. A Very Short Introduction. Oxford: Oxford University Press.

Freeden, M. (2004) 'Ideology, Political Theory and Political Philosophy', in Gaus, G. and Kukatha, C. (eds) Handbook of Political Theory. SAGE Publications, pp. 3-17.

Freeden, M. (2005a) Liberal Languages. Ideological Imaginations and Twentieth-Century Progressive Thought. Princeton, New Jersey: Princeton University Press.

Freeden, M. (2005b) 'What Should the "Political” in Political Theory Explore?', The Journal of Political Philosophy, 13(2), pp. 113-134. 
Freeden, M. (2006) 'Ideology and political theory', Journal of Political Ideologies, 11(1), pp. 322. doi: 10.1080/13569310500395834.

Freeden, M. (2013) 'The Morphological Analysis of Ideology', in Freeden, M., Sargent, L. T., and Stears, M. (eds) The Oxford Handbook of Political Ideologies. Oxford University Press, pp. $115-133$.

Freeden, M. (2015) 'Conceptual History, Ideology and Language’, in Freeden, M., Steinmetz, W., and Fernández-Sebastián, J. (eds) Conceptual History in the European Space. New York, NY: Berghahn Books, pp. 118-138.

Freeden, M. (2017) 'After the Brexit referendum: revisiting populism as an ideology', Journal of Political Ideologies, 22(1), pp. 1-11. doi: 10.1080/13569317.2016.1260813.

Friedman, T. L. (2000) The Lexus and the Olive Tree. Revised an. Anchor Books.

Friend, T. (2017) 'Silicon Valley's Quest to Live Forever', The New Yorker. Available at: https://www.newyorker.com/magazine/2017/04/03/silicon-valleys-quest-to-live-forever.

Frommherz, G. (2017) 'Meme Wars: Visual Communication in Popular Transhumanism', The International Journal of the Image, 8(4), pp. 1-19. doi: 10.18848/2154-8560/CGP/v08i04/119.

Fukuyama, F. (1992) The End of History and the Last Man. Free Press.

Fukuyama, F. (2003) Our Posthuman Future: Consequences of the Biotechnology Revolution. New Xork: Picador.

Fukuyama, F. (2004) 'Transhumanism', Foreign Policy, (144), pp. 42-43. doi: 10.2307/4152980.

Fukuyama, F. and Furger, F. (2007) Beyond Bioethics: A Proposalfor Modernizing the Regulation of Human Biotechnologies. Baltimore: Johns Hopkins University Press.

Fuller, S. (2013) Preparing for Life in Humanity 2.0. London: Palgrave Macmillan UK. doi: $10.1057 / 9781137277077$.

Fuller, S. (2015a) 'Political and legal Prolegomena to an extended republic of humanity, or transhumanity', Sociology of Science and Technology, 6(2), pp. 77-91.

Fuller, S. (2015b) Transhumanism as the Heir of Ethical Modernism - or Against Virtue, Institute for Ethics and Emerging Technologies. Available at: https://ieet.org/index.php/IEET2/more/fuller20150910 (Accessed: 9 November 2017).

Fuller, S. (2016) 'Morphological Freedom and the Question of Responsibility and Representation 
in Transhumanism', Confero: Essays on Education, Philosophy and Politics, 4(2), pp. 3345. doi: 10.3384/confero.2001-4562.161206.

Fuller, S. and Lipińska, V. (2014a) The Proactionary Imperative. London: Palgrave Macmillan UK. doi: 10.1057/9781137302922.

Fuller, S. and Lipińska, V. (2014b) ‘The Proactionary Manifesto’, in The Proactionary Imperative. London: Palgrave Macmillan UK, pp. 129-137. doi: 10.1057/9781137302922_6.

Gallie, W. B. (1955) 'Essentially Contested Concepts', Proceedings of the Aristotelian Society. Aristotelian Society, Wiley, 56, pp. 167-198. Available at: http://www.jstor.org/stable/4544562.

Gaus, G. F. and Kukatha, C. (eds) (2004) Handbook of Political Theory. SAGE Publications. Geertz, C. (1973) 'Ideology As a Cultural System', in The Interpretation of Cultures. Selected Essays by Clifford Geertz. New York, NY: Basic Books, pp. 193-232.

'Genetics and Other Human Modification Technologies: Sensible International Regulation or a New Kind of Arms Race?' (2008). Washington, D.C.: U.S. Government Printing Office. Available at: https://fas.org/irp/congress/2008_hr/genetics.pdf.

Gerring, J. (1997) 'Ideology: A Definitional Analysis', Political Research Quarterly, 50(4), p. 957. doi: $10.2307 / 448995$.

Giddens, A. (1983) 'Four Theses on Ideology', Canadian Journal of Political and Social Theory, 7(1-2), pp. 18-21.

Goertzel, B. (2002) 'Thoughts on AI Morality', Dynamical Psychology, 9(May). Available at: https://goertzel.org/dynapsyc/2002/AIMorality.htm.

Gollier, C., Jullien, B. and Treich, N. (2000) 'Scientific progress and irreversibility: an economic interpretation of the "Precautionary Principle", Journal of Public Economics, 75(2), pp. 229-253. doi: 10.1016/S0047-2727(99)00052-3.

Grant, Z. P. and Tilley, J. (2019) 'Fertile soil: explaining variation in the success of Green parties', West European Politics. Routledge, 42(3), pp. 495-516. doi: 10.1080/01402382.2018.1521673.

Gray, J. (2017) 'Dear Google, please solve death', New Statesman. Available at: http://www.newstatesman.com/culture/books/2017/04/john-gray-dear-google-please-solvedeath. 
Gray, J. N. (1977) 'On the Contestability of Social and Political Concepts', Political Theory, 5(3), pp. 331-348.

de Grey, A. (2007) Ending Aging. New York, NY: St. Martin’s Press.

'H+' (2018) H+pedia. Available at: https://hpluspedia.org/wiki/H\%2B.

Habermas, J. (2003) The Future of Human Nature. Cambridge: Polity Press.

Haldane, J. B. S. (1924) 'Daedalus, or Science and the Future', The Eugenics review, 16(2), pp. 143-145. doi: 10.2307/2014395.

Hall, M. (2017) The Bioethics of Enhancement: Transhumanism, Disability, and Biopolitics. Lanham: Lexington Books.

Haraway, D. (1987) 'A manifesto for Cyborgs: Science, technology, and socialist feminism in the 1980s', Australian Feminist Studies, 2(4), pp. 1-42. doi: 10.1080/08164649.1987.9961538.

Haraway, D. (1991) Simians, Cyborgs, and Women: The Reinvention of Nature. Routlege.

Harrison, P. and Wolyniak, J. (2015) 'The History of "Transhumanism"', Notes and Queries, 62(3), pp. 465-467. doi: 10.1093/notesj/gjv080.

Hauskeller, M. (2016) Mythologies of Transhumanism. Cham: Springer International Publishing. doi: 10.1007/978-3-319-39741-2.

Hewitt, J. (2016) 'An interview with Zoltan Istvan, leader of the Transhumanist Party and 2016 presidential contender', ExtremeTech. Available at: https://www.extremetech.com/extreme/192385-an-interview-with-zoltan-istvan-leader-ofthe-transhumanist-party-and-2016-presidential-contender.

Holtug, N. (2011) 'Equality and the Treatment-Enhancement Distinction', Bioethics, 25(3), pp. 137-144. doi: 10.1111/j.1467-8519.2009.01750.x.

Hughes, J. (2010) 'Contradictions from the enlightenment roots of transhumanism', Journal of Medicine and Philosophy, 35(6), pp. 622-640. doi: 10.1093/jmp/jhq049.

Hughes, J. (2015) 'Politics', in Ranisch, R. and Sorgner, S. L. (eds) Post- and Transhumanism. An Introduction. Frankfurt am Main: Peter Lang, pp. 133-148.

Hughes, J. J. (2001) 'The Future of Death: Cryonics and the Telos of Liberal Individualism', Journal of Evolution and Technology, 6. Available at: http://www.jetpress.org/volume6/death.htm.

Hughes, J. J. (2004) Citizen Cyborg. Cambridge, Massachusetts: Westview Press. 
Humanity+ (no date) 'Transhumanist FAQ'. Humanity+. Available at: https://humanityplus.org/philosophy/transhumanist-faq/.

Hurka, T. (1993) Perfectionsim. Oxford: Oxford University Press (Oxford Ethics).

Hype Cycle for Emerging Technologies (2018). Stamford: Gartner. Available at: https://www.gartner.com/en/newsroom/press-releases/2018-08-20-gartner-identifies-fiveemerging-technology-trends-that-will-blur-the-lines-between-human-and-machine.

Istvan, Z. (2017) 'Why I'm Running for California Governor As a Libertarian.', Newsweek, 2 December. Available at: http://www.newsweek.com/zoltan-istvan-california-governorlibertarian-555088.

Jost, J. T., Kay, A. C. and Thorisdottir, H. (eds) (2009) Social and Psychological Bases of Ideology and System Justification. Oxford University Press.

Kass, L. R. (1997) 'The Wisdom of Repugnance', New Republic. TNR II, LLC, 216(22), pp. 1726. Available

at: http://search.ebscohost.com/login.aspx?direct=true \&db=a9h\&AN=9705184208\&site=edslive\&authtype=uid.

Kass, L. R. (2002) Life, liberty, and the defense of dignity: the challenge for bioethics. Sanf frncisco: Encounter Books.

Kass, L. R. (2003) Beyond Therapy: Biotechnology and the Pursuit of Human Improvement. Available at: https://bioethicsarchive.georgetown.edu/pcbe/background/kasspaper.html.

Koselleck, R. (1990) Futures Past: On the Semantics of Historical Time (Studies in Contemporary German Social Thought). Reprint Ed. Cambridge, Massachusetts: MIT Press.

Kostick, K. (2017) Engineering Eden: The quest for eternal life, BCM.edu. Available at: https://blogs.bcm.edu/2017/06/02/engineering-eden-quest-eternal-life/ (Accessed: 5 June 2017).

Kurzweil, R. (2000) The Age of Spiritual Machines: When Computers Exceed Human Intelligence. Penguin Books.

Kyle, J. and Gultchin, L. (2018) Populists in Power Around the World. Available at: https://institute.global/sites/default/files/articles/Populists-in-Power-Around-the-World.pdf.

'Lethal Autonomous Weapon Pledge' (2019). The Future of Life Institute. Available at: 
https://futureoflife.org/lethal-autonomous-weapons-pledge/.

Mack, E. (2019) 'Meet the cyborg who's running against Donald Trump for president', $c \mid n e t, 18$ November. Available at: https://www.cnet.com/news/meet-zoltan-istvan-cyborg-runningagainst-donald-trump-for-president/ (Accessed: 19 May 2020).

Madden, C. (2019) Hello Gen Z: Engaging the Generation of Post-Millennials. Revised Ed. Sidney: Hello Clarity.

Makin, J. G., Moses, D. A. and Chang, E. F. (2020) 'Machine translation of cortical activity to text with an encoder-decoder framework', Nature Neuroscience, 23(4), pp. 575-582. doi: 10.1038/s41593-020-0608-8.

Making Perfect Life. European Governance Challenges in 21st Century Bio-engineering (2012). Available at: http://www.europarl.europa.eu/RegData/etudes/etudes/join/2012/471574/IPOLJOIN_ET(2012)471574_EN.pdf.

Mansour, A. A. et al. (2018) 'An in vivo model of functional and vascularized human brain organoids', Nature Biotechnology, 36(5), pp. 432-441. doi: 10.1038/nbt.4127.

Martuzzi, M. and Tickner, J. A. (eds) (2004) The precautionary principle: protecting public health, the environment and the future of our children. World Health Organization.

Masci, D. (2016) Human Enhancement. Available at: https://www.pewresearch.org/science/2016/07/26/human-enhancement-the-scientific-andethical-dimensions-of-striving-for-perfection/.

Matthews, D. (2019) 'Andrew Yang, the 2020 long-shot candidate running on a universal basic income, explained', Vox.

Maughan, T. (2015) 'Meet Zoltan, the presidential candidate who drives a coffin', BBC, 30 November. Available at: https://www.bbc.com/future/article/20151127-meet-zoltan-thestrangest-candidate-running-for-president (Accessed: 19 May 2020).

Maynard, J. L. (2013) 'A map of the field of ideological analysis', Journal of Political Ideologies, 18(3), pp. 299-327. doi: 10.1080/13569317.2013.831589.

McCrory, C. and Kenny, R. A. (2018) 'Rebuking the concept of ageing as a disease', The Lancet Diabetes \& Endocrinology, 6(10), p. 768. doi: 10.1016/S2213-8587(18)30266-3.

McGee, G. (2000) 'Ethical Issues in Enhancement: An Introduction', Cambridge Quarterly of 
Healthcare Ethics, 9(3), pp. 299-303. doi: 10.1017/S0963180100903013.

Metzinger, T. (2017) 'Silicon Valley is selling an ancient dream of immortality', The Financial

Times. Available at: https://www.ft.com/content/7a89c998-828d-11e7-94e2-c5b903247afd (Accessed: 18 November 2018).

Minar, D. M. (1961) 'Ideology and Political Behavior', Midwest Journal of Political Science, 5(4), pp. $317-331$. Available at:

https://www.jstor.org/stable/2108991?seq=1\#metadata_info_tab_contents.

More, M. (1990a) 'Editorial', Extropy, Summer(6), pp. 1-41.

More, M. (1990b) 'The Extropian Principles', Extropy, (6 Summer), pp. 17-18.

More, M. (1990c) ‘Transhumanism: Towards a Futurist Philosophy', Extropy, (Summer), pp. 612.

More, M. (1990d) ‘Transhumanism. Towards a Futurist Philosophy', Extropy Magazine, pp. 6-10. More, M. (1990e) ‘Transhumanism’, Extropy, pp. 6-12.

More, M. (2003) Principles of Extropy. Available at: http://www.extropy.org/proactionaryprinciple.htm.

More, M. (2004) 'The Proactionary Principle', in. Extropy Institute. Available at: http://www.extropy.org/proactionaryprinciple.htm.

More, M. (2011) 'True Transhumanism: A Reply to Don Ihde', in Hansell, G. R. and Grassie, W. (eds) H+/-: Transhumanism and Its Critics. Philadelphia: Metanexus Institute.

More, M. (2013) 'The Philosophy of Transhumanism', in More, M. and Vita-More, N. (eds) The Transhumanist Reader: Classical and Contemporary Essays on the Science, Technology, and Philosophy of the Human Future. Wiley-Blackwell, pp. 3-17.

More, M. and Vita-More, N. (2013) The Transhumanist Reader: Classical and Contemporary Essays on the Science, Technology, and Philosophy of the Human Future, The Transhumanist Reader: Classical and Contemporary Essays on the Science, Technology, and Philosophy of the Human Future. Edited by M. More and N. Vita-More. Wiley-Blackwell. doi: $10.1002 / 9781118555927$.

Mudde, C. (2004) 'The Populist Zeitgeist', Government and Opposition, 39(4), pp. 542-563. doi: 10.1111/j.1477-7053.2004.00135.x.

Murphy, K. and Topel, R. (2005) The Value of Health and Longevity. Cambridge, MA. doi: 
$10.3386 / \mathrm{w} 11405$.

Musk, E. (2019) 'An integrated brain-machine interface platform with thousands of channels', bioRxiv. doi: 10.1101/703801.

Network Italiani H+ Transhumanisti (2013) 'Il Network H+ sull'interrogazione parlamentare dell'on. Giuseppe Vatinno.' Network H+ Transhumanisti Italiani. Available at: http://transumanisti.org/index.php?option=com_content\&view=article\&id=32:il-networkh-sullinterrogazione-parlamentare-dellon-giuseppe-vatinno\&catid=2:notizie (Accessed: 12 April 2018).

Nevejans, N. (2016) European Civil Law Rules in Robotics. Available at: https://www.europarl.europa.eu/RegData/etudes/STUD/2016/571379/IPOL_STU(2016)571 379_EN.pdf.

Niman, J. (2012) ‘Transhumanism and Eugenics'. Institute for Ethics and Emerging Technologies. Available at: https://ieet.org/index.php/IEET2/more/niman20120406 (Accessed: 30 March 2020).

'No Title' (1966) The Reader's Digest Great Encyclopedia Dictionary. Reader's Digest.

Nordhaus, W. (2002) The Health of Nations: The Contribution of Improved Health to Living Standards, American Economic Review. Cambridge, MA. doi: 10.3386/w8818.

Nosta, J. (2018) 'It's Official, The Transhuman Era Has Begun', Forbes. Available at: https://www.forbes.com/sites/johnnosta/2018/08/22/its-official-the-transhuman-era-hasbegun/\#1497cf581b84.

Novossiolova, T. (2017) Governance of Biotechnology in Post-Soviet Russia. Palgrave Macmillan. Nozick, R. (2013) Anarchy, State, And Utopia. Reprint. Basic Books.

Olshansky, J. S. (2013) 'The Longevity Dividend', Public Policy \& Aging Report, 23(2), pp. 1010. doi: 10.1093/ppar/23.2.10.

Pearce, D. (1995) The Hedonistic Imperative. Available at: https://www.hedweb.com/welcome.htm.

Pendry, T. (2013) 'Politics and the Future of Transhumanism', H+ Magazine. Available at: http://hplusmagazine.com/2013/01/22/letter-to-the-editor-politics-and-the-future-oftranshumanism/.

Persson, I. and Savulescu, J. (2010) 'Moral Transhumanism’, Journal of Medicine and Philosophy, 
35(6), pp. 656-669. doi: 10.1093/jmp/jhq052.

Persson, I. and Savulescu, J. (2012) Unfit for the Future. Oxford: Oxford University Press. doi: 10.1093/acprof:oso/9780199653645.001.0001.

'Platform of the United States Transhumanist Party' (no date). Available at: http://transhumanistparty.org/platform/\#EconomicPolicy (Accessed: 15 March 2019).

Porter, A. (2017) 'Bioethics and Transhumanism', The Journal of Medicine and Philosophy, 42(3), pp. 237-260. doi: 10.1093/jmp/jhx001.

Putman, H. (1964) 'Robots: Machines or Artificially Created Life?', The Journal of Philosophy, 61(21), p. 668. doi: 10.2307/2023045.

Rand, A. (1964) The Virtue of Selfishness: A New Concept of Egoism. Fiftieth A. New York, NY: Signet.

Ranisch, R. (2014) 'Morality (of Transhumanism and Posthumanism), in: Post- and Transhumanism: An Introduction', pp. 149-172. doi: 10.3726/978-3-653-05076-9.

Recommendations to the Commission on Civil Law Rules on Robotics (2017). Available at: https://www.europarl.europa.eu/doceo/document/A-8-2017-0005_EN.html.

Regis, E. (1994) 'Meet the Extropians', Wired. Available at: https://www.wired.com/1994/10/extropians/.

Rejai, M. (1995) Ideologies: A Comparative Approach. Second. Routledge.

Ricœur, P. (1986) Lectures on Ideology and Utopia. Edited by G. Taylor. Columbia University Press. Available at: https://books.google.hu/books?id=zN-NQgAACAAJ.

Rifkin, J. (2001) 'Odd Coupling of Political Bedfellows Takes Shape in the New Biotech Era', Los Angeles Times. Available at: https://www.latimes.com/archives/la-xpm-2001-jul-24-me25902-story.html.

Rosenzweig, M. (2003) Win-Win Ecology. Oxford: Oxford University Press.

Rothman, P. (2014) 'Transhumanism Gets Political', H+ Magazine. Available at: http://hplusmagazine.com/2014/10/08/transhumanism-gets-political/.

Rutt, J. (2018) 'An Introduction to Liquid Democracy', Medium. Available at: https://medium.com/@memetic007/liquid-democracy-9cf7a4cb7f (Accessed: 15 May 2019).

Rutt, J. (2019) 'Making Liquid Democracy Work - Pay The Delegates', Medium. Available at: 
https://medium.com/@memetic007/making-liquid-democracy-work-pay-the-delegatesbd813a9cb60a (Accessed: 15 May 2019).

Sahota, N. (2018) 'Human 2.0 Is Coming Faster Than You Think. Will You Evolve With The Times?', Forbes. Available at: https://www.forbes.com/sites/cognitiveworld/2018/10/01/human-2-0-is-coming-faster-thanyou-think-will-you-evolve-with-the-times/ (Accessed: 18 November 2018).

Sample, I. (2019) 'Chinese scientist who edited babies' genes jailed for three years', The Guardian, 31 December. Available at: https://www.theguardian.com/world/2019/dec/30/gene-editingchinese-scientist-he-jiankui-jailed-three-years.

Sandberg, A. (2007) 'Policy Scenarios for the Longevity Dividend', in Securing the Longevity Dividend. Chicago: Institute for Ethics and Emerging Technologies. Available at: https://medium.com/@emergingtechnology/policy-scenarios-for-the-longevity-dividend$2 \mathrm{~b} 56090 \mathrm{a} 45 \mathrm{c} 1$.

Sandberg, A. (2013) 'Morphological Freedom - Why We Not Just Want it, but Need it', in More, M. and Vita-More, N. (eds) The Transhumanist Reader: Classical and Contemporary Essays on the Science, Technology, and Philosophy of the Human Future. Wiley-Blackwell, pp. 5564.

Savulescu, J. (2001) 'Procreative beneficence: why we should select the best children.', Bioethics, 15(5-6), pp. 413-426. doi: 10.1111/1467-8519.00251.

Savulescu, J. (2007) 'In defence of Procreative Beneficence', Journal of Medical Ethics, 33(5), pp. 284-288. doi: 10.1136/jme.2006.018184.

Schaefer, O. (2016) 'China May Be the Future of Genetic Enhancement', BBC. Available at: http://www.bbc.com/future/story/20160804-china-may-be-the-future-of-geneticenhancement.

Scharre, P. (2015) 'The Future of Warfare'. Center for a New American Security. Available at: https://www.armed-services.senate.gov/imo/media/doc/Scharre_11-03-15.pdf.

Schiener, D. (2015) 'Liquid Democracy: True Democracy for the 21st Century', Medium, 23 November. Available at: https://medium.com/organizer-sandbox/liquid-democracy-truedemocracy-for-the-21st-century-7c66f5e53b6f (Accessed: 15 May 2019).

Schwarzmantel, J. (1998) The Age of Ideology. Political Ideologies from the American Revolution 
to Postmodern Times. London: Macmillan Press.

Scialabba, G. (2002) 'Our Posthuman Future', American Prospect. Available at: https://prospect.org/features/posthuman-future/.

Scott, I. (2016) 'A Brief History of Cyberfeminism', Artsy. Available at: https://www.artsy.net/article/artsy-editorial-how-the-cyberfeminists-worked-to-liberatewomen-through-the-internet.

Shen, F. X. (2019) 'Sex robots are here, but laws aren't keeping up with the ethical and privacy issues they raise', The Conversation. Available at: http://theconversation.com/sex-robotsare-here-but-laws-arent-keeping-up-with-the-ethical-and-privacy-issues-they-raise-109852.

Shorten, R. (2007) 'The status of ideology in the return of political religion theory', Journal of Political Ideologies, 12(2), pp. 163-187. doi: 10.1080/13569310701285016.

Sirius, R. (2009) 'Solutions \& Rights', HPlus Magazine, pp. 8-9. Available at: https://hplusmagazine.com/issues/hplusmagazine-2009-spring.pdf.

Sorgner, S. L. (2009) 'Nietzche, the Overhuman, and Transhumanism', Journal of Evolution \& Technology, 20(1), pp. 29-42. Available at: http://jetpress.org/v20/sorgner.htm (Accessed: 23 January 2017).

Sorgner, S. L. (2016) 'Three Types of (Post)Human Perfection', in Hurlbut, B. J. and TiroshSamuelson, H. (eds) Perfecting Human Futures. Transhuman Visions and Technological Imaginations. Springer VS, pp. 141-158.

Sorgner, S. L. and Ranisch, R. (eds) (2015) Post- and Transhumanism. An Introduction. Frankfurt am Main: Peter Lang (Beyond Humanism: Trans- And Posthumansim). doi: 10.3726/978-3653-05076-9.

Staes, B. (2009) 'Impact of Human Enhancement on Member States' Health Costs'. Available at: http://www.europarl.europa.eu/ sides/getDoc.do?type=WQ\&reference=E-2009$2200 \&$ format $=X M L \&$ language $=\mathrm{EN}$.

Stanley, B. (2008a) 'The thin ideology of populism', Journal of Political Ideologies, 13(1), pp. 95110. doi: 10.1080/13569310701822289.

Stanley, B. (2008b) 'The thin ideology of populism', Journal of Political Ideologies, 13(1), pp. 95-110. doi: 10.1080/13569310701822289.

Steger, M. B. (2008) The Rise of the Global Imaginary: Political Ideologies from the French 
Revolution to the Global War on Terror. Oxford: Oxford University Press.

Steger, M. B. (2009) Globalisms. The Great Ideological Struggle of the Twenty-first Century. Third Edit. New York, NY: Rowman \& Littlefield Publishers.

Stockemer, D. (2017) The Front National in France. Toronto: Springer, Cham. doi: 10.1007/9783-319-49640-5.

Susser, B. (1996) 'The domains of ideological discourse', Journal of Political Ideologies, 1(2), pp. 165-181. doi: 10.1080/13569319608420735.

Szabados, K. (2019) 'Transhumanist Parties as Niche Parties', Journal of Posthuman Studies, 2(2), pp. 213-237. doi: 10.5325/jpoststud.2.2.0007.

'Technoprogressive Declaration' (2014) in. Paris: Transvision 2014. Available at: https://ieet.org/index.php/IEET2/more/tpdec2014.

Tennison, M. N. (2012) 'Moral Transhumanism: The Next Step', Journal of Medicine and Philosophy, 37(4), pp. 405-416. doi: 10.1093/jmp/jhs024.

The Lancet Diabetes \& Endocrinology (2018) 'Opening the door to treating ageing as a disease', The Lancet Diabetes \& Endocrinology, 6(8), p. 587. doi: 10.1016/S2213-8587(18)30214-6.

'The Science of Genetics and Modern Medicine' (2001). Brussels: European Parliament. Available at: http://www.europarl.europa.eu/meetdocs/committees/gene/20010426/436218EN.pdf.

'The Transhumanist Bill of Rights' (2015a). H+pedia. Available at: https://hpluspedia.org/wiki/Transhumanist_Bill_of_Rights.

The Transhumanist Bill of Rights (2015b). H+pedia. Available at: https://hpluspedia.org/wiki/Transhumanist_Bill_of_Rights (Accessed: 7 November 2017).

'The Transhumanist Declaration' (2002). World Transhumanist Association. Available at: https://web.archive.org/web/20060820074110/http://transhumanism.org/index.php/WTA/de claration/.

Tirosh-Samuelson, H. (2015) 'Religion', in Sorgner, S. L. (ed.) Post- and Transhumanism. An Introduction. Frankfurt am Main: Peter Lang, pp. 49-72.

Transhumanist FAQ - Version 3.0 (2001). Available at: https://whatistranshumanism.org/.

Transhumanity.net (2014) 'Gabriel Rothblatt Lost the Race', Transhumanity.net website, 5 November.

Transpolitica Manifesto (2016). London: Transpolitica 2016. Available at: 
https://transpolitica.org/manifesto/ (Accessed: 7 November 2017).

TransVision2017 (2017) '2017 update to the Technoprogressive Declaration', in. Available at: https://transvision-conference.org/tpdec2017/.

Twyman, A. (2014) Liberal Democracy, The Third Way, \& Social Futurism, IEET Website. Available at: https://ieet.org/index.php/IEET2/more/twyman20140707.

U.S. Public Wary of Biomedical Technologies to 'Enhance' Human Abilities (2016). Available at: http://assets.pewresearch.org/wpcontent/uploads/sites/14/2016/07/02120148/PS_2016.07.26_Human-EnhancementSurvey_FINAL.pdf.

US Transhumanist Party (2019) 'U.S. Transhumanist Party 2019 Electronic Primary Results Johannon Ben Zion Endorsed as Candidate for President of the United States', US Transhumanist Party website. Available at: https://transhumanist-party.org/2019/10/02/ustp2019-electronic-primary-results/.

Valovic, T. (2018) 'A peek inside the transhumanist agenda', The Sociable. Available at: https://sociable.co/technology/transhumanist-agenda/ (Accessed: 18 November 2018).

Vita-More, N. (1983) 'Transhumanist Arts Statement'. Available at: https://www.digitalmanifesto.net/manifestos/35/.

Vita-More, N. (2019) 'History of Transhumanism', in Lee, N. (ed.) The Transhumanism Handbook. Cham: Springer, pp. 49-61. doi: 10.1007/978-3-030-16920-6_2.

Weber, M. (1949) Methodology of Social Sciences. Edited by E. A. Shils. Glencoe, IL.

Woensel, L. Van, Kurrer, C. and Kritikos, M. (2016) Ethical Aspects of Cyber-Physical Systems. doi: $10.2861 / 68949$.

Wood, D. W. (2018) Transcending Politics. London: Delta Wisdom.

Wood, D. W. (2019a) 'Fully Automated Luxury Communism: a timely vision'. Institute for Ethics and Emerging Technologies. Available at: https://ieet.org/index.php/IEET2/more/Wood20190617 (Accessed: 13 May 2020).

Wood, D. W. (2019b) Sustainable Superabundance: A Universal Transhumanist Invitation. London: Delta Wisdom (Transpolitica Books).

Wood, D. W. (2020) RAFT 2035. London. Available at: https://transpolitica.org/projects/raft$2035 /$. 
Zizek, S. (1994) Mapping Ideology. Edited by S. Zizek. London: Verso.

'Zoltan Istvan does not speak for the Transhumanist Party' (2015). UK Transhumanist Party. Available at: https://transhumanistparty.wordpress.com/2015/10/12/zoltan-istvan-does-notspeak-for-the-transhumanist-party/. 


\section{Author's Publications}

\section{Publications on transhumanism}

Szabados, K. (2018) 'Transhumanist Parties as Niche Parties' Journal of Posthuman Studies, 2(2), pp. 213-237, doi: 10.5325/jpoststud.2.2.0007

\section{Conference presentations on transhumanism}

$2019 \quad$ 11 $^{\text {th }}$ Beyond Humanism Conference, Catholic University, Lille, France presenter ("Transhumanism as a Thin ideology")

2019 MPSA Annual Conference, Chicago, IL, USA presenter ("Transhumanism as a Thin-Centered Ideology")

2019 PhD Conference, Corvinus University of Budapest, Hungary presenter ("The Ideological Analysis of Transhumanism")

$2017 \quad 9^{\text {th }}$ Beyond Humanism Conference, John Cabot University, Rome, Italy panellist ("How Transhumanists Can Win The War On Science")

\section{Other publications (selection)}

Szabados, Krisztián. "Combating anti-science: the pathologies of social media and modern journalism.” In: Sajna-Kunowky, Radoslaw \& Anna Garczewska (eds.): Future of Media, Changing Journalism and New Communication. Wydawnictwo Uniwersytetu Kazimierzka Wielkiego, Bydgoszcz, 2020. pp. 23-38. ISBN 978-83-8018-329-2 
Szabados, Krisztian. "Can We Win The War On Science? Understanding the Link Between

Political Populism and Anti-science Politics." Populism 2, no. 2 (2019): 207-236.

https://www.jstor.org/stable/10.5325/jpoststud.2.2.0007. DOI: 10.1163/25888072-02021028

Szabados, Krisztian. “The particularities and Uniqueness of Hungary's Jobbik.” In: Giorgos

Charalambous (ed): The European Far Right: Historical and Contemporary Perspectives.

PRIO Cyprus Centre, Friedrich-Ebert-Stiftung, 2016

Szabados, Krisztián; Krekó, Péter; Juhász, Attila. "Fidesz und der Nationalpopulismus in

Ungarn." In: Ernst, Hillebrand (ed.) "Rechtspopulismus in Europa: Gefahr für die

Demokratie." Bonn: Verlag J.H.W. Dietz, $2^{\text {nd }}$, extended edition (2017) pp. 97-105

Szabados, Krisztián: Szexbotrányok a politikában. In: Válság? Kommunikáció! Political Capital, 2009

Szabados, Krisztián: Banánhéjköztársaság. Válogatott írások. Political Capital, 2008

Szabados, Krisztián (ed.): Gyurcsány vagy Orbán? Két párhuzamos politikai pálya. Political Capital, 2006

Szabados, Krisztián: Tornádó. Nicolas Sarkozy politikai pályája. Political Capital, 2002

Juhász, Attila; Szabados, Krisztián. “A populizmus éve.” In: “Magyarország Politikai Évkönyve 2005-ről.” Demokrácia Kutatások Magyarországi Központja Közhasznú Alapítvány, 2006.

Juhász, Attila; Szabados, Krisztián: A populisták mindent visznek. Mozgó Világ 2006/1., 76-85.

http://www.mozgovilag.hu/2006/01/10szabados.htm

\section{Other conference presentations (since 2016)}

2019 "After Liberalism? Populism and the Future of Democracy" conference, The Alfred Deakin Institute for Citizenship and Globalisation, Deakin University, Melbourne, Australia presenter ("The Populist Anti-Science Paradox")

2019 SISP 2019 Annual Conference, Lecce, Italy presenter ("Populism and Anti-Science Politics: A New Analytical Framework") 
2019 "Emotions, Populism and Polarised Politics, Media, and Culture" conference, University of Helsinki, Helsinki, Finland presenter ("Populism and Anti-Science")

2019 “The Future of Media, Mediatization, Journalism and Communication” conference, Kazimierz Wielki University, Bydgoszcz, Poland presenter ("Combating Anti-Science: The Pathologies of Modern Journalism and Social Media")

2018 IPSA World Congress, Brisbane, Australia presenter ("Can We Win the War on Science? Understanding the Link Between AntiScience and Populism")

2016 "Germany, Greece and the Balkans" conference, Munk School of Global Affairs, University of Toronto, Toronto, Canada speaker ("Security Concerns in the Western Balkans Refugee Route")

2016 "Multiple Challenges for Europe" conference, Institut pro politiku a společnost, Prague, Czech Republic panellist in the "Eurozone, Greece, and Sovereign Debt Crisis" session

2016 Krynica Economic Forum, Krynica, Poland panellist in the "Do We Need a Ministry for the Future? Strategy Planning in Economy and Politics" session 
2016 Personal Democracy Forum, Gdanks, Poland keynote speaker 